\title{
تقييم الاداء المالي لعينة من المصارف العاملة في اقليم كوردستان-العراق للمدة (2009 -2019)
}

\author{
يونس على احمد , 2, ، وريا محمد زاهر 1

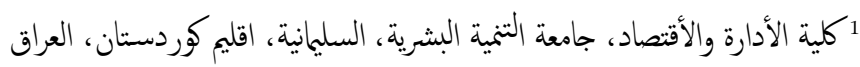

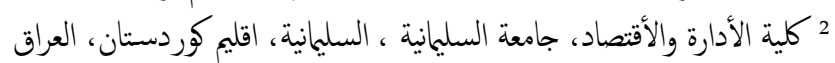

\section{المقدمة}

من الناحية العلمية والعملية فإن الوظيفة الرئيسية للمصارف ذات جانبين ها قبول

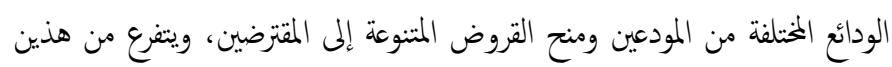

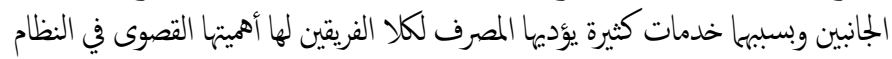

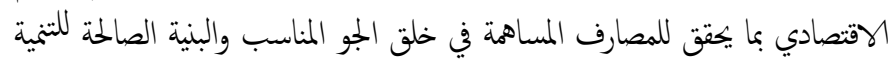

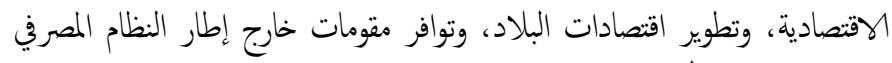

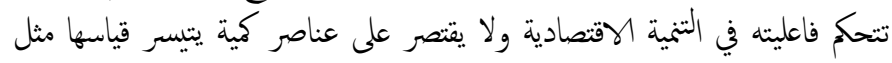

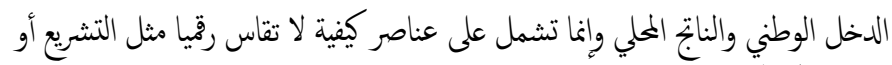

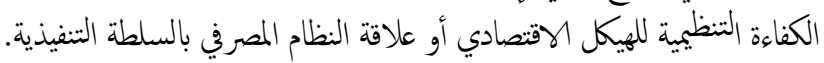

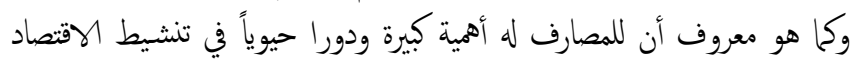

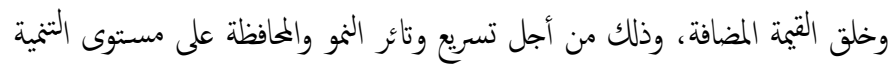

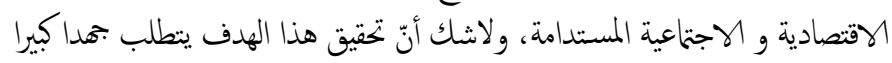

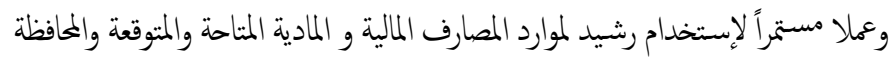

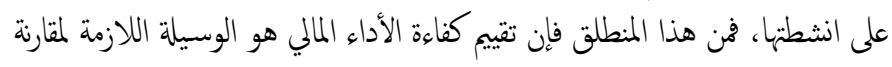

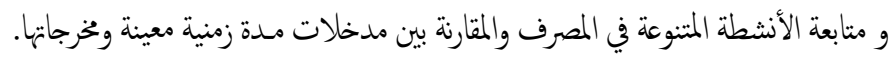

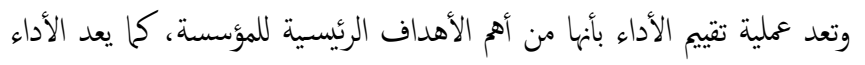

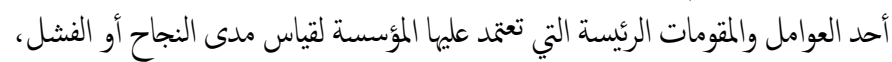

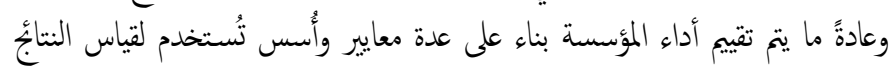

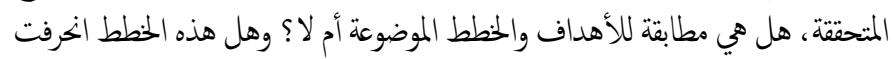

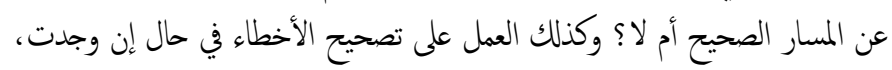

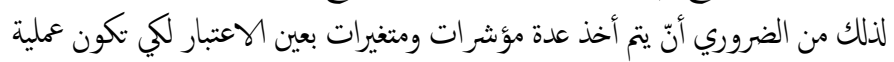

$$
\text { التقييم والمقارنة صحيحة. }
$$

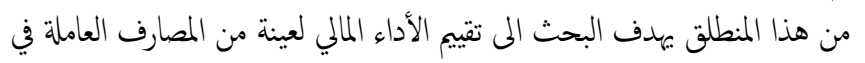

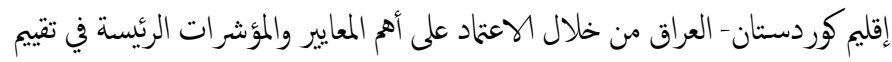
الأداء الملالي بالاعتماد على الأساليب القياسية المتقدمة.
المستخلص- تعد عملية تقييم الأداء بأهها من الأهداف الرئيسية للمؤسسة، ويمثل

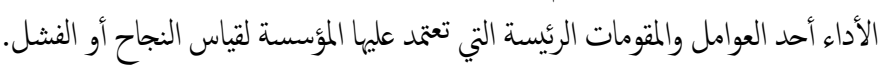

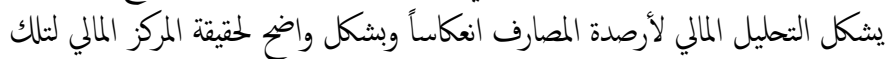

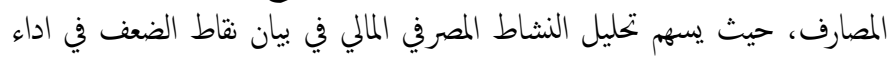

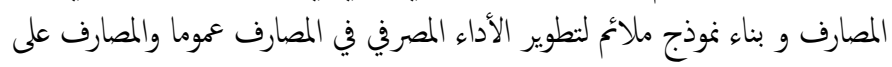

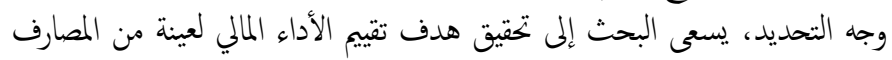

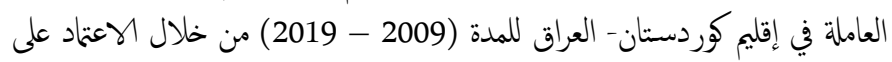

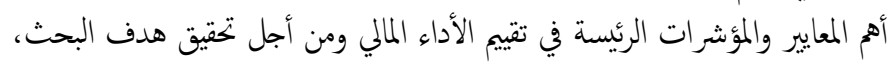

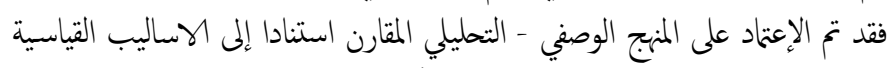

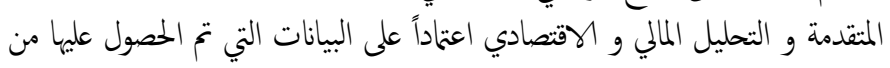

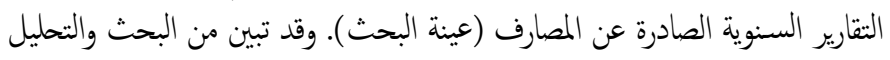

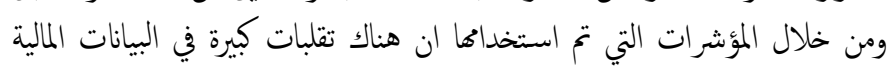

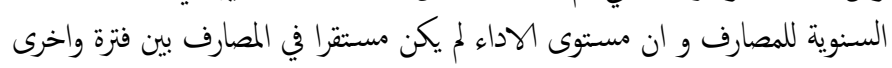
وذلك بسبب الاوضاع المالية والسياسية غير المستقرة وكذلك ضعف المات المبن السياسات

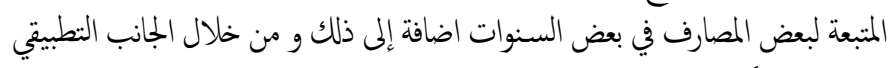

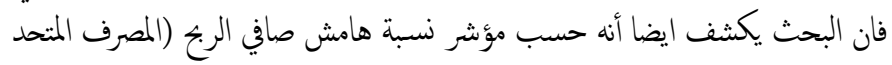

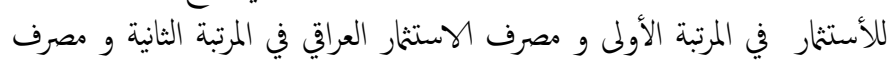

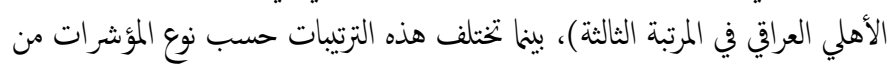

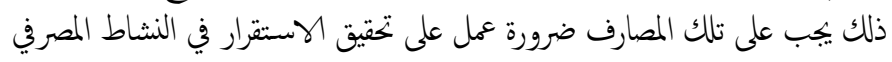

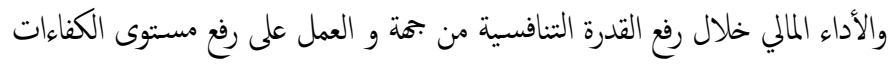

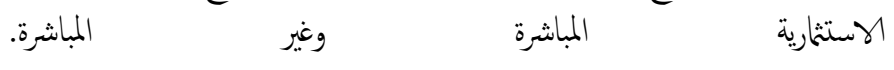
الكلمات الدالة- تقييم الاداء، التحليل المالي، المصارف، اقليم وزردستان العراق. 
2. لم تتمكن المصارف موضوع البحث تحقيق أهدافها وفقآ لموارد المالية المتاحة لها

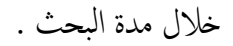
3. لم تتمكن المصارف موضول مد البحث ، البحث من تحقيق أهدافها بصورة جيدة في ضوء وجود

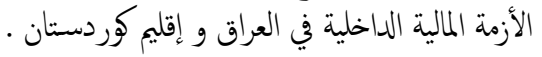

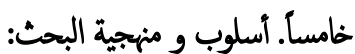

من أجل تحقيق هدف البحث، فقد تم الوعتماد على المنهج الوصفي - التحليلي المقارن

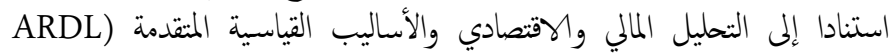

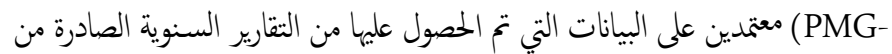
المصارف (عينة البحث). (Pعند البيان

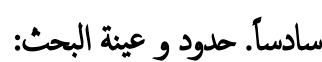

يهدف تحقيق هدف البحث واثبات فرضياته تم اختيار بمحوعة من المصارف العاملة

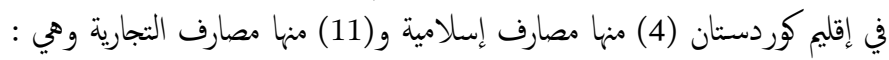

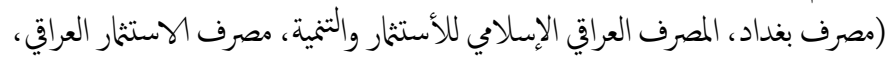

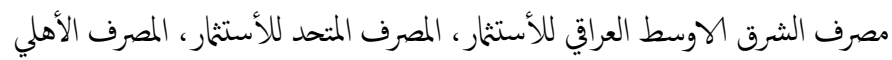

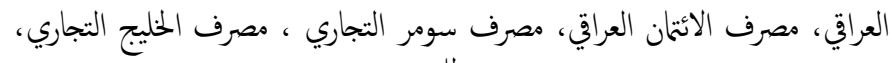

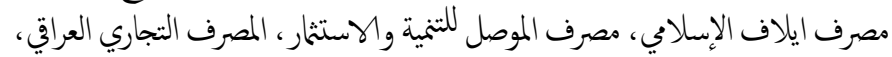

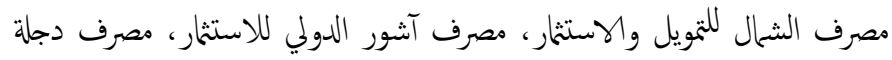

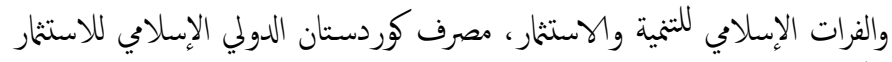

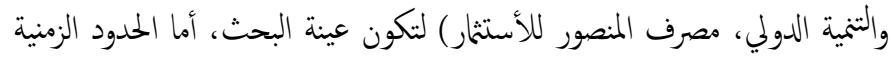

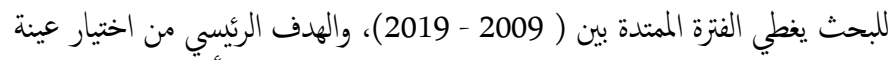

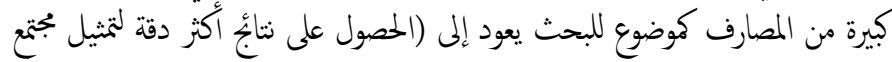

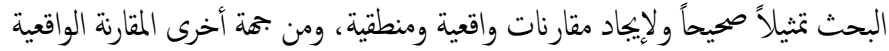

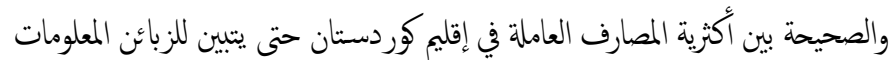

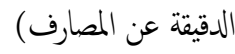

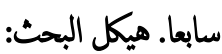

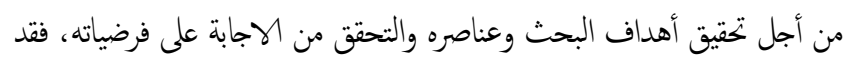

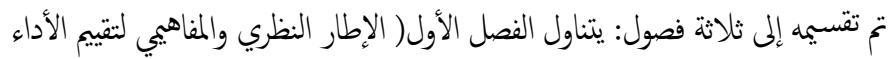

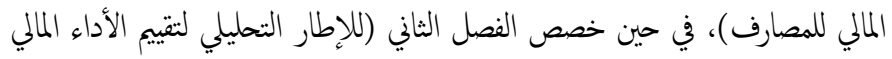

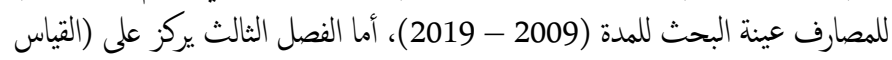

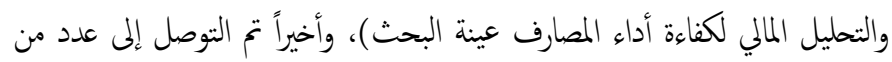

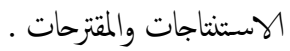

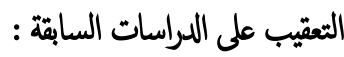

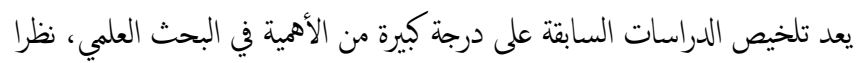

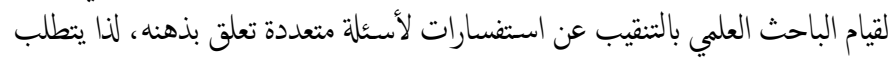

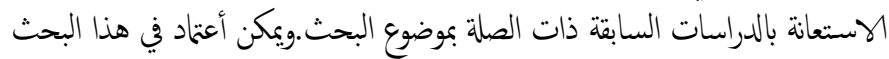

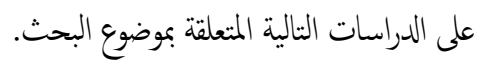

\section{منهجية البحث و الدراسات السابقة}

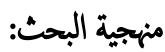

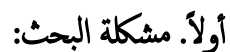

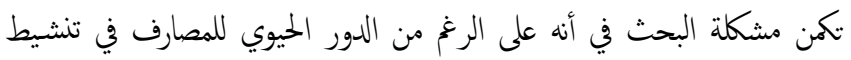

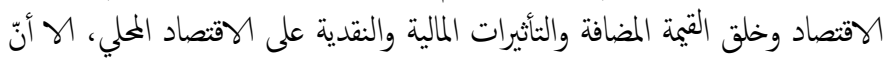

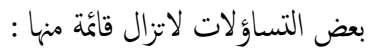
1. إلى أي مدى تحقق المصارف المختارة أهدافها المحددة وفقا لقدرتها المالية المتاحة

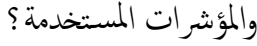

2. إلى اي مدى ساهت المصارف في تحقيق الاستقرار المالي وفقا لقدرتها السوقية

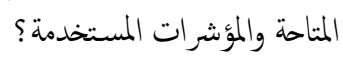

3. هل يساهم تقييم الأداء المالي للمصارف في تعزيز موقعها التنافسي ؟

\section{ثانياً. أهمية البحث :}

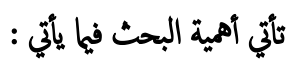

1. الدور الحيوي للمصارف في تنشيط المئ الاقتصاد من خلال دور الوساطة المالية

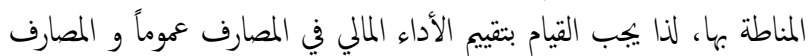

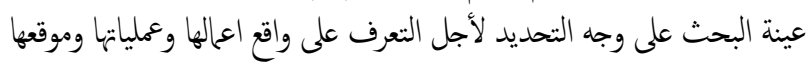
التنافسي في ميدان التعاملات المصرفية . 2. التعرف على كفاءة أداء المصارف العاملة في إقليم كوردستان بالإعتاد على الثلى

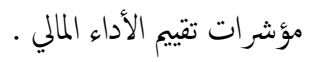

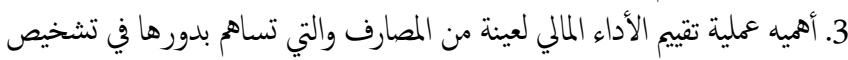

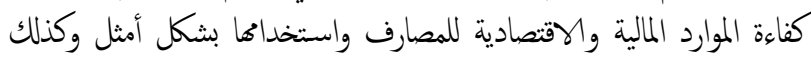

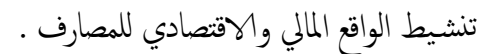

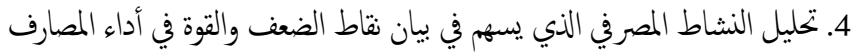

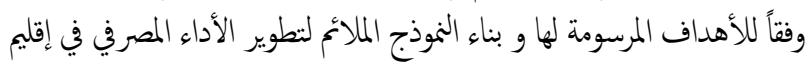

$$
\begin{aligned}
& \text { كوردستان - العراق . } \\
& \text { ثالثاً. هدف البحث : } \\
& \text { مهدف البحث إلى : }
\end{aligned}
$$

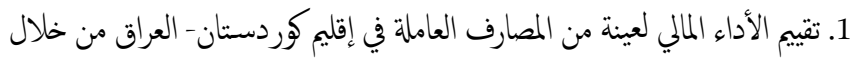
الاعتماد على أهم المعايير والمؤشرات الرئيسة في تقييم الأداء المالي.

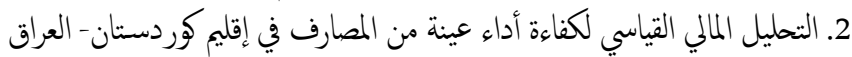

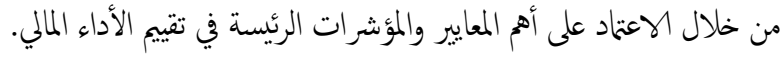

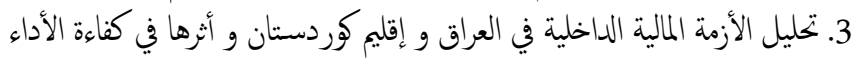
لعينة من المصارف بالاعتاد على الأساليب القياسية المتقدمة.

$$
\text { رابطلق البحث من البحث : }
$$

1. يساهم تقييم الأداء المالي في تعزيز المركزالمالمي والقدرات التنافية المناتية للمصارف عينة 


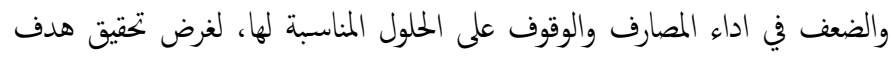

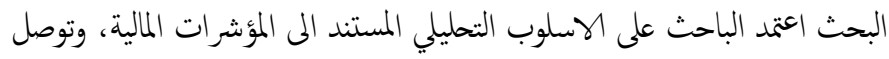

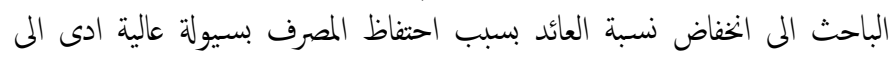

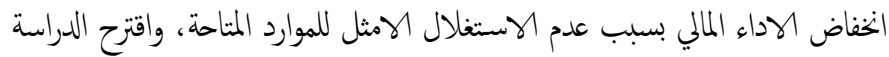

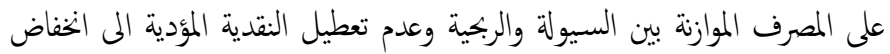

$$
\text { مؤثرات الربكية. }
$$

\section{6. نعان محصول و سراح موصو (2019) :}

بعنوان تقييم الأداء الملالي للبنوك التجارية (دراسة حالة بعان بنك المؤسسة العربية المصرفية

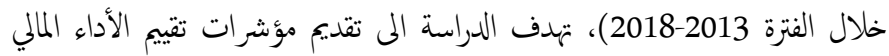

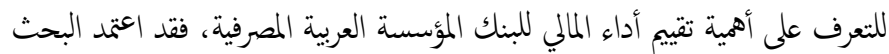

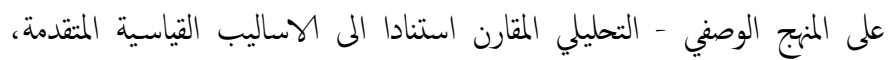

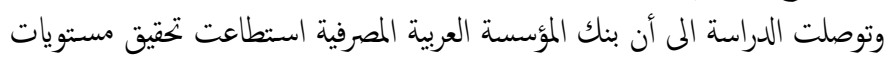
ربحية جيدة، ويفسر هذا بقدرته على استغلال الموارد المتاحة أمامه بكفاءة وفعالية .

\section{7 دراسة (2012)Doan Siscus Kaldianto Lingga and Junius Tirok} بعنوان دراسات تجريبية حول إيفا ونسبة الربحية المرتبطة بعائد الأسهم السنوي

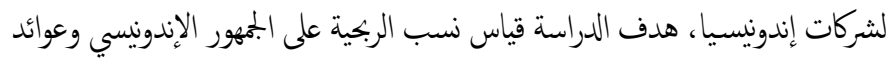

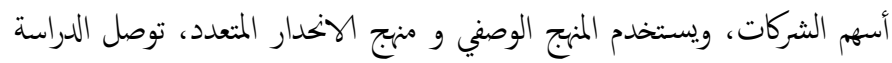

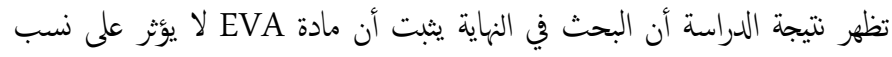

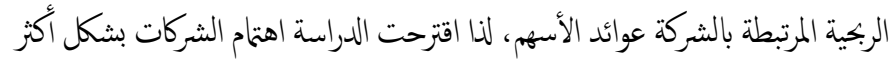

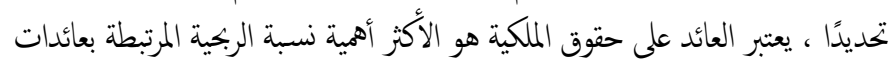

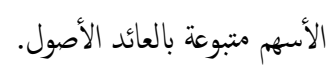

8 (2017) Iqbal Thonse Hawaldar دراسة بعنوان تقييم الأداء المالي للبنوك التجارية، هدف هذه البهابل الدراسة تقيم المالية لأداء البنوك

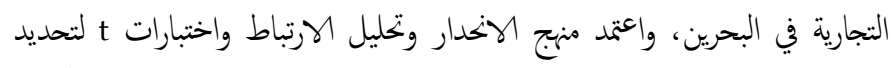

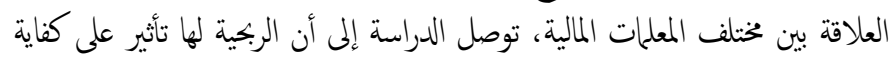

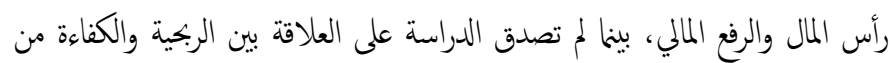

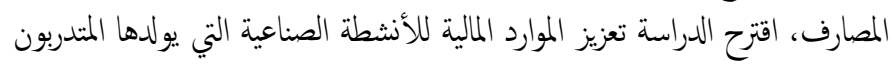
فرص العمل والتنمية الشاملة للبلاد.

\section{المبحث الاول \\ الاطار النظري والمفاهيمي لتقييم الاداء المللي للمصارف}

يعد التقييم عملية منظمة لقياس مدى قدرة الأداء الحالي على إتمام المهام المطلوبة كما

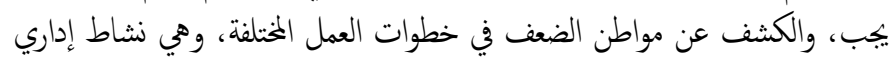

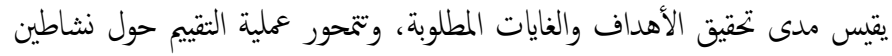

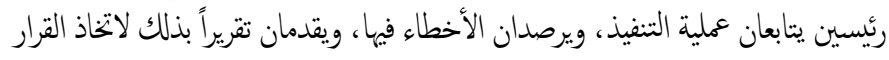

المناسب بشأنهان(مصول و موصو :122، 2019).
1. دراسة احلام بوعبدلي و خليل عبدالرزاق (2002) :

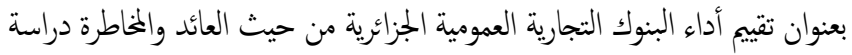

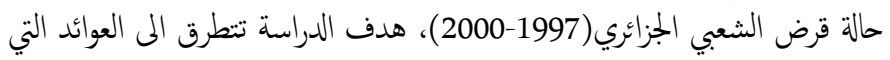

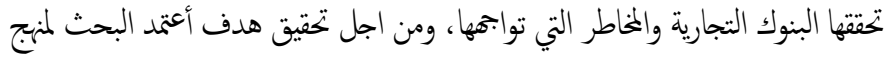

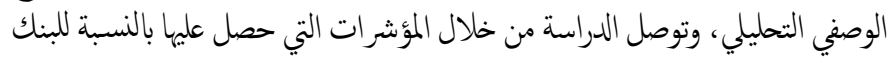

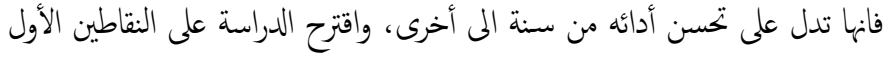

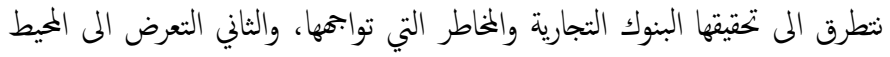

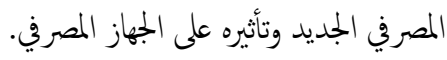

2. دراسة سنان زهير محمد جميل و سوسن احمد سعيد

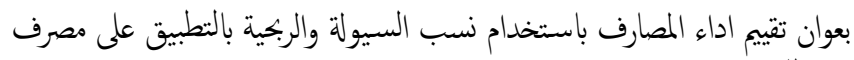

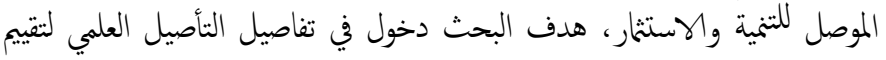

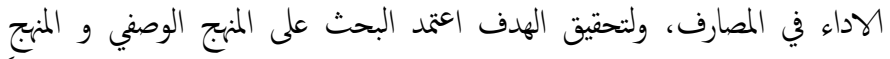

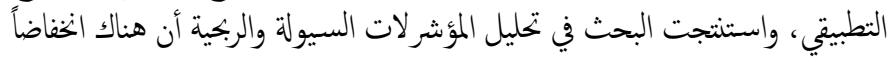

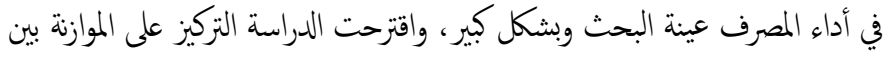

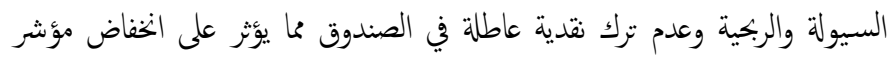

\section{3. دراسة كومي آسبة (2016) :}

بعنوان تثييم أداء البنوك التجارية بواسطة النسب المالية - دراسة تطبيقية خلال

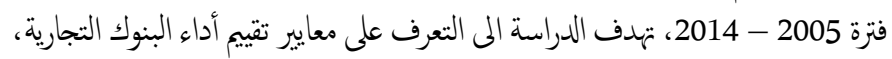

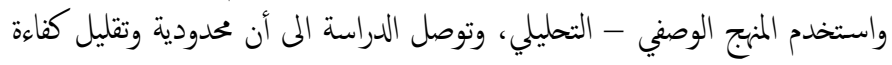

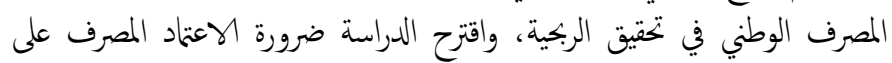

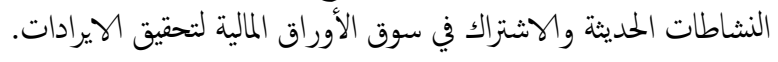

4. دراسة سليان بن بوزيد (2017) :

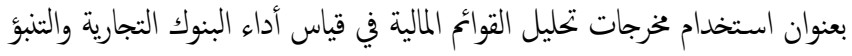

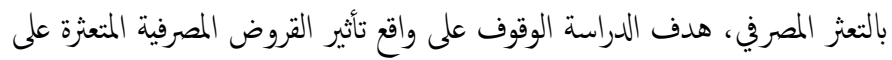

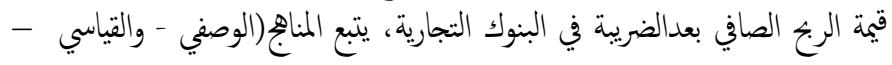

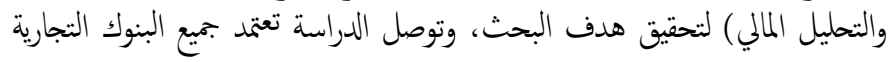

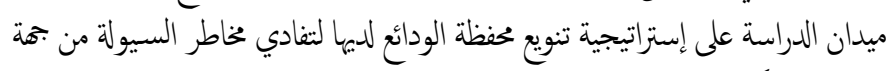

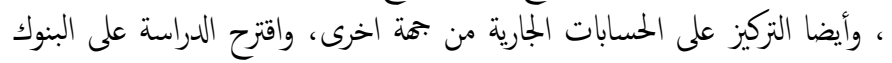

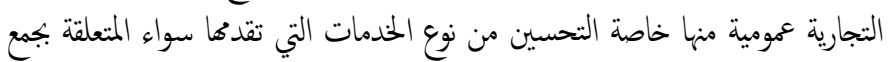

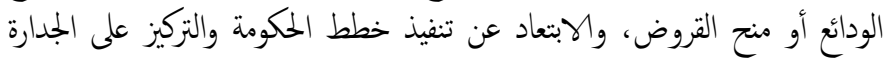

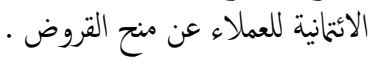

5. 5راسة عثمان أمين احمد (2018) :

تأييم الاداء المصرفي باستخدام ادوات المدات التحليل المالي(النسب المالية) دراسة تطبيقية

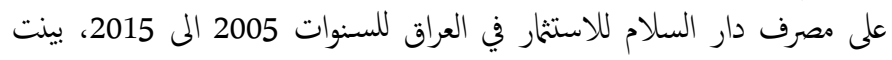

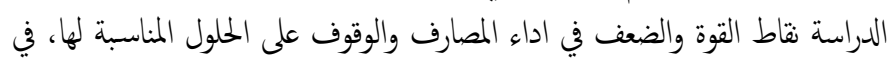
هدف الدراسة ضمان توفير معلومات ذات جودة عالية تمكن من الاثشارة المى نقاط القوة الماند 
ج. على مستوى العمليات يؤدي الى اجراء مسح ميداني شامل للوحدة الاقتصادية

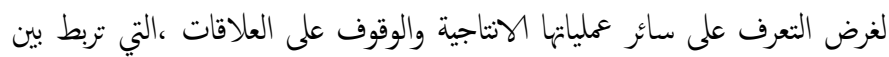

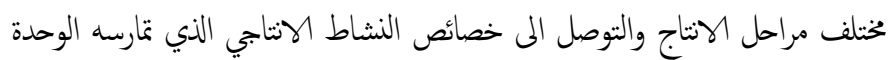

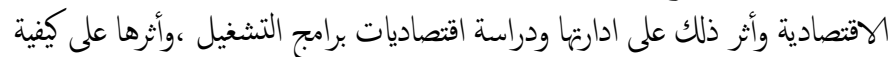

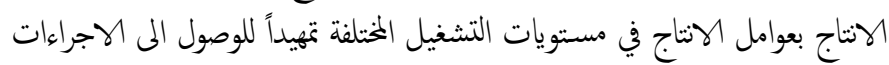

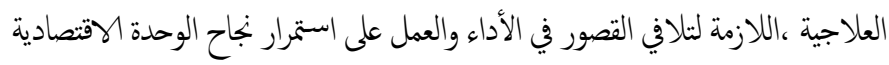

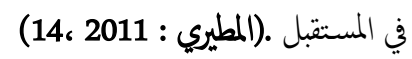

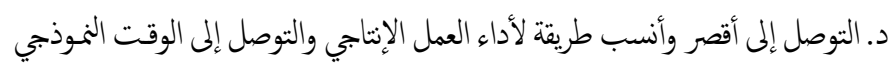

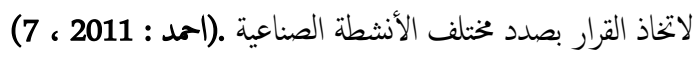

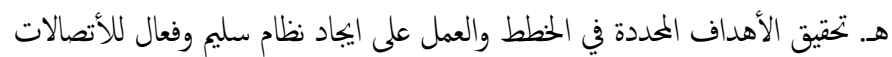

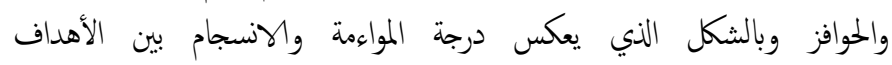
والأستراتيجيات المتمندة وعلاقتها بالبيئة التنافسية للوحدة الأقتصادية (محمد : 2008

. (144،

\section{2. الامية الخاصة :}

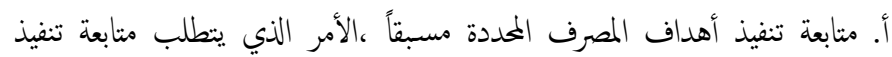

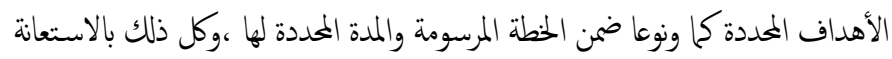

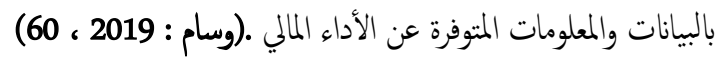

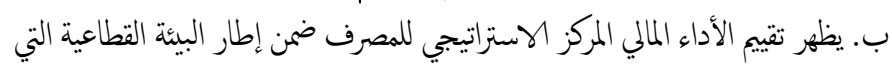

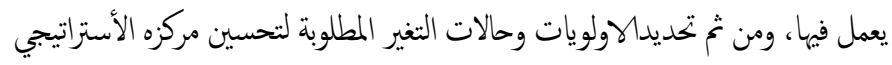

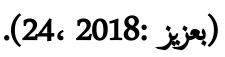

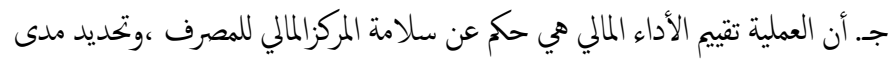

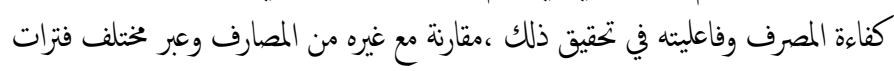

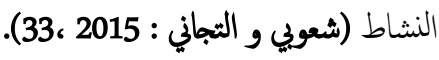
د. تساعد عملية تقييم الأداء المالي على المصارف في الإفصاح عن درجة الماتلألمأمة والانسجام

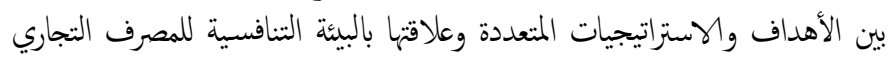

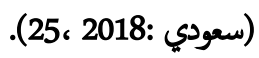

ثالثاً : أهداف الثقييم الملالي في المصارف:

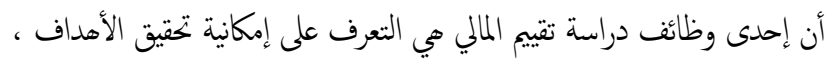

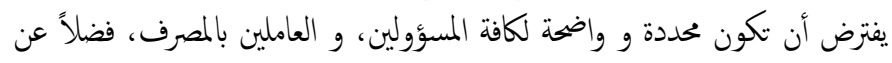

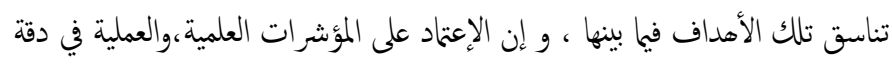

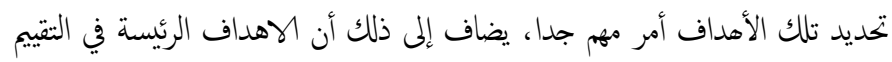

1. الاهداف العامة:

أ. الكشف عن مواصلة الخللل والضعف في نشاط الوحدة الاقتصادية واجراء تحليل

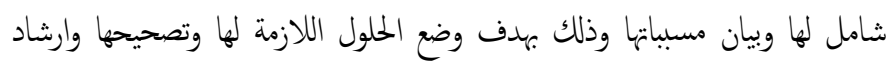

المنفذين الى وسائل تلاقيها مستقبلا (شادي : 2014 ، 42).

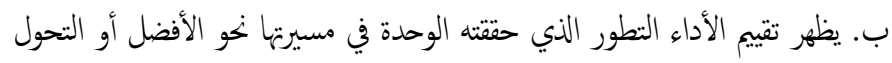

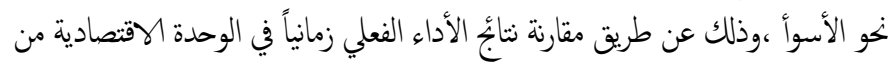

مدة لأخرى و مكانياً مع الوحدات المثاثلة(ناسوسي : 2011 ، 27).
وإن فهم البيانات المالية الخاصة بالنشاط ككل او الأنشطة التابعة من اهم أسباب

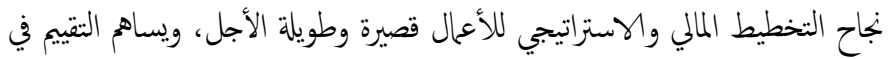

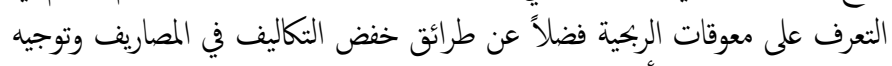

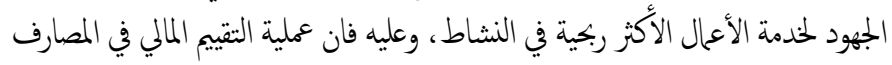

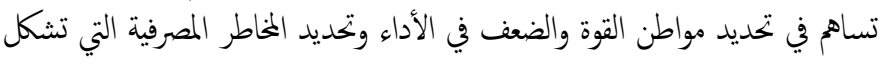

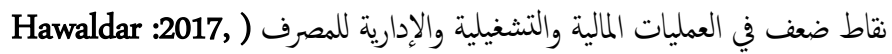

.607

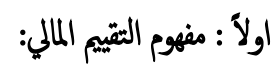

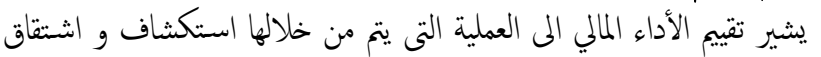

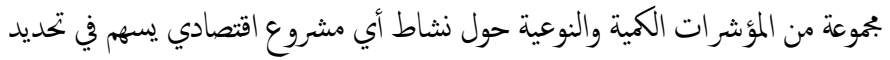

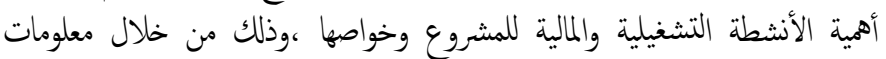

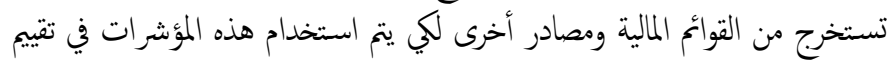

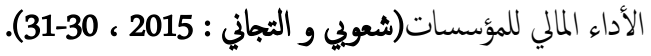

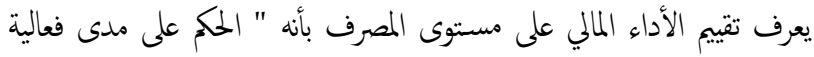

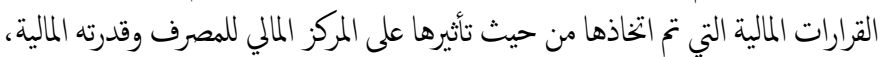

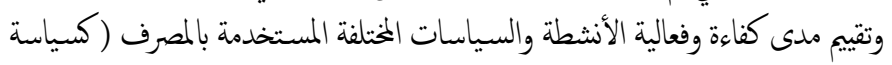

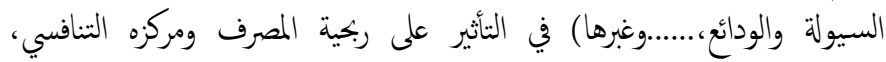

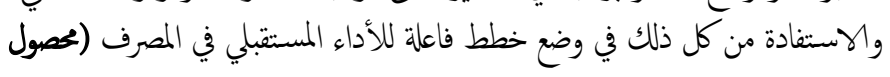

و موصو :123، 2019).

في ضوء ماسبق مككن وضح تعريف لتقييم الاداء المالي في المصارف على أنه

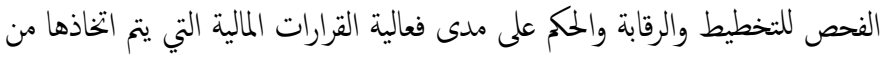

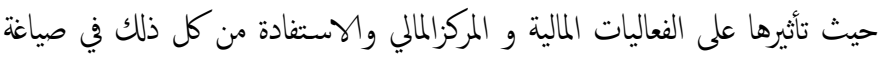

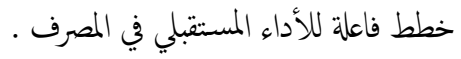

ثانيا : أهمية التقييم الملالي في المصارف: إن استخدام تقييم الاداء المالي بالمصارف يشكل أهمية كبيرة لبيئة العمل فيها،

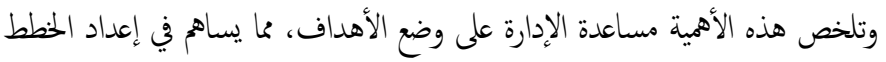

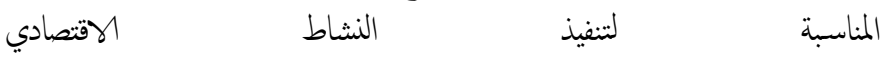
لمساعدة المستثمين على اتخاذ القرار المالي السليم للاستثمار، وبقدر محدد من رأس المال

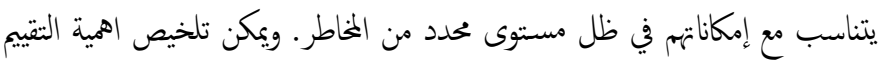

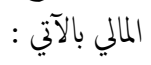

\section{1. الاهمية العامة :}

أ. مساعدة المستويات الإدارية الخختلفة داخل المشروع على اكتشاف الإنرافات والتي

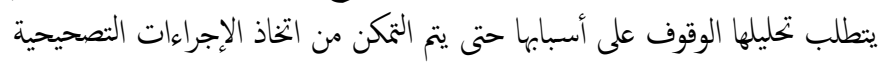

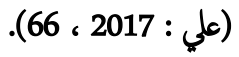

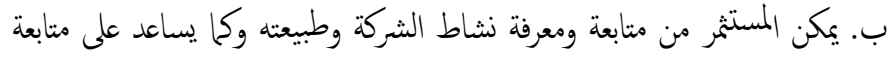

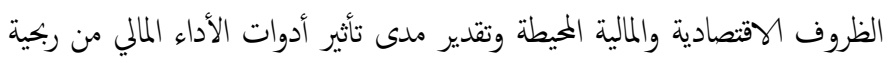

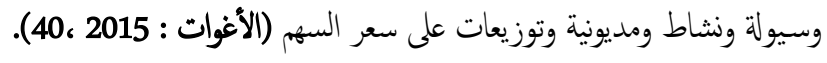


عادة الى صافي رأس المال العامل بكلمة حقيقي عندما يتعلق الأمر بالمكانن

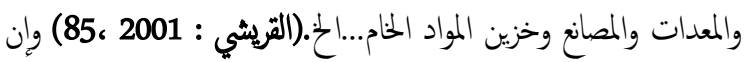

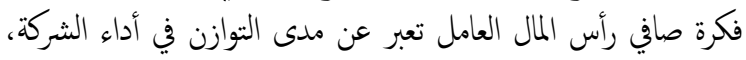
ويمتازبالتغرفي الدوران الأموال، ويحسب على أساس على العاس العلاقة الآتية:

(بودبوز:52،2015)

صافي رأس المال العامل = الموجودات المثداولة - المطلوبات المتداولة 3.هامش صافي اليح (Net Profit Margin) : تعد هذه النسبة مؤشر على كفاءة إدارة الشركة في تحقيق أرباح صافية من الايرادادات، فكلما

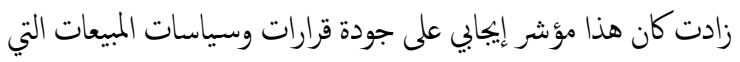

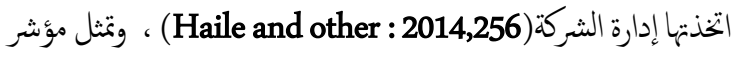

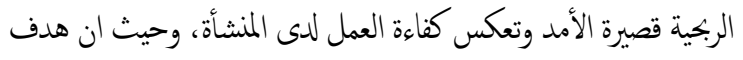

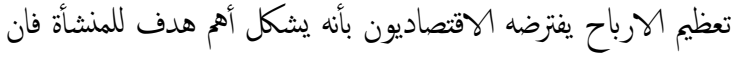

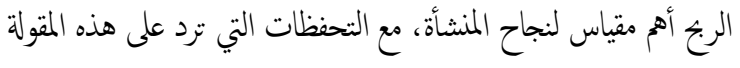
2001 : 248 في

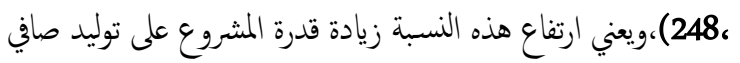

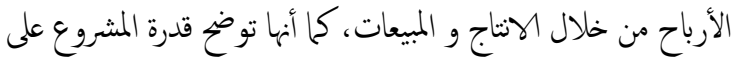

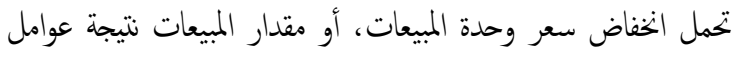

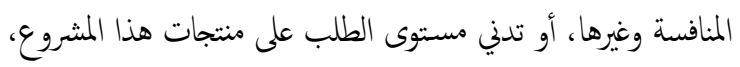

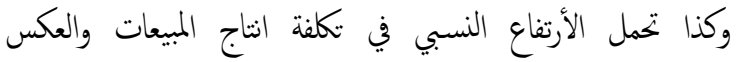

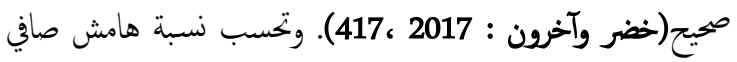

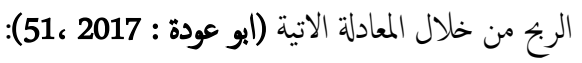

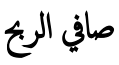

\section{هامش صافي الريح}

\section{الإيرادات}

4. نسبة القمة السوقية الى الدفترية: تستخدم هذه النسبة من اجل ايياد العلاقة

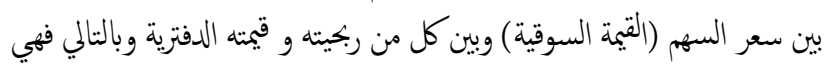

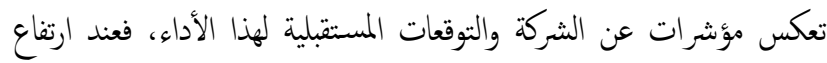

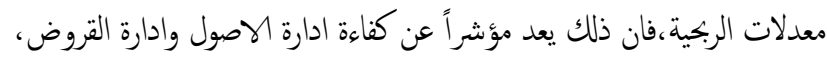

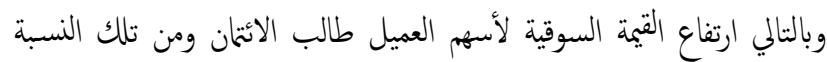

(الهاجري : (Morthy : 2004,23 ; 41، 2016 )

سعر السوقي للسهم

نسبة القيمة السوقية المى الدفتية

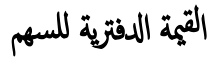

5. معدل العائد على السهم (Rate of Return Per share) :يوضح هذا المعدل نصيب السهم الواحد من صافي الريح بعد الضرائب، سواء في صورة توزيعات
جـ تصحيح الموازنات التخطيطية ووضع مؤشراتها في المسار الصحيح بما يوازن بين

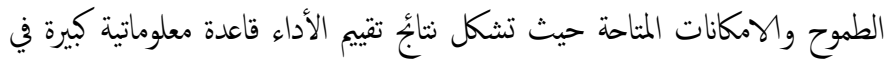
رسم السياسات و الخطط العلمية البعيدة عن المزاجية و التقديرات غير الواقعية (وساء

.61، 2019 :

:

أ. بهدف تقييم الاداء الملالي في مجال المصارف الم قياس مدى كفاءتها في استخدام الموارد

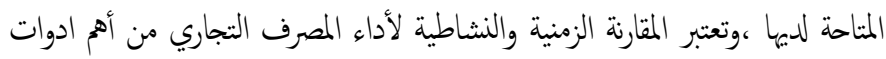

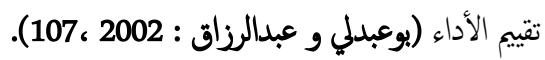

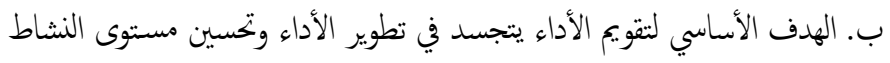

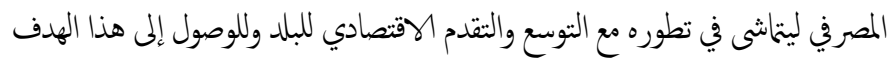

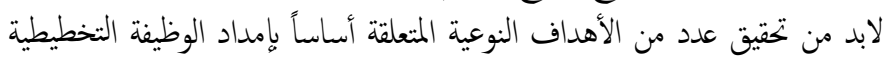
والإنشرافية بالمعلومات والبيانات التي تمكهم من حسن أدائه الأهم المهامم (زيود و آخرون :

(181، 2005 رابعا: معايير ومؤشرات الثتييم الملالي في المصارف :

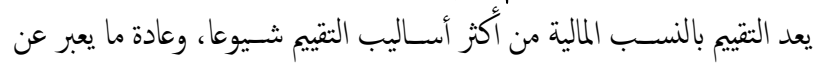

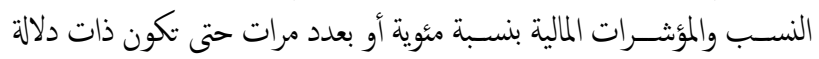

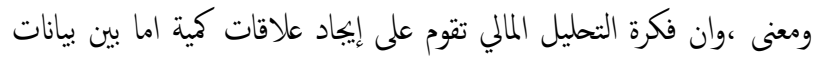

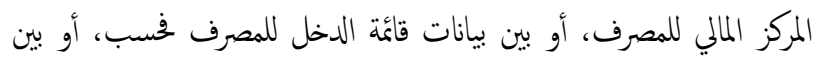

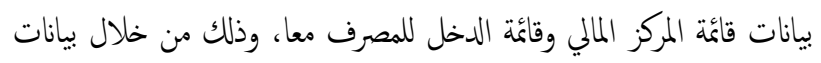

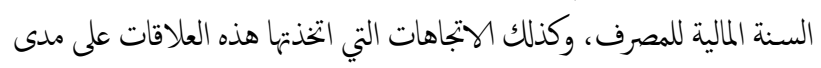

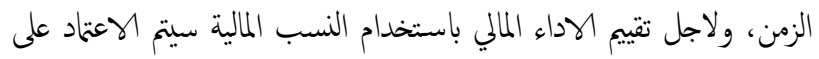

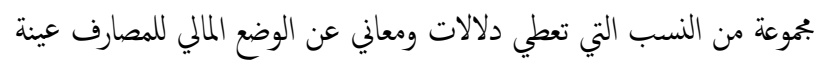
البحث وكالآتي : (Singh : 2020,22)

1 ـ نسبة الثداول (CURRENT RATIO) : وهي تقيس مدى كفاية

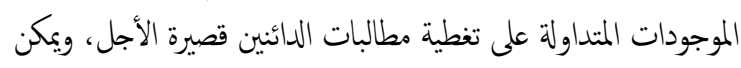

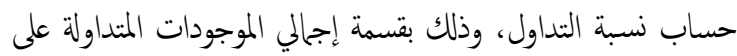

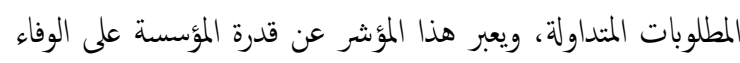

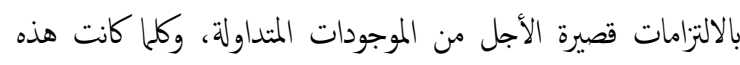

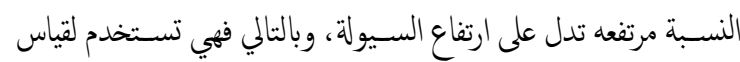

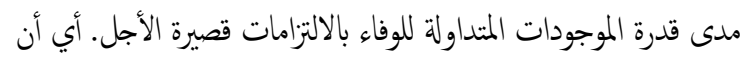

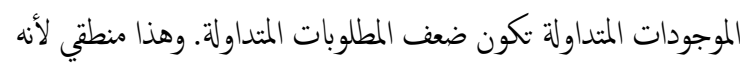

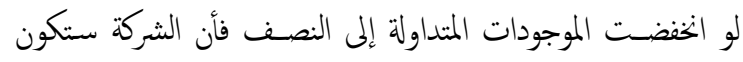

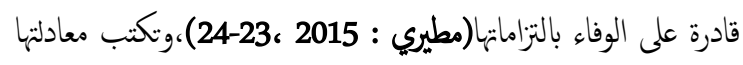

$$
\text { كما يلي (وحيد : } 2018 \text { ، 14): }
$$

الموجودات المثداولة

المطلوبات المثداولة

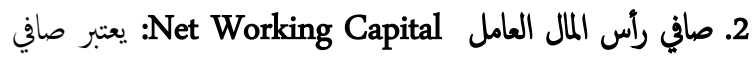

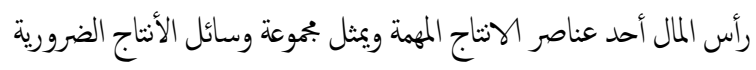

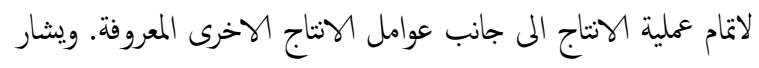




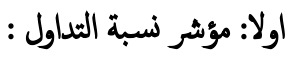
من الممكن أن يتم تقييم المصارف عينة البحث وفقا لمؤشر نسبة التداول وهي في

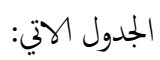

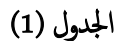

مؤشر نسبة التداول للمصارف عينة البحث

\begin{tabular}{|c|c|c|c|c|c|c|c|c|c|c|c|c|}
\hline مستوى/لمصرف على & 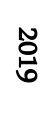 & 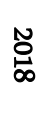 & 号 & 予 & $\begin{array}{l}\text { O } \\
\text { 它 }\end{array}$ & 总 & 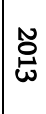 & 号 & 总 & 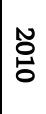 & ర్రి & المصارف / المنوات \\
\hline $\begin{array}{l}\mathscr{\infty}_{\infty} \\
\dot{\vec{v}}\end{array}$ & $\dot{i}$ & $\omega$ & ن̈ & $\stackrel{N}{N}$ & $\ddot{i}$ & $\overrightarrow{i v}$ & $\stackrel{\vec{H}}{\dot{A}}$ & $\dot{i}$ & $\dot{\omega}$ & $\dot{t}$ & फ़ & بغداد \\
\hline 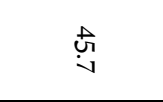 & $\stackrel{\theta}{\theta}$ & $\dot{0}$ & $\stackrel{w}{v}$ & $\dot{\omega}$ & $\stackrel{\infty}{\infty}$ & $N$ & $\stackrel{\omega}{\omega}$ & 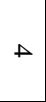 & $\ddot{i}$ & $\triangle$ & بூ & الإسلامي \\
\hline 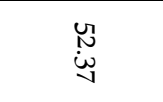 & & $\stackrel{+}{\dot{t}}$ & $\stackrel{\omega}{\dot{\omega}}$ & in & $\ddot{i}$ & $\overrightarrow{i 6}$ & $\stackrel{u}{i}$ & $a$ & $\ddot{i}$ & $\stackrel{v}{\infty}$ & $\stackrel{+\infty}{\infty}$ & الاستثمار \\
\hline $\begin{array}{l}\mathscr{N}_{\text {N }} \\
\text { }\end{array}$ & ن्w & $\stackrel{n}{i}$ & ir & $\stackrel{N}{i}$ & $\ddot{i}$ & $\stackrel{+\infty}{\infty}$ & $\overrightarrow{\dot{\omega}}$ & $\underbrace{0}_{0}$ & $\stackrel{\vec{v}}{v}$ & $\vec{\sigma}$ & $\dot{w}$ & الأوسط شرق \\
\hline 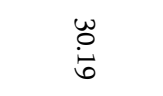 & $\stackrel{\vec{i}}{i^{\prime}}$ & $\stackrel{N}{6}$ & $\stackrel{n}{\sim}$ & N & $\dot{w}$ & $\dot{N}$ & $\stackrel{N}{\dot{r}}$ & $\stackrel{5}{v}$ & $\ddot{\dot{\phi}}$ & $\omega$ & $\stackrel{\vec{\omega}}{\dot{\omega}}$ & للأستثمر \\
\hline $\begin{array}{l}\stackrel{\sim}{\omega} \\
\dot{\omega}\end{array}$ & $\dot{\omega}$ & $\stackrel{N}{i}$ & $\ddot{a}$ & $\tilde{\omega}$ & $\stackrel{N}{\infty}$ & $\stackrel{N}{\stackrel{N}{\perp}}$ & $\ddot{v}$ & $\mathscr{w}_{i}$ & N & $\stackrel{N}{N}$ & $\vdash$ & لأهلي العراقي \\
\hline$\stackrel{u}{\dot{\omega}}$ & $\stackrel{u}{-}$ & $\stackrel{2}{i}$ & $\stackrel{v}{v}$ & v & $\stackrel{v}{i}$ & $i$ & $\underset{\sigma}{\omega}$ & $\stackrel{w}{i}$ & $\dot{\omega}$ & ŭ & $\stackrel{N}{i}$ & لألتمان العراقي \\
\hline$\underset{\dot{\omega}}{\stackrel{w}{\omega}}$ & $\stackrel{9}{-}$ & $\ddot{\dot{\phi}}$ & $\stackrel{N}{\infty}$ & $\stackrel{+}{\infty}$ & $\stackrel{+}{\infty}$ & $\underset{\infty}{\omega}$ & فे & $\dot{\infty}$ & $\dot{\sigma}$ & $\dot{i}$ & na & سومر التجاري \\
\hline 岕 & ஸे & $\stackrel{w}{i}$ & w & $\stackrel{\omega}{\dot{\phi}}$ & $\dot{i}$ & $\stackrel{\sim}{\omega}$ & $\stackrel{N}{i}$ & $\dot{5}$ & $\dot{\omega}$ & $\dot{v}$ & $\ddot{\sigma}$ & التجاري \\
\hline 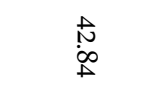 & $\stackrel{\omega}{\dot{\omega}}$ & $\stackrel{N}{\sigma}$ & $\ddot{i}$ & $\ddot{i}$ & $\ddot{\sigma}$ & $\stackrel{N}{\infty}$ & $\underset{\sigma}{\omega}$ & $\ddot{\sharp}$ & $\dot{\omega}$ & $\omega$ & $N$ & الإسلافي \\
\hline$\underset{\stackrel{w}{w}}{\stackrel{w}{w}}$ & $\infty$ & $\overrightarrow{i r}$ & $\checkmark$ & $\ddot{\infty}$ & $\dot{t}$ & $\hat{\sigma}$ & $+\infty$ & aे & $\tilde{\sigma}^{\omega}$ & $\ddot{v}$ & $\dot{0}$ & الموصل \\
\hline $\begin{array}{l}\hat{D} \\
\dot{0}\end{array}$ & $\omega$ & $\dot{i}$ & $\dot{\omega}$ & $u$ & $\dot{a}$ & بَ & $\underset{\dot{\omega}}{\omega}$ & $\stackrel{\omega}{\dot{\phi}}$ & $\ddot{w}$ & $\dot{\vec{t}}$ & 它 & التجاري \\
\hline $\begin{array}{l}\vec{\circ} \\
\dot{\square}\end{array}$ & N & $\stackrel{n}{n}$ & ن & $\dot{i}$ & $\dot{\omega}$ & $\stackrel{N}{\stackrel{N}{*}}$ & $\vec{i}$ & $\stackrel{N}{\mathrm{~N}}$ & $\dot{5}$ & N & $\dot{\omega}$ & الشمال \\
\hline$\stackrel{N}{\stackrel{N}{H}}$ & $\vdash$ & $\overrightarrow{\dot{a}}$ & بூ & $\dot{\infty}$ & 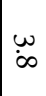 & $\stackrel{N}{\sim}$ & $\vec{\sigma}$ & $\stackrel{w}{\dot{\omega}}$ & $\dot{\infty}$ & N & $\stackrel{N}{i}$ & لشاستثمار آشور الدي \\
\hline $\begin{array}{l}\stackrel{\infty}{\infty} \\
\dot{\omega}\end{array}$ & $\dot{\omega}$ & $\stackrel{+}{\infty}$ & $\stackrel{\infty}{\infty}$ & iे & $\ddot{i}$ & $\begin{array}{l}\infty \\
\alpha\end{array}$ & $\ddot{\omega}$ & $\underset{i}{w}$ & $\stackrel{n}{y}$ & $\stackrel{n}{r}$ & $\stackrel{N}{\infty}$ & الفراتل \\
\hline $\begin{array}{l}\text { P } \\
\text { in }\end{array}$ & $\stackrel{\vec{b}}{\vec{b}}$ & $\ddot{i}$ & wa & $\ddot{\infty}$ & $\leftarrow$ & & $\stackrel{\bullet}{v}$ & $\stackrel{v}{v}$ & $\overrightarrow{\dot{\omega}}$ & $\overrightarrow{\text { vr }}$ & $\stackrel{\infty}{i}$ & الالدوليت \\
\hline
\end{tabular}

نقدية على المساهمين، أو في صورة تكوين احتياطات وأرباح غير موزعة ،ويكن

يجسب كالآتي : (Lingga and Tirok : 2012,99)

\section{صافي الارباح بعدالضرائب}

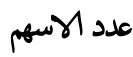

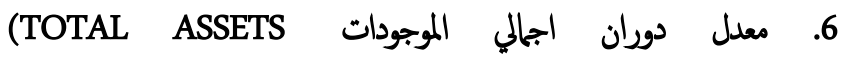
6 :يستعمل هذا المعدل كمقياس لمدى كفاءة إدارة الشركة في استخدام:TURNOVER)

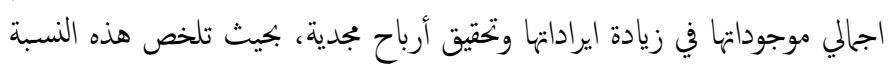

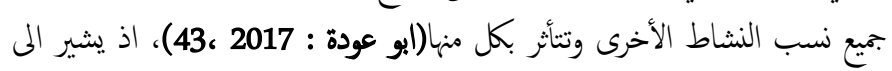

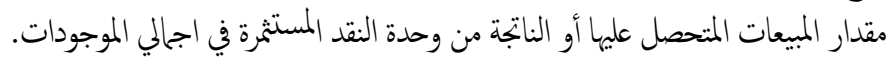

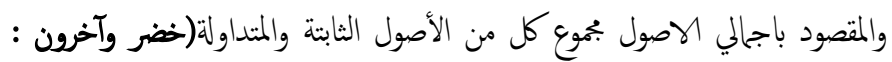

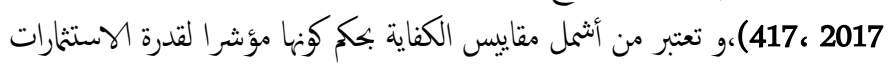

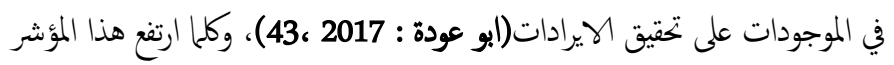

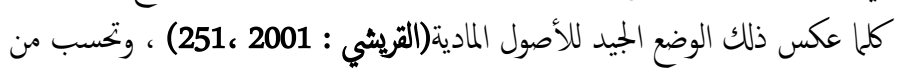

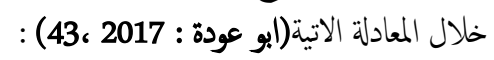
الايرادات

$$
\text { معدل دوران اجلالي الموجودات = }
$$

اجالي الموجودات

\section{المبحث الثاني \\ الاطار التحليلي لثقييم الاداء المالي للمصارف عينة البحث \\ للمدة (2009 - 2019)}

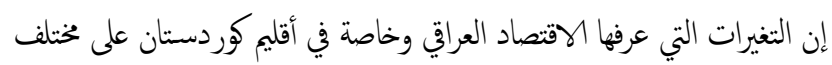

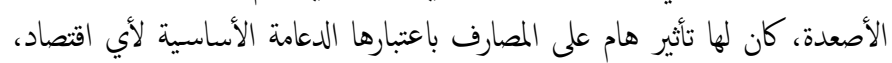

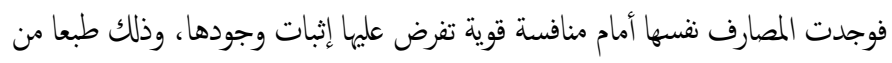

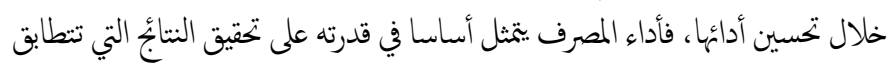

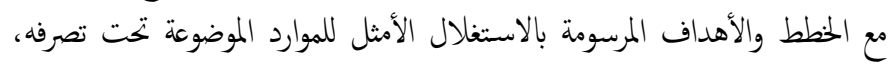

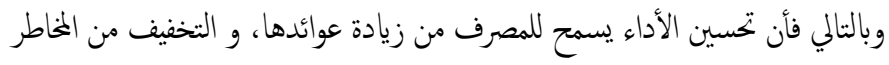

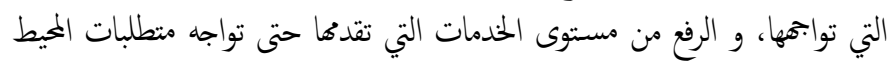

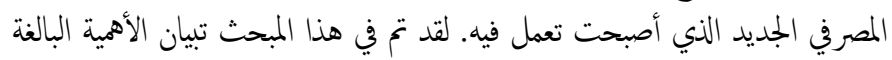

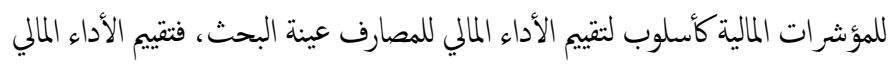

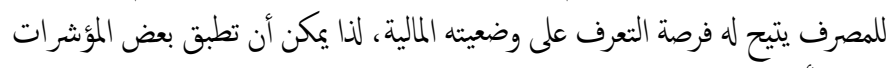

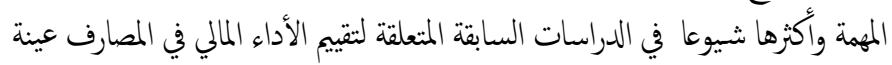
البحث للمدة (2009 - 2019) وكالآتي : 
من الممكن أن يتم تقييم المصارف عينة البحث وفقا لمؤشر صافي رأس المال العامل والتي تم ذكها سابقا وهي كما تزد في الجدول الانتي:

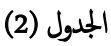

مؤشر صافي رأس المال العامل للمصارف عينة البحث

\begin{tabular}{|c|c|c|c|c|c|c|c|c|c|c|c|c|}
\hline متوسط على & 苋 & 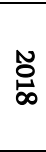 & 号 & ్ㅗㅇ & $\begin{array}{l}\text { O } \\
\text { ज }\end{array}$ & 号 & $\underset{\omega}{\stackrel{N}{\omega}}$ & 号 & 号 & $\begin{array}{l}\text { No } \\
\text { ○े }\end{array}$ & ర్ర్ర & المسنوات / المات \\
\hline 175.1 & $\begin{array}{l}\text { y్ } \\
\text { an }\end{array}$ & ָু & $\stackrel{\sqrt[N]{ }}{ }$ & $\begin{array}{l}\vec{N} \\
\dot{\omega}\end{array}$ & $\stackrel{N}{N}$ & $\underset{\sim}{\sim}$ & $\underset{\sim}{N}$ & $\vec{\Phi}$ & $\begin{array}{l}\overrightarrow{0} \\
\text { an }\end{array}$ & $\begin{array}{l}\infty \\
\infty \\
\text { نा }\end{array}$ & $\begin{array}{l}\not \\
\dot{\alpha}\end{array}$ & بغداد \\
\hline 192 & $\begin{array}{l}\text { N్ } \\
0 \\
0\end{array}$ & బ్ & $\stackrel{N}{\infty}$ & $\stackrel{\sim}{\Omega}$ & $\begin{array}{l}\text { U్ } \\
\text { Oू. }\end{array}$ & 点 & $\stackrel{N}{\sim}$ & ज్ & 훕 & 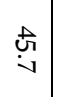 & के & الإسلامي \\
\hline 197.1 & $\underset{\omega}{\infty}$ & ్ㅡㅇ & N & $\begin{array}{l}\tilde{N} \\
2 \\
\infty\end{array}$ & N్ & $\tilde{\sigma}$ & $\vec{\Delta}$ & $\vec{\omega}$ & $\begin{array}{l}\overrightarrow{0} \\
\dot{w} \\
\text { in }\end{array}$ & $\stackrel{\infty}{\stackrel{\infty}{-}}$ & $\begin{array}{l}\text { U } \\
\dot{\sigma}\end{array}$ & العراقتثر \\
\hline 152.9 & 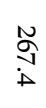 & N & N & 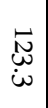 & 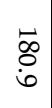 & $\underset{\stackrel{N}{\sim}}{\stackrel{N}{N}}$ & $\vec{v}$ & E & $\underset{\perp}{\vec{D}}$ & $\stackrel{N}{\sim}$ & $\begin{array}{l}\infty \\
i \\
i \sim\end{array}$ & شرق الأوسط \\
\hline 231.2 & $\underset{\perp}{N}$ & W్ & N & హ్ & $\underset{\stackrel{\tilde{\omega}}{\omega}}{\stackrel{\sim}{\omega}}$ & $\begin{array}{l}\stackrel{N}{N} \\
\stackrel{N}{N}\end{array}$ & 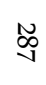 & హ్ & $\begin{array}{l}\tilde{w} \\
\sigma \\
\sigma\end{array}$ & $\begin{array}{l}\vec{y} \\
\dot{\sigma}\end{array}$ & ஓ̊ & المتحد للأستثمار \\
\hline 190.2 & $\begin{array}{l}\text { Wू } \\
\text { ă }\end{array}$ & N্心 & $\stackrel{N}{Y}$ & $\begin{array}{l}\text { హ్ } \\
\sigma\end{array}$ & $\underset{\stackrel{\omega}{\omega}}{\stackrel{\sim}{\omega}}$ & $\begin{array}{l}\tilde{\infty} \\
\stackrel{\infty}{+} \\
\text { N }\end{array}$ & s & $\vec{E}$ & $\underset{\vec{\rho}}{\vec{\rho}}$ & $\vec{b}$ & అ. & الأهلي العراقي \\
\hline 235.8 & $\underset{\stackrel{\omega}{\omega}}{\omega}$ & $\underset{v}{\omega}$ & $\stackrel{\omega}{\omega}$ & $\begin{array}{l}\tilde{e}_{\tilde{W}} \\
\dot{\sigma}\end{array}$ & $\begin{array}{l}\text { No } \\
\stackrel{0}{0} \\
\dot{0}\end{array}$ & 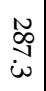 & $\overrightarrow{\&}$ & $\vec{\omega}$ & $\begin{array}{l}\vec{U} \\
\stackrel{D}{v}\end{array}$ & $\underset{\breve{w}}{\breve{w}}$ & $\vec{\sigma}$ & الأنتمان العراقي \\
\hline 170.6 & \begin{tabular}{l}
\multirow{\sigma}{0}{} \\
$\dot{0}$
\end{tabular} & N్ & ஜ & $\begin{array}{l}\tilde{N} \\
\stackrel{+}{\infty}\end{array}$ & 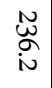 & 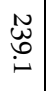 & $\vec{\varnothing}$ & $\Xi$ & $\begin{array}{l}2 \\
\infty\end{array}$ & $\infty$ & UN & سومر التجاري \\
\hline 211.7 & $\underset{\overrightarrow{+}}{\stackrel{\omega}{\vec{t}}}$ & W & $\underset{\infty}{\omega}$ & $\stackrel{N}{\stackrel{N}{y}}$ & $\begin{array}{l}\text { N } \\
\text { N }\end{array}$ & 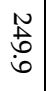 & $\tilde{\Sigma}$ & ज্ & $\underset{i}{\ell}$ & ث্் & $\stackrel{4}{\dot{\omega}}$ & الخليج التجاري \\
\hline 180.5 & $\begin{array}{l}\omega \\
\stackrel{+}{\infty} \\
\dot{0}\end{array}$ & $\stackrel{t}{\omega}$ & $\underset{w}{N}$ & $\begin{array}{l}\text { N } \\
\infty \\
\sigma\end{array}$ & $\begin{array}{l}\stackrel{N}{N} \\
\stackrel{D}{D}\end{array}$ & $\begin{array}{l}\overrightarrow{\vec{\omega}} \\
\text { ir }\end{array}$ & $\breve{\omega}$ & ஜृ & 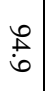 & $\$$ & $\overrightarrow{\dot{\omega}}$ & الإيلاف \\
\hline 203.7 & \begin{tabular}{l}
\multirow{2}{\infty}{} \\
$\infty$ \\
$\dot{1}$
\end{tabular} & $\tilde{\sigma}$ & 藏 & 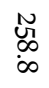 & 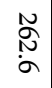 & 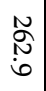 & N & $\stackrel{N}{v}$ & $\begin{array}{l}\infty \\
\sigma \\
\sigma\end{array}$ & $\underset{\text { Uू }}{\text { Uू }}$ & $\underset{\infty}{.}$ & الموصل \\
\hline 245.4 & ن) & స్ & ज్రి & 근 & W్ & 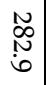 & $\vec{b}$ & $\vec{E}$ & $\begin{array}{l}\vec{w} \\
\underset{\sigma}{ }\end{array}$ & w & $\stackrel{\infty}{\dot{\omega}}$ & التجاري العراقي \\
\hline 207.3 & फ्ठ & & త్ & $\begin{array}{l}N \\
\stackrel{N}{\infty}\end{array}$ & $\begin{array}{l}\text { N } \\
\text { i } \\
\text { in }\end{array}$ & $\underset{\infty}{\mathbb{W}}$ & N & $\stackrel{\bullet}{\ominus}$ & $\begin{array}{l}\infty \\
\infty \\
\dot{v}\end{array}$ & $\underset{\stackrel{N}{N}}{\vec{N}}$ & $\underset{\stackrel{u}{v}}{\vec{v}}$ & الشمال \\
\hline 183.9 & ث & N & $\stackrel{N}{N}$ & $\stackrel{N}{N}$ & $\stackrel{N}{ \pm}$ & $\begin{array}{l}N \\
N\end{array}$ & \& & ખ્心 & 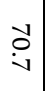 & $\begin{array}{l}\text { ஓे } \\
\dot{A}\end{array}$ & స్ & آشور الدولي \\
\hline 145.2 & $\vec{\sigma}$ & $\vec{E}$ & 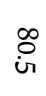 & $\begin{array}{l}\stackrel{\vec{\omega}}{\dot{\omega}} \\
\dot{\omega}\end{array}$ & $\stackrel{N}{\infty}$ & $\begin{array}{l}\text { స్ } \\
\text { نे }\end{array}$ & N్ర & $\vec{N}$ & $\begin{array}{l}\vec{N} \\
+ \\
\infty\end{array}$ & $\stackrel{\omega}{\dot{\omega}}$ & $\stackrel{\overrightarrow{0}}{i}$ & دجلة و الفرات \\
\hline 478.3 & $\begin{array}{l}\text { ज্ } \\
\stackrel{1}{1}\end{array}$ & ळे & Uु & 岕 & $\begin{array}{l}\text { ूू } \\
\text { ì }\end{array}$ & 站 & 命 & W్ర & $\begin{array}{l}\omega \\
0 \\
0\end{array}$ & 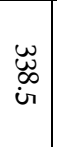 & 䜣 & كوردستان الالدولي \\
\hline 214.7 & N & N্ল & $\stackrel{\Omega}{\not}$ & హ్ & W & N & శ్రి & $\stackrel{n}{ \pm}$ & 芯 & $\stackrel{\infty}{\oplus}$ & $\infty$ & المنصور \\
\hline
\end{tabular}

\begin{tabular}{|c|c|c|c|c|c|c|c|c|c|c|c|c|}
\hline $\begin{array}{l}\stackrel{\partial}{0} \\
\infty\end{array}$ & $\omega$ & $\grave{\infty}$ & $\vec{\sigma}$ & $\overrightarrow{\dot{\omega}}$ & $\vec{F}$ & $\underset{\omega}{\omega}$ & $\stackrel{0}{*}$ & $\stackrel{u}{i}$ & $\omega$ & $\begin{array}{l}n \\
\sigma\end{array}$ & $\stackrel{N}{v}$ & المنصور \\
\hline 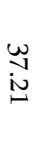 & $\begin{array}{l}\text { W. } \\
\text { in }\end{array}$ & 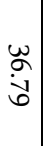 & $\begin{array}{l}\vec{J} \\
\dot{\perp} \\
\dot{t}\end{array}$ & $\begin{array}{l}\omega \\
\stackrel{\omega}{\omega} \\
\stackrel{\omega}{ }\end{array}$ & 岕 & $\underset{\text { i }}{\stackrel{t}{J}}$ & 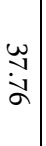 & $\begin{array}{l}\underset{N}{w} \\
\infty \\
\infty\end{array}$ & $\begin{array}{l}w \\
+ \\
\stackrel{N}{u} \\
\text {. }\end{array}$ & $\begin{array}{l}w \\
\dot{\omega} \\
\dot{ర}\end{array}$ & $\begin{array}{l}\infty \\
\dot{c}\end{array}$ & متوسط على \\
\hline
\end{tabular}

\section{الجدول من اعداد الباحثان بالأعثاد على : المقان}

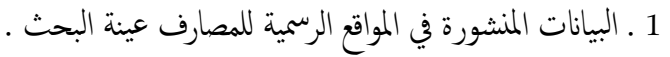

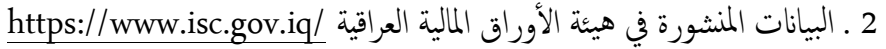

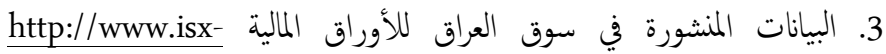
iq.net/isxportal/portal/homePage.html

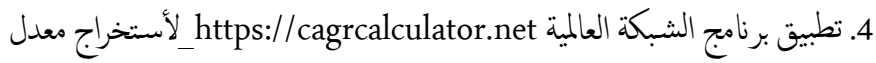

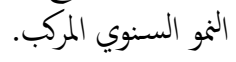

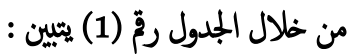

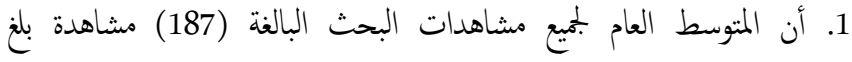

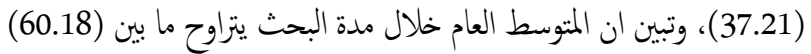

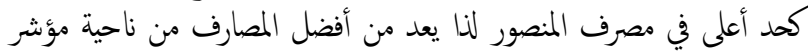

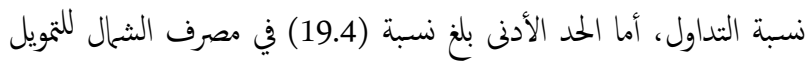

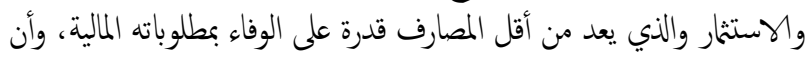

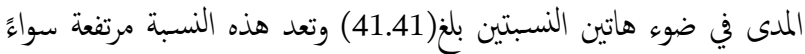

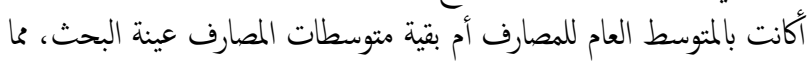

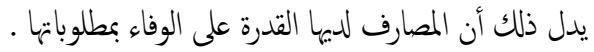

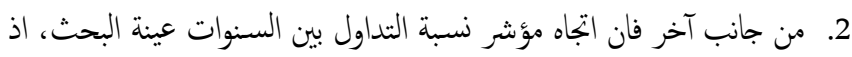

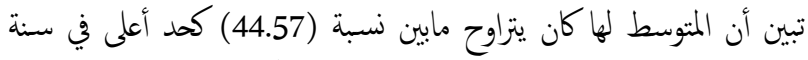

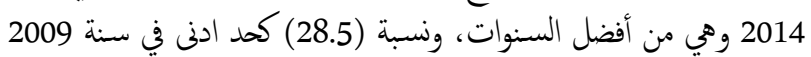

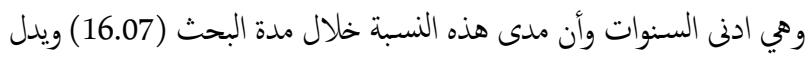

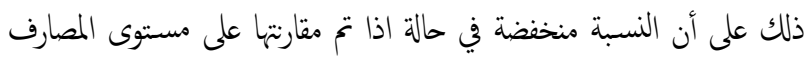

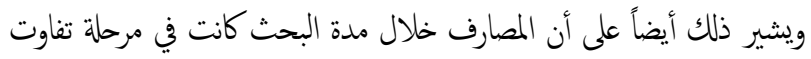

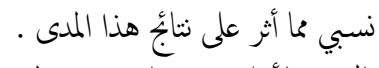

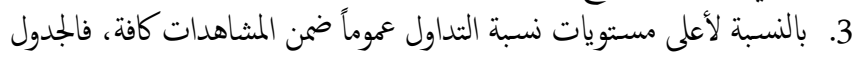

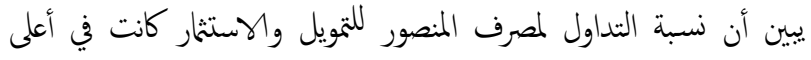

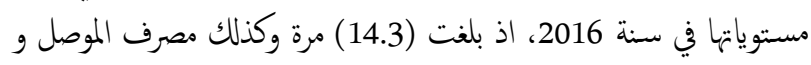

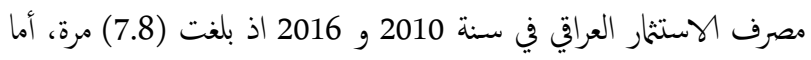

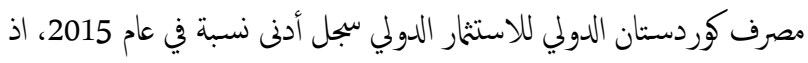

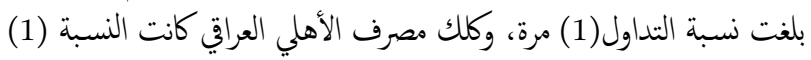

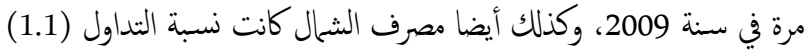

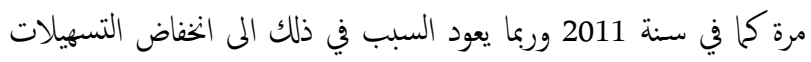

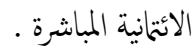

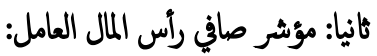


(3) الجدول

مؤشر هامش صافي الريح للمصارف عينة البحث

\begin{tabular}{|c|c|c|c|c|c|c|c|c|c|c|c|c|}
\hline مستوى/ المصرف على & वें & 吕 & సิ่ & 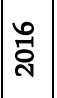 & 预 & ัั & $\stackrel{m}{\tilde{c}}$ & స్ & $\overline{\text { กี }}$ & 옳 & ઠ્તે & المصنوات / المصات \\
\hline 0.03 & $\begin{array}{l}\infty \\
\vdots \\
0 \\
0\end{array}$ & $\begin{array}{l}0 \\
0 \\
0 \\
0\end{array}$ & 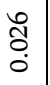 & $\begin{array}{l}\hat{A} \\
0 \\
0\end{array}$ & \begin{tabular}{|l}
$E$ \\
0 \\
0
\end{tabular} & $\begin{array}{l}\stackrel{0}{0} \\
\dot{0} \\
\dot{0}\end{array}$ & $\begin{array}{l}\hat{\tilde{o}} \\
\dot{0}\end{array}$ & $\begin{array}{l}\text { ठ } \\
\text { Oे }\end{array}$ & $\begin{array}{l}\hat{\tilde{O}} \\
0 \\
0\end{array}$ & 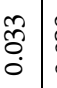 & 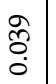 & بغداد \\
\hline 0.04 & 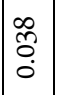 & 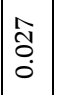 & $\begin{array}{l}\tilde{\tilde{O}} \\
\stackrel{0}{0}\end{array}$ & $\mid \begin{array}{l}\mathscr{\delta} \\
0 \\
0 \\
0\end{array}$ & Õ & $\begin{array}{l}\mathbb{J} \\
0 \\
0\end{array}$ & $\begin{array}{l}\hat{\hat{n}} \\
0 \\
0\end{array}$ & 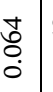 & 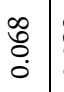 & है. & 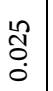 & العراقي \\
\hline 0.12 & 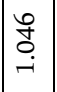 & 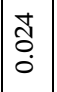 & $\begin{array}{l}\infty \\
0 \\
0 \\
0\end{array}$ & $\overrightarrow{\hat{O}}$ & \begin{tabular}{l}
\multirow{2}{*}{} \\
$\stackrel{0}{0}$
\end{tabular} & $\begin{array}{l}\infty \\
\substack{0 \\
0 \\
0}\end{array}$ & $\begin{array}{l}\text { } \\
\text { } \\
0 \\
0\end{array}$ & 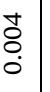 & 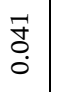 & 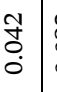 & ల్రి & العراتثنار \\
\hline
\end{tabular}

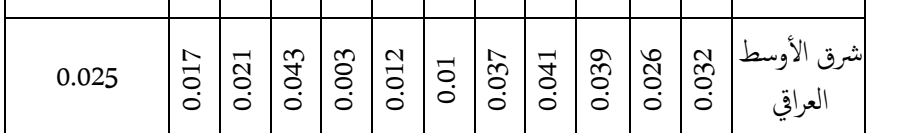

\begin{tabular}{|c|c|c|c|c|c|c|c|c|c|c|c|}
\hline 0.15 & ते & $\underset{\rightarrow}{\mathbb{S}}$ & : & \begin{tabular}{l}
8 \\
\multirow{2}{*}{} \\
0
\end{tabular} & \begin{tabular}{l|l}
$Z$ \\
0 \\
0
\end{tabular} & $\begin{array}{ll}\text { lo } \\
0 \\
0 \\
0\end{array}$ & 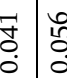 & $\stackrel{8}{8}$ & 范 & గ̂. & للأستثخار \\
\hline
\end{tabular}

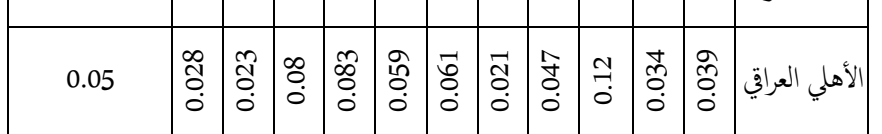

\begin{tabular}{|c|c|c|c|c|c|c|c|c|c|c|c|}
\hline 0.029 & 7 & $\begin{array}{l}\hat{\tilde{o}} \\
\dot{0} \\
\dot{0}\end{array}$ & 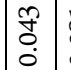 & $\begin{array}{l}\vec{m} \\
\dot{\delta} \\
\dot{0}\end{array}$ & \begin{tabular}{l|l}
$\qquad$ \\
0 \\
0
\end{tabular} & 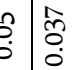 & $\mid \begin{array}{l}1 \\
\dot{0} \\
\dot{0}\end{array}$ & $\begin{array}{l}\text { d } \\
0\end{array}$ & $\begin{array}{l}\tilde{m} \\
\hat{\delta} \\
\dot{0}\end{array}$ & $\stackrel{m}{0}$ & الأتئان العراقي \\
\hline
\end{tabular}

\begin{tabular}{|c|c|c|c|c|c|c|c|c|c|c|c|c|}
\hline 0.03 & $\begin{array}{l}0 \\
\stackrel{0}{0}\end{array}$ & $\begin{array}{l}\text { Iै } \\
\text { ¿े }\end{array}$ & 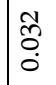 & 令 & 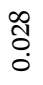 & $\begin{array}{l}m \\
0 \\
0 \\
0\end{array}$ & 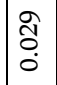 & $\begin{array}{l}\tilde{\delta} \\
\delta \\
0\end{array}$ & $\begin{array}{l}\text { ते } \\
\text { ठठ }\end{array}$ & $\begin{array}{l}\hat{A} \\
\text { Oे } \\
\text { O. }\end{array}$ & $\begin{array}{l}\hat{\delta} \\
\text { Oे } \\
\dot{0}\end{array}$ & سومر النجاري \\
\hline 0.005 & ల్లి & 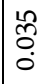 & \begin{tabular}{l}
\multirow{N}{0}{} \\
Oे.
\end{tabular} & $\begin{array}{l}\mathscr{0} \\
\stackrel{0}{0} \\
\stackrel{0}{0}\end{array}$ & $\begin{array}{l}n \\
\stackrel{n}{0} \\
0\end{array}$ & 㕝 & $\begin{array}{l} \pm \\
\text { 蒿 } \\
0\end{array}$ & $\begin{array}{l}\stackrel{\Omega}{0} \\
\stackrel{0}{0}\end{array}$ & \begin{tabular}{l}
$F$ \\
\multirow{0}{*}{}
\end{tabular} & $\begin{array}{l}\text { ते } \\
\text { ¿ें }\end{array}$ & $\begin{array}{l}\hat{⿵} \\
\stackrel{0}{0}\end{array}$ & \\
\hline
\end{tabular}

\begin{tabular}{|c|c|c|c|c|c|c|c|c|c|c|c|c|}
\hline 0.04 & $\stackrel{m}{0}$ & $\begin{array}{l}\stackrel{2}{0} \\
\hat{0} \\
0\end{array}$ & $\begin{array}{l}0 \\
\square \\
0 \\
0\end{array}$ & $\begin{array}{l}\mathscr{1} \\
\tilde{\delta} \\
0 \\
0\end{array}$ & \begin{tabular}{l}
$\infty$ \\
\multirow{0}{0}{} \\
0 \\
0
\end{tabular} & $\begin{array}{l}\vec{m} \\
\dot{\delta} \\
0\end{array}$ & 胥 & $\begin{array}{l}\hat{n} \\
0 \\
0\end{array}$ & oे & $\begin{array}{l}m \\
\mathscr{0} \\
0 \\
0\end{array}$ & \begin{tabular}{l}
5 \\
\multirow{5}{0}{} \\
0
\end{tabular} & الايلاف \\
\hline
\end{tabular}

\begin{tabular}{|c|c|c|c|c|c|c|c|c|c|c|c|c|}
\hline 0.026 & $\begin{array}{l}\hat{o} \\
0 \\
0\end{array}$ & \begin{tabular}{l}
\multirow{2}{*}{} \\
0 \\
0 \\
0
\end{tabular} & $\begin{array}{l}\vec{m} \\
\dot{0} \\
\dot{0}\end{array}$ & $\begin{array}{l}\mathscr{b} \\
\stackrel{1}{i} \\
\dot{i}\end{array}$ & $\mid \begin{array}{l}0 \\
0 \\
0 \\
0 \\
i\end{array}$ & $\stackrel{0}{0}$ & \begin{tabular}{|l|} 
\\
$\varnothing$ \\
0 \\
0
\end{tabular} & $\begin{array}{l}\vec{\delta} \\
0 \\
0\end{array}$ & $\begin{array}{l}n \\
\tilde{O} \\
0 \\
0\end{array}$ & ڤ̂े & 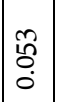 & الموصل \\
\hline 0.04 & $\begin{array}{l}m \\
\text { Oे } \\
0 \\
0\end{array}$ & 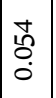 & $\begin{array}{l}\text { Tे } \\
\text { fo. } \\
0\end{array}$ & 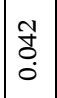 & $\begin{array}{l}\infty \\
\tilde{\sigma} \\
0 \\
0\end{array}$ & 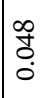 & \begin{tabular}{l}
$\mathcal{y}$ \\
\multirow{0}{0}{} \\
0 \\
0
\end{tabular} & $\begin{array}{l}\hat{A} \\
0 \\
0\end{array}$ & $\begin{array}{l}\text { No } \\
0 \\
0\end{array}$ & $\begin{array}{l}\infty \\
0 \\
0 \\
0\end{array}$ & 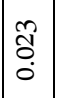 & العراقي \\
\hline 0.09 & $\begin{array}{l}0 \\
\dot{i} \\
\dot{i}\end{array}$ & \begin{tabular}{|l|}
2 \\
$\tilde{m}$ \\
0 \\
0
\end{tabular} & $\vec{i}$ & $\begin{array}{l}0 \\
0 \\
i\end{array}$ & $\begin{array}{ll}7 \\
\\
0 \\
\end{array}$ & 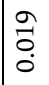 & $\underset{0}{0}$ & 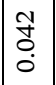 & $\begin{array}{l}\infty \\
\tilde{c} \\
0 \\
0\end{array}$ & $\begin{array}{l}\hat{\tilde{O}} \\
0 \\
0\end{array}$ & 苑 & الشمال \\
\hline
\end{tabular}

\begin{tabular}{|c|c|c|c|c|c|c|c|c|c|c|c|c|}
\hline 0.04 & $\begin{array}{l}\hat{o} \\
0 \\
0\end{array}$ & $\mid \begin{array}{c}\hat{N} \\
0 \\
\dot{0}\end{array}$ & $\mid \begin{array}{l}0 \\
0 \\
0 \\
0\end{array}$ & $\begin{array}{l}\text { tै } \\
\text { Oे. }\end{array}$ & $\mid \begin{array}{l}\tilde{D} \\
0 \\
0 \\
0\end{array}$ & $\begin{array}{l}\text { ते } \\
\text { o. }\end{array}$ & $\begin{array}{l}\vec{n} \\
0 \\
0\end{array}$ & $\ddot{0}$ & $\begin{array}{l}\text { do } \\
\text { Oे }\end{array}$ & $\begin{array}{l}0 \\
0 \\
0 \\
0 \\
0\end{array}$ & $\begin{array}{l}\mathscr{L} \\
\text { ô } \\
0\end{array}$ & آلاستثرار الدولي \\
\hline & $\begin{array}{l}\vec{b} \\
0 \\
0 \\
i\end{array}$ & $\mid$ & $\begin{array}{l}\infty \\
0 \\
0 \\
0 \\
i\end{array}$ & $\begin{array}{l}0 \\
\text { : } \\
\text { i }\end{array}$ & ్ָָ & : & 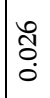 & 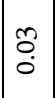 & $\begin{array}{l}\tilde{n} \\
\tilde{\delta} \\
0 \\
0\end{array}$ & $\begin{array}{l}\text { I } \\
\text { Oे }\end{array}$ & $\begin{array}{l}\infty \\
0 \\
0 \\
0 \\
0\end{array}$ & دجلة و الفرات \\
\hline
\end{tabular}

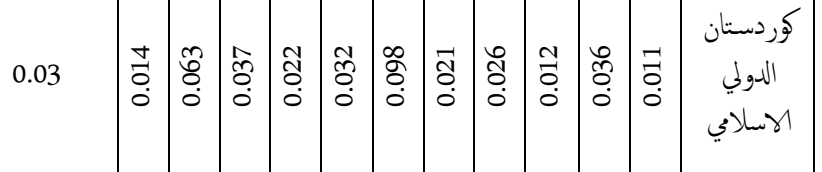

\begin{tabular}{|c|c|c|c|c|c|c|c|c|c|c|c|c|}
\hline 218.6 & 岕 & $\underset{w}{w}$ & 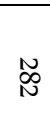 & 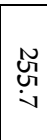 & $\underset{i}{\sim} \underset{i}{\sim}$ & హ్ & $\stackrel{N}{N}$ & $\vec{\partial}$ & $\stackrel{\vec{N}}{\stackrel{H}{t}}$ & $\begin{array}{l}\stackrel{8}{1} \\
\$\end{array}$ & $\infty$ & مستوسط على السنوات \\
\hline
\end{tabular}

\section{الجدول من اعداد الباحثان بالأعتاد على :}

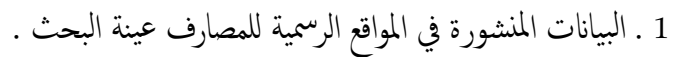

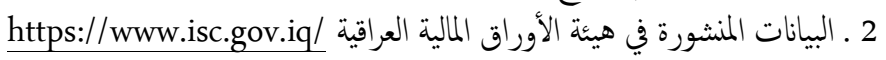

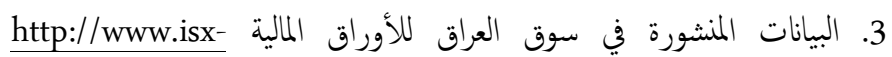
iq.net/isxportal/portal/homePage.html 4. تطبيق برنامج الشبكة العالمية المبلـhttps://cagrcalculator.net لأستخراج معدل

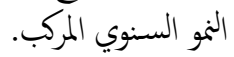

\section{من خلال الجدول رة (2) يتيبن:}

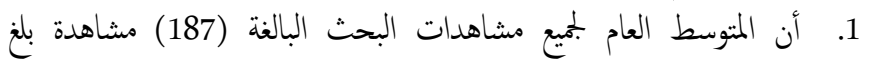

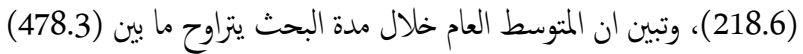

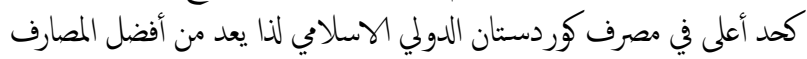

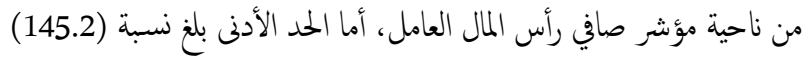

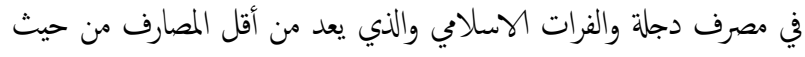

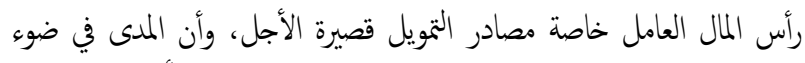

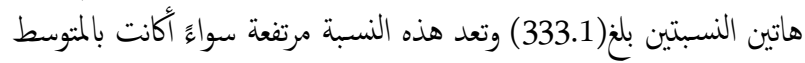

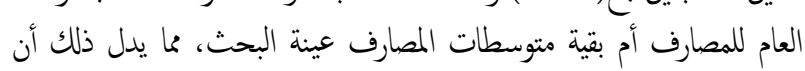

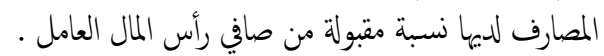

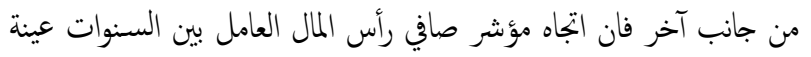

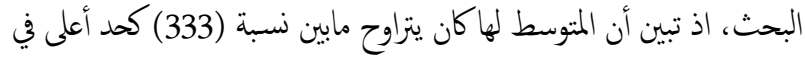

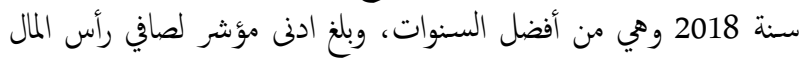

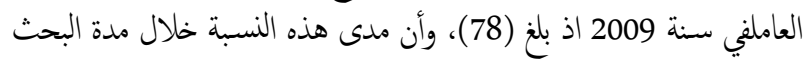

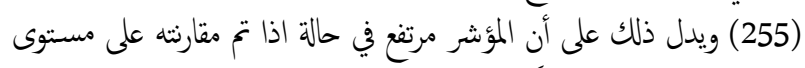

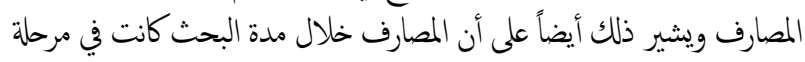

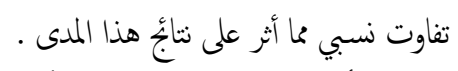

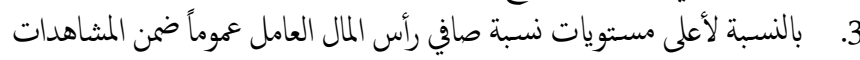

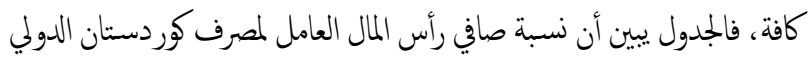

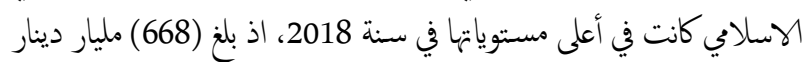

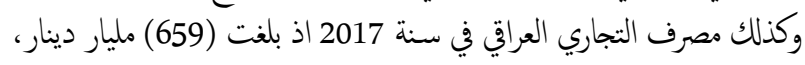
أما مصرف ايلاف الاسلامي سبحل أدنى نسبة في عام 2009 اذ بلغ نسبة الغبة

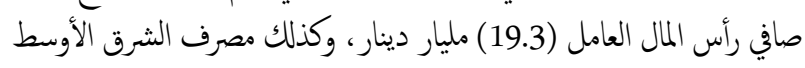

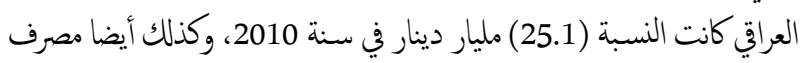
الأهلي العراقي كانت نسبة التداول (25.9) مليار دينار في النية دينار كما في سنة 2009

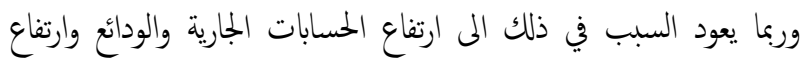
الدائنون.

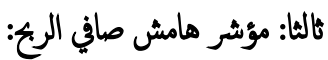

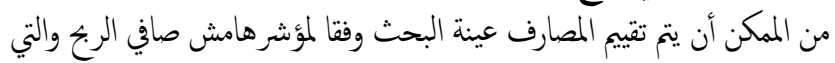

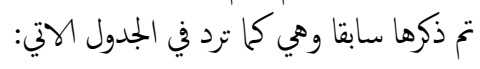


رابعا: نسبة القيمة السوقية الى القيمة الدفترة:

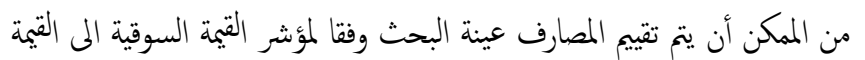
الدفترية والتي ذكرها سابقا وهي كما ترد في الجدول المتئي

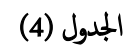

تطبيق مؤشر نسبة القيمة السوقية المى القيمة الدفترية للمصارف عينة البحث

\begin{tabular}{|c|c|c|c|c|c|c|c|c|c|c|c|c|}
\hline مستوى/المصرف على & 苂 & 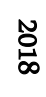 & 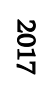 & 灾 & 怘 & 莫 & 总 & 於 & 苂 & 옹 & ర్రి & المصارف / السنوات \\
\hline 1.32 & : & $\dot{9}$ & $\dot{9}$ & $\stackrel{\circ}{\text { N }}$ & $\ddot{\tilde{n}}$ & $\stackrel{\vec{\Delta}}{\Delta}$ & 䓵 & $\dot{a}$ & $\stackrel{N}{\mathrm{v}}$ & $\overrightarrow{\dot{\infty}}$ & $\dot{\omega}$ & بغداد \\
\hline 0.81 & $\stackrel{\circ}{\text { ¿े }}$ & के & ف & $\stackrel{\dot{\omega}}{\dot{\omega}}$ & 家 & 용 & $\ddot{i}$ & $\begin{array}{l}\circ \\
\dot{0}\end{array}$ & $\begin{array}{l}\circ \\
\infty \\
\infty\end{array}$ & $\begin{array}{l}\text { 잉 } \\
\text { lo }\end{array}$ & $\dot{\infty}$ & الإسلامي \\
\hline 0.78 & $\stackrel{\circ}{\infty}$ & 윽 & $\begin{array}{l}\text { } \\
\dot{w}\end{array}$ & $\dot{\dot{\omega}}$ & ஜू & $\stackrel{\circ}{\infty}$ & $\stackrel{0}{\circ}$ & 啰 & $\dot{\circ}$ & نे & $\dot{\infty}$ & العراقتثر \\
\hline 0.84 & نั & $\stackrel{0}{+}$ & 离 & 哯 & i & 여 & $\dot{\vec{\infty}}$ & 官 & $\stackrel{\dot{\omega}}{\infty}$ & $\stackrel{\dot{\sim}}{\perp}$ & $\dot{\text { in }}$ & شرق الأوسط \\
\hline 0.98 & ن & $\stackrel{\circ}{ \pm}$ & $\dot{\omega}_{\perp}$ & $\stackrel{\circ}{\stackrel{\circ}{\circ}}$ & $\stackrel{\dot{D}}{\infty}$ & $\stackrel{\circ}{\infty}$ & 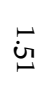 & $\dot{\text { نु }}$ & $\dot{\omega}$ & $\overrightarrow{\dot{\omega}}$ & $\stackrel{\vec{b}}{\vec{b}}$ & للأستثمر \\
\hline 0.62 & i् & $\stackrel{0}{\text { iv }}$ & i் & ن. & : & $\stackrel{\circ}{\infty}$ & $\stackrel{\circ}{\text { ù }}$ & 崩 & : & 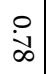 & : & الأهلي العراقي \\
\hline 1.33 & $\begin{array}{l}\circ \\
\infty \\
\infty\end{array}$ & 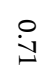 & 여 & ن & ஓ & $\dot{\dot{\alpha}}$ & No & के & $\stackrel{N}{\dot{\omega}}$ & $\stackrel{\vec{\omega}}{\vec{\omega}}$ & $\stackrel{N}{\dot{\omega}}$ & لألئتان العراقي \\
\hline 0.83 & $\stackrel{\circ}{\cup}$ & : & $\stackrel{\infty}{\infty}$ & @ & $\dot{8}$ & $\stackrel{\circ}{0}$ & $\dot{8}$ & $\stackrel{\circ}{y}$ & $\stackrel{0}{\text { Uु }}$ & $\stackrel{0}{\infty}$ & ஜ & سومر التجاري \\
\hline 0.68 & $\stackrel{\circ}{\dot{w}}$ & i & نे & 요 & $\stackrel{\circ}{\stackrel{D}{\perp}}$ & 임 & i̊ & 임 & 兑 & $\stackrel{\circ}{\circ}$ & $\vec{\sigma}$ & التجاري \\
\hline 0.55 & i̊ & $\stackrel{\circ}{\dot{b}}$ & ì & 定 & ì & : & فㅇ & ல் & $\stackrel{\circ}{\text { ป }}$ & $\stackrel{0}{\text { y }}$ & $\begin{array}{l}\stackrel{0}{\infty} \\
\dot{\omega}\end{array}$ & الإسلافي \\
\hline 0.65 & نํ & $\begin{array}{l}\stackrel{0}{b} \\
\dot{b}\end{array}$ & $\stackrel{\dot{\Delta}}{\text { N }}$ & $\stackrel{\text { iu }}{\mathrm{v}}$ & ن্ّ & نू & ì & $\stackrel{0}{\infty}$ & சे & $\stackrel{\circ}{\text { Ù }}$ & $\dot{\vec{v}}$ & الموصل \\
\hline 0.67 & $\begin{array}{l}\text { ثे } \\
\dot{\text { जे }}\end{array}$ & $\stackrel{\dot{t}}{\dot{t}}$ & ن्. & i् & i & $\stackrel{\circ}{\text { ¿ }}$ & $\stackrel{\circ}{\dot{\perp}}$ & ○ & ஜ̊ & $\stackrel{0}{\infty}$ & $\dot{\tilde{\sigma}}$ & العزاقي \\
\hline 1.10 & i & 离 & $\dot{\dot{\omega}}$ & $\stackrel{\ominus}{\dot{v}}$ & $\begin{array}{l}0 \\
\dot{b}\end{array}$ & ن̈ & $\dot{b}$ & 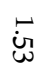 & N & i & نं & الشمال \\
\hline 0.59 & 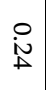 & 家 & ن্ট & 它 & ن্ & $\stackrel{\circ}{\text { ù }}$ & $\stackrel{\circ}{\text { ু }}$ & $\stackrel{\circ}{\stackrel{\ominus}{b}}$ & $\stackrel{\circ}{\infty}$ & ஜ & $\begin{array}{l}\circ \\
\dot{0}\end{array}$ & للاستتمار الدولي \\
\hline 0.42 & 䆬 & $\stackrel{\circ}{ \pm}$ & ن্ & ì & in & $\stackrel{0}{\dot{\omega}}$ & $\stackrel{\dot{D}}{\infty}$ & $\stackrel{\circ}{ \pm}$ & $\begin{array}{l}0 \\
\dot{b}\end{array}$ & 离 & 离 & الفرات \\
\hline 1.19 & $\stackrel{\vec{\partial}}{0}$ & के & 它 & $\dot{\tilde{N}}$ & $\ddot{\tilde{\sigma}}$ & $\begin{array}{l}\circ \\
\dot{0}\end{array}$ & i & ن & ஜे & $\stackrel{\circ}{\infty}$ & 荀 & ولالدودستان \\
\hline 1.03 & $\dot{8}$ & io & $\stackrel{\infty}{\infty}$ & $\stackrel{\circ}{\text { ă }}$ & $\stackrel{\circ}{N}$ & i̊ & $\dot{\sigma}$ & $\dot{\vec{b}}$ & $\dot{\dot{\omega}}$ & $\dot{\vec{\infty}}$ & $\dot{\tilde{N}}$ & المنصور \\
\hline
\end{tabular}

\begin{tabular}{|c|c|c|c|c|c|c|c|c|c|c|c|c|}
\hline 0.05 & $\begin{array}{l}0 \\
\text { Oे } \\
0 \\
0\end{array}$ & $\begin{array}{l}\text { No } \\
\text { Oे. }\end{array}$ & $\begin{array}{l}\hat{n} \\
0 \\
0\end{array}$ & $\begin{array}{l}\infty \\
\stackrel{0}{0} \\
0\end{array}$ & \begin{tabular}{l} 
గ̂ \\
\hdashline
\end{tabular} & 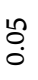 & $\begin{array}{l}0 \\
\stackrel{0}{0} \\
0\end{array}$ & 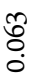 & 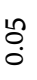 & 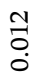 & $\begin{array}{l}\text { ते } \\
\text { ¿े. }\end{array}$ & المنصور \\
\hline 0.046 & $\begin{array}{l}\stackrel{a}{0} \\
0 \\
0\end{array}$ & $\begin{array}{l}\mathbb{1} \\
0 \\
0 \\
0\end{array}$ & 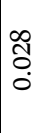 & $\begin{array}{l}\text { वे } \\
0 \\
\dot{\varphi}\end{array}$ & $\begin{array}{l}\stackrel{\Delta}{\Delta} \\
\text { Oे }\end{array}$ & $\begin{array}{l}\hat{\%} \\
\stackrel{0}{\circ}\end{array}$ & $\begin{array}{l}\text { Tे } \\
\text { Oे. } \\
0\end{array}$ & $\begin{array}{l}\text { fे } \\
\text { o. } \\
\text {. }\end{array}$ & $\begin{array}{l}\stackrel{a}{0} \\
\dot{0}\end{array}$ & \begin{tabular}{l}
$\mathbb{J}$ \\
\multirow{0}{*}{}
\end{tabular} & $\begin{array}{l}\text { के } \\
\text { oे }\end{array}$ & متوسط على السنوى \\
\hline
\end{tabular}

الجدول من اعداد الباحثان بالأعتماد على :

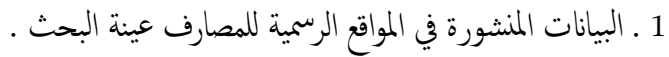

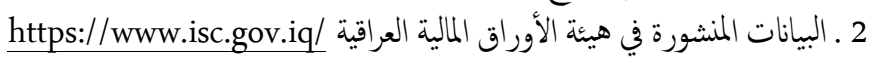

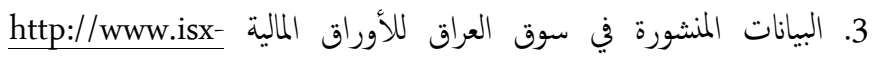
iq.net/isxportal/portal/homePage.html 4. تطبيق برنامج الشبكة العالمية https://cagrcalculator.net معدل النمو السنوي المركب.

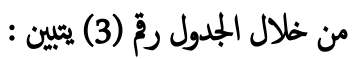

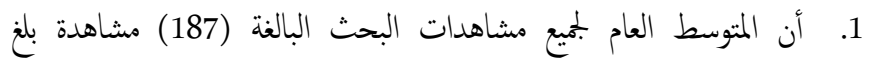
(0.046)، وتبين ان المتوسط العام خلال مدة البحث يتراوح ما بين (0.15)

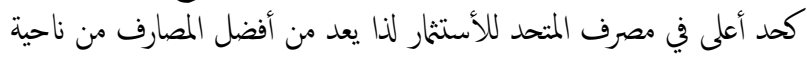

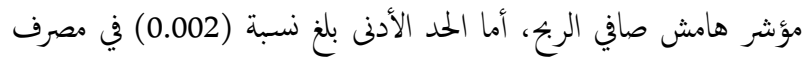
دجلة والفرات الاسلامي والذي يعد من أقل المصارف من حيث هامش صافي الفي الربح خاصة بسبب ارتفاع ججم المصاريف و إنخفاض قيمة ارباح بيع العملات يعاني من خفض حجم هامش صافي ارباحم، وأن المدى في ضوء هاتين النسبتين

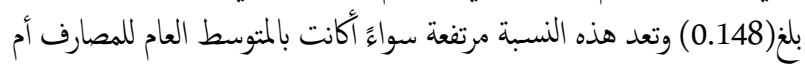

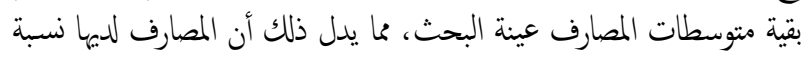

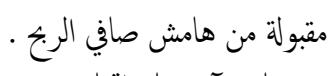

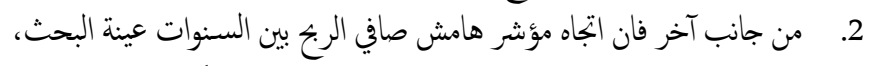

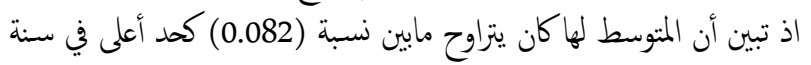
2018 وهي من أفضل السنوات، ونسبة (-0.016) كحد ادنى في سنة 2015 وهي ادنى السنوات، وأن مدى هذه النسبة خلال مدة البحث (0.066)

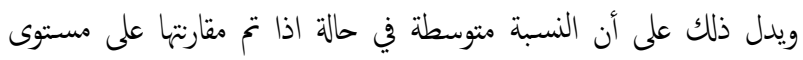

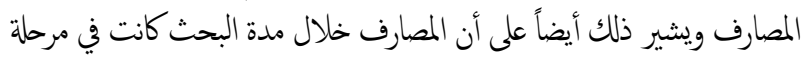
تفاوت نسبي مما أثر على نتائج هذا المدى . 3. بالنسبة لأعلى مستويات نسبة هامش صافي الريح عموماً ضمن المشاهدات

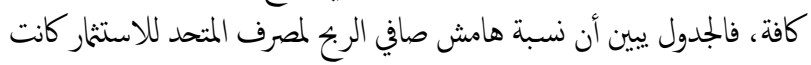
في أعلى مستوياتها في سنة 2018، اذ بلغت (1.24) وكذلك مصرف التهن التجاري

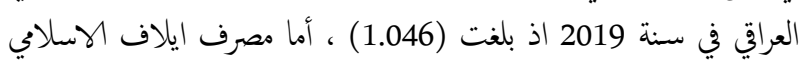

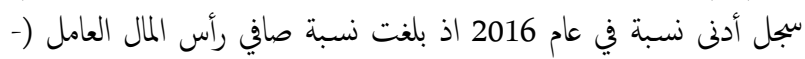

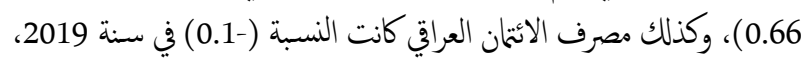

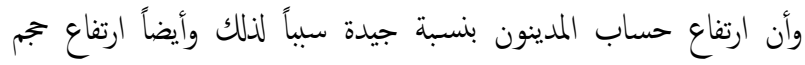
مصروفات العمليات المصرفية و ارتفاع في اجلالي المصاريف الإدارية والأندثارات

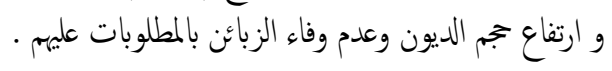




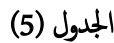

مؤشر معدل عائدعلى السهم للمصارف عينة البحث

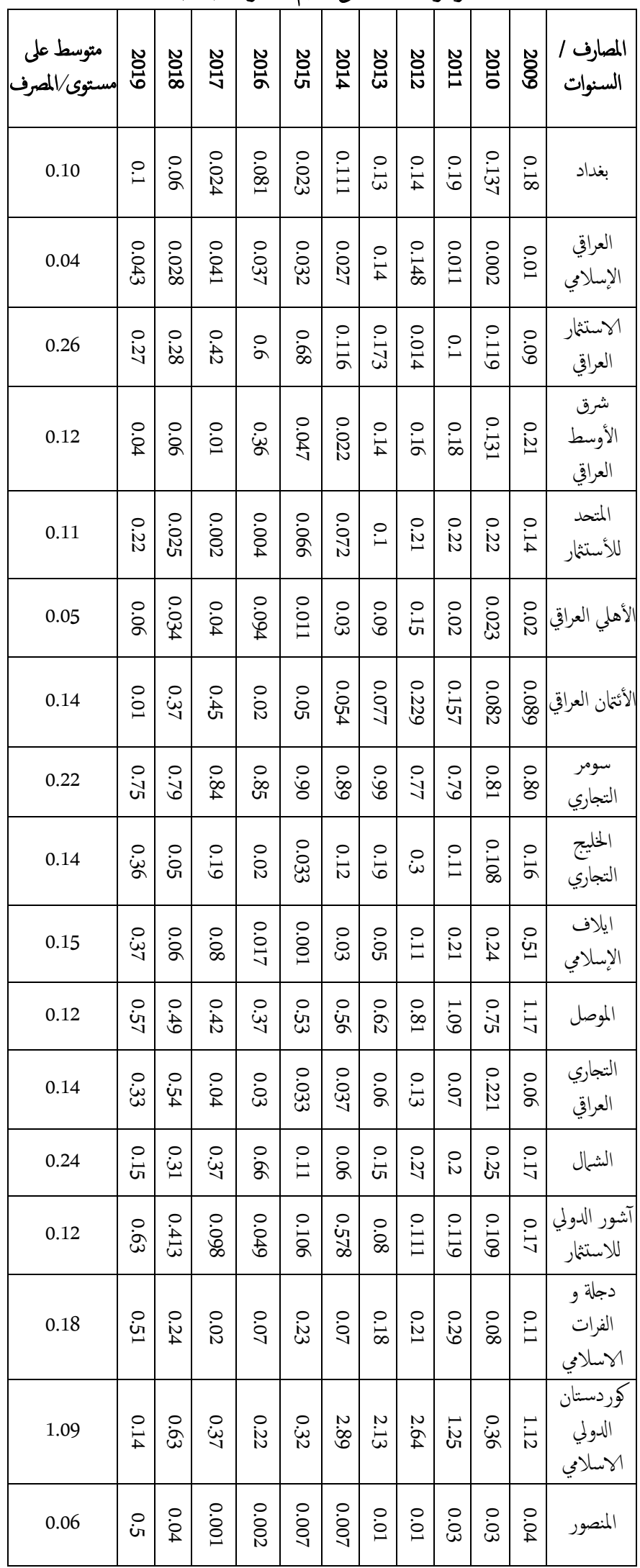

0.85

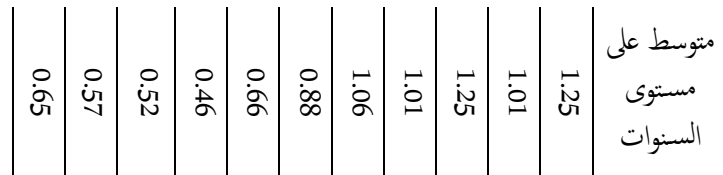

الجدول من اعداد الباحثان بالأعتماد على :

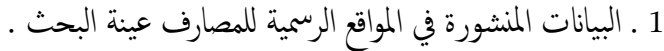
2 ـ البيانات المنشورة في هيئة الأوراق المالية العراقية المعاتية الماتية

https://www.isc.gov.iq/

3ttp://www.isx- البيانات المنشورة في سوق العراق للأوراق المالية iq.net/isxportal/portal/homePage.html 4. . تطبيق برنامج الشبكة العالمية لألمبت_https://cagrcalculator.net

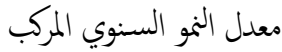

\section{من خلال الجدول رقّ (4) يتيبن :}

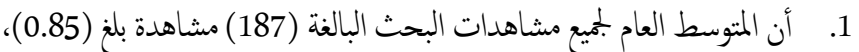

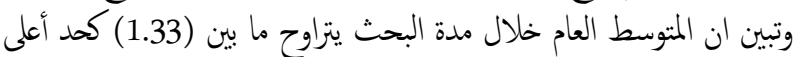

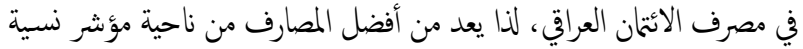

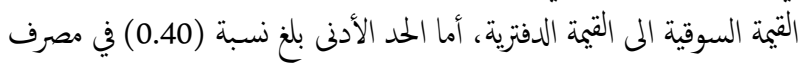

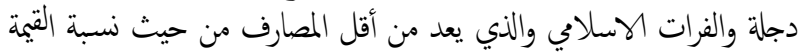

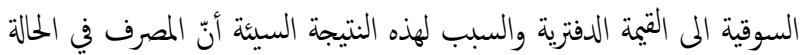

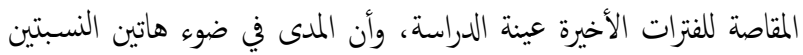

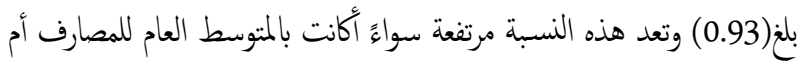

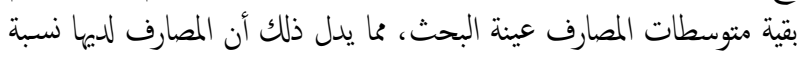
مقبولة من نسبة القيمة السوقية الى القيمة الدفنرية .

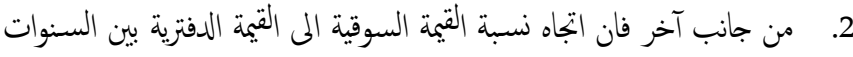

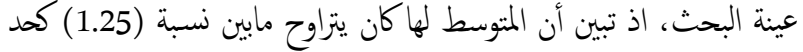
أعلى في سنتين 2009 و 2011 وهي من أفضل السنوات، ونسبة (0.46) كحد ادنى في سنة 2016 وهي ادنى السنوات، وأن مدى هذه النين النسبة خلال مدة البحث (0.39) ويدل ذلك على أن النسبة متوسطة في حالة اذا تم مقارنتها

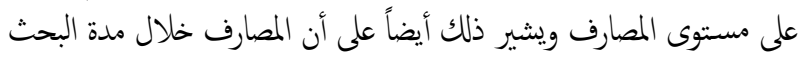

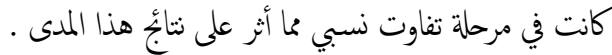

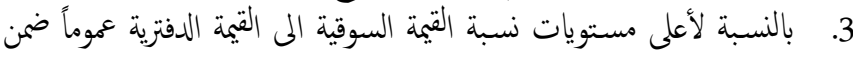

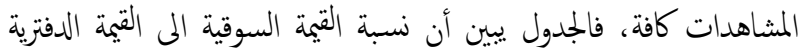
لمصرف بغداد كانت في أعلى مستوياتها في سنة 2011، اذ بلغن بلغت (2.51)

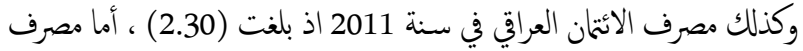
ايلاف الاسلامي سجل أدنى سبة في عام 2018 اذ بلغت نسبة الفية القيمة السوقية

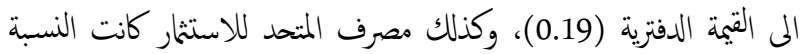

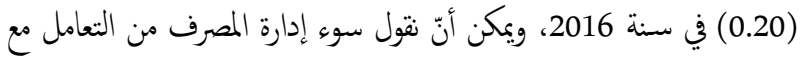

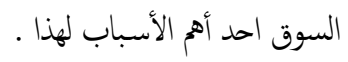

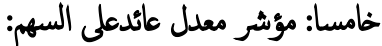

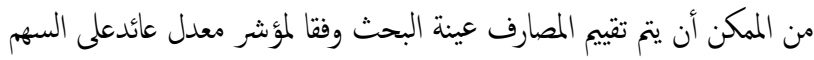
والتي تم ذكرها سابقا وهي كما ترد في الجدول الاتمتي: 
(6) الجدول (5) (3)

مؤشر معدل دوران اجالي الاصول للمصارف عينة البحث

\begin{tabular}{|c|c|c|c|c|c|c|c|c|c|c|c|c|}
\hline مستوى/المصرف متى & 葛 & 芯 & 莕 & 苂 & $\begin{array}{l}\text { 苍 } \\
\text { v }\end{array}$ & 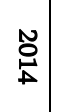 & $\stackrel{\stackrel{0}{\omega}}{\omega}$ & 蒿 & 怘 & 莕 & : & /السنوات \\
\hline 0.041 & : & : & : & $\begin{array}{l}\dot{2} \\
\dot{2}\end{array}$ & : & $\dot{8}$ & $\dot{8}$ & $\begin{array}{l}0 \\
\dot{0} \\
\end{array}$ & $\begin{array}{l} \\
\dot{2}\end{array}$ & $\dot{\square}$ & $\dot{8}$ & بغداد \\
\hline 0.047 & $\stackrel{\circ}{\dot{\omega}}$ & : & $\dot{\circ}$ & $\stackrel{\circ}{\circ}$ & $\dot{\circ}$ & i̊ & P & \begin{tabular}{l|}
0 \\
$\dot{0}$
\end{tabular} & $\begin{array}{l}\circ \\
\dot{0} \\
\text { i }\end{array}$ & $\stackrel{\circ}{\dot{\omega}}$ & : & الإسلائي \\
\hline 0.083 & : & : & $\dot{\omega}$ & i & $\stackrel{\dot{\theta}}{\mathrm{v}}$ & P & i & $\begin{array}{l}0 \\
\dot{0} \\
\dot{j}\end{array}$ & $\stackrel{0}{\dot{0}}$ & $\dot{\infty}$ & : & العراقتثار \\
\hline 0.045 & : & $\dot{\theta}$ & 岀 & $\begin{array}{l}0 \\
\dot{0} \\
\text { i }\end{array}$ & $\dot{\alpha}$ & : & $\dot{\ddot{g}}$ & $\begin{array}{l}0 \\
\dot{j} \\
\end{array}$ & $\dot{\ddot{v}}$ & $\dot{0}$ & $\dot{\alpha}$ & الأوسط شرق \\
\hline 0.065 & : & : & : & $\stackrel{\circ}{\circ}$ & 完 & $\dot{\dot{j}}$ & : & $\begin{array}{l}\dot{\theta} \\
\dot{\omega}\end{array}$ & : & $\stackrel{\circ}{\circ}$ & $\dot{8}$ & للأستثمار \\
\hline 0.057 & $\stackrel{8}{i}$ & $\dot{8}$ & ஜे & $\begin{array}{l}0 \\
\text { i̊ } \\
\text { ì }\end{array}$ & : & ஜ̊ & ஜ̊ & $\dot{0}$ & : & ஜ் & iे & أهلي العراقي \\
\hline 0.044 & $\dot{8}$ & : & 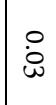 & $\begin{array}{l}\circ \\
\dot{\omega} \\
\end{array}$ & 这 & : & : & : & \begin{tabular}{l|} 
\\
$\dot{0}$ \\
$\dot{\infty}$
\end{tabular} & $\begin{array}{l}\dot{0} \\
\dot{\omega}\end{array}$ & ஜ̊ & العرائتمان \\
\hline 0.050 & $\stackrel{\circ}{0}$ & $\dot{\dot{g}}$ & 这 & $\stackrel{\circ}{\dot{1}}$ & 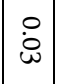 & $\stackrel{\circ}{\dot{\omega}}$ & $\stackrel{\circ}{\vec{L}}$ & $\begin{array}{l}0 \\
\dot{\infty}\end{array}$ & $\stackrel{0}{\circ}$ & : & $\dot{0}$ & التجاري \\
\hline 0.065 & $\dot{0}$ & : & $\stackrel{\circ}{\circ}$ & : & $\stackrel{\circ}{\dot{v}}$ & : & $\stackrel{\circ}{\dot{\Xi}}$ & \begin{tabular}{l|}
$\dot{\theta}$ \\
$\dot{\omega}$
\end{tabular} & $\stackrel{\circ}{\circ}$ & $\stackrel{\circ}{\dot{0}}$ & : & التجاري \\
\hline 0.058 & ì & : & 宓 & 这 & 完 & :̊े & نे & $\dot{0}$ & \begin{tabular}{l|}
0 \\
$\dot{\infty}$ \\
$\dot{\infty}$
\end{tabular} & $\dot{0}$ & 恚 & الإسلاي \\
\hline 0.044 & : & : & iे & 憂 & 号 & $\stackrel{\dot{\omega}}{\dot{\omega}}$ & : & $\begin{array}{l}0 \\
\dot{0} \\
\text { ù }\end{array}$ & $\stackrel{\circ}{\dot{v}}$ & : & ஜ் & الموصل \\
\hline 0.047 & $\stackrel{\circ}{\dot{1}}$ & $\stackrel{\circ}{\circ}$ & : & $\dot{\circ}$ & $\stackrel{\circ}{\dot{1}}$ & $\stackrel{\circ}{\dot{1}}$ & ஜ் & $\begin{array}{l}0 \\
\dot{0} \\
\text { in }\end{array}$ & $\begin{array}{l}0 \\
\dot{0} \\
ن\end{array}$ & $\dot{\dot{g}}$ & : & التجاري \\
\hline 0.105 & $\dot{\dot{\omega}}$ & i & 家 & $\stackrel{\circ}{\dot{\Xi}}$ & $\begin{array}{l}0 \\
\dot{8}\end{array}$ & $\dot{\infty}$ & i & $\begin{array}{l}0 \\
\dot{8}\end{array}$ & \begin{tabular}{l|}
$\dot{\vec{\omega}}$ \\
$\dot{\omega}$
\end{tabular} & $\begin{array}{l}0 \\
\dot{0}\end{array}$ & $\dot{\dot{\omega}}$ & الشمال \\
\hline 0.081 & : & ن. & i & $\begin{array}{l}0 \\
\dot{U} \\
\text { ப⿴囗十 }\end{array}$ & $\stackrel{\circ}{\text { o }}$ & 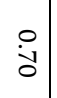 & $\stackrel{\circ}{\circ}$ & $\dot{\overrightarrow{8}}$ & $\begin{array}{l}0 \\
\dot{\Delta}\end{array}$ & $\begin{array}{l}\dot{\Xi} \\
0\end{array}$ & $\dot{\dot{\theta}}$ & للاستثار آلدور \\
\hline 0.047 & : & $\stackrel{\circ}{\dot{\omega}}$ & $\dot{\circ}$ & $\dot{\omega}$ & $\stackrel{\circ}{\dot{\omega}}$ & $\stackrel{\text { : }}{\omega}$ & $\dot{\infty}$ & $\stackrel{\circ}{\dot{v}}$ & : & : & : & الفسلامي \\
\hline 0.008 & $\stackrel{\circ}{\circ}$ & : & : & 完 & 这 & : & غे & : & : & ஜ் & 这 & كوردستان \\
\hline 0.037 & $\dot{0}$ & $\dot{0}$ & $\dot{\circ}$ & $\begin{array}{l}0 \\
\text { : } \\
\text { D }\end{array}$ & $\dot{\omega}$ & $\dot{\dot{\omega}}$ & $\dot{\circ}$ & ì & $\begin{array}{l}0 \\
\dot{0}\end{array}$ & $\dot{\alpha}$ & $\dot{\circ}$ & المنصور \\
\hline 0.054 & $\stackrel{\circ}{\dot{\omega}}$ & : & 通 & : & $\begin{array}{l}\dot{0} \\
\dot{0}\end{array}$ & : & $\dot{\dot{\circ}}$ & $\dot{\dot{\Xi}}$ & 这 & 这 & $\stackrel{\circ}{\dot{8}}$ & متوسط على \\
\hline
\end{tabular}

الجدول من اعداد الباحثان بالأعتاد على :

1 ـ البيانات المنشورة في المواقع الرسمية للمصارف عينة عينة البحث .

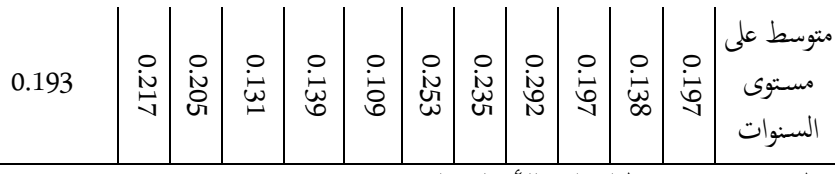

الجدول من اعداد الباحثان بالأعتماد على :

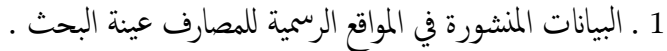

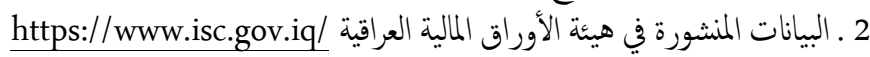

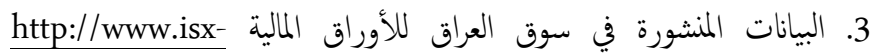

iq.net/isxportal/portal/homePage.html

4. تطبيق برنامج الشبكة العالمية https://cagrcalculator.net لأستخراج

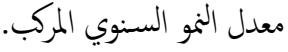

من خلال الجدول رق (5) يتيبن:

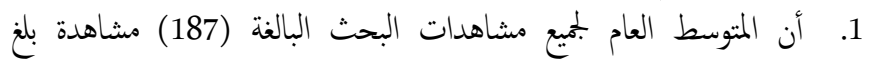

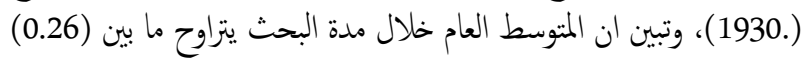

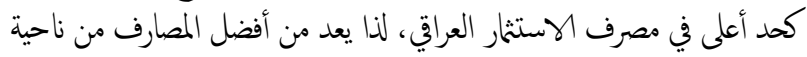

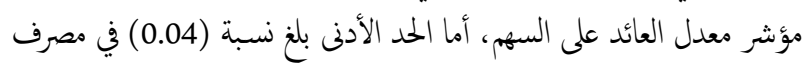

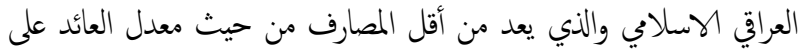

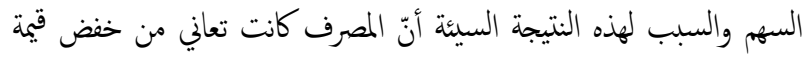

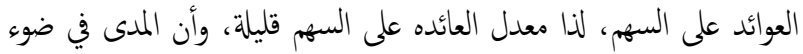

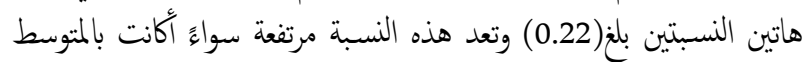

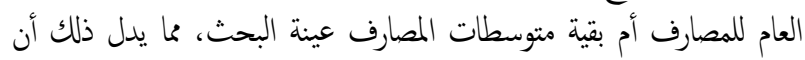

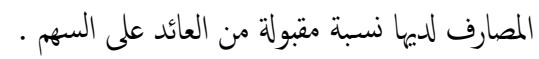

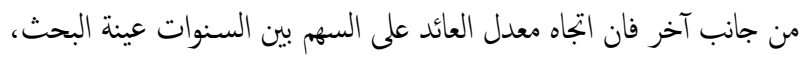
.2

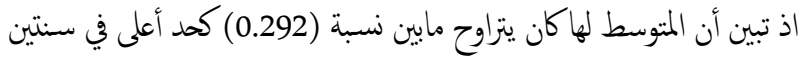

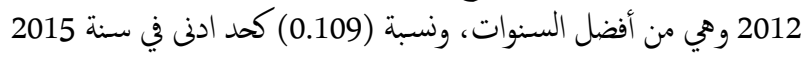
وهي ادنى السنوات، وأن مدى هذه النسبة خلال مدة البحن البحث (0.183)

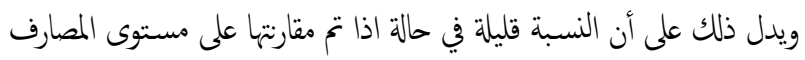

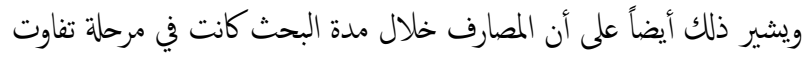

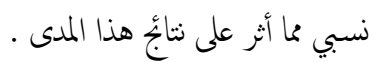
3. بالنسبة لأعلى مستويات معدل العائ هذائد على السهم عموماً ضمن المشاهدات كافة،

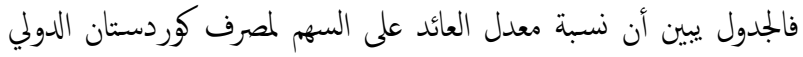

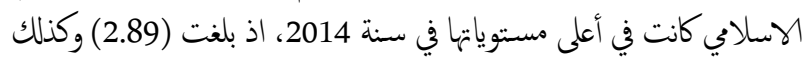

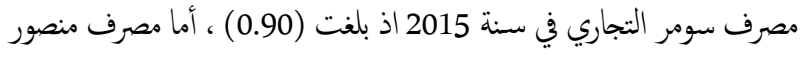

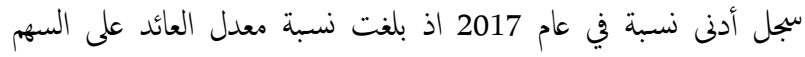

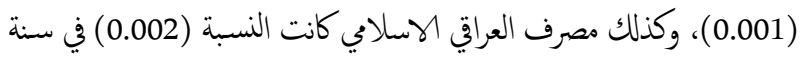

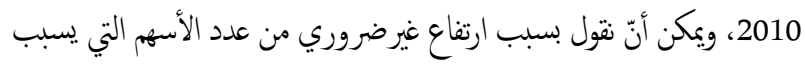
تقليل قيمته.

سادساً : مؤشر معدل دوران اجلالي الاصول :

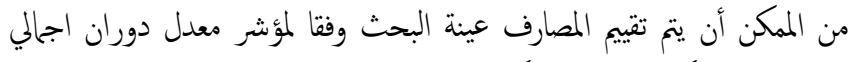

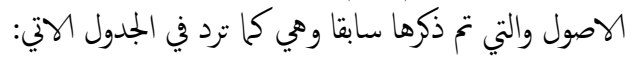


نموذج الاقتصاد التياسي لتفسير سلوك جزء من مجتمع يجتوي على الأقل متغيراً مستقلاً

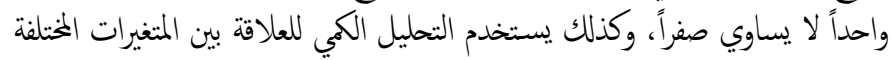

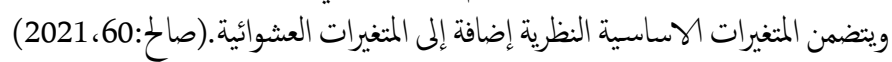

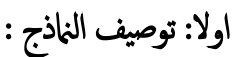

يطبق هذا البحث الناذج القياسية لبيان تقييم تأثير بعض المؤشرات في اداء

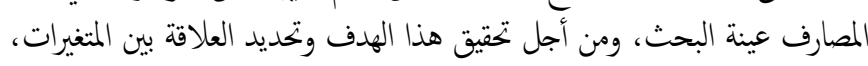

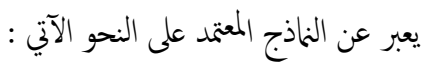

Y1it $=$ X1it $-\mathrm{X} 2 i t+\mathrm{X} 3 i t+\mathrm{X} 4 \mathrm{it}+\mathrm{D}+\mathrm{U}$

\section{النموذج الأول : نسبة التداول}

$$
\begin{aligned}
& \text { اذ آن : } \\
& \text { Y1 } \\
& \text { X1 } \\
& \text { X2 } \\
& \text { X3 } \\
& \text { X4 = هامش صافي الريح }
\end{aligned}
$$

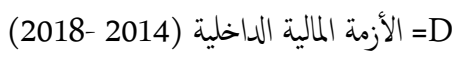

$$
\begin{aligned}
& \text { U = الخطأ العشوائي } \\
& \text { i } \\
& \text { t }
\end{aligned}
$$

\section{الموذج الثاني : صافي رأس المال العامل}

\section{Y2it $=$ X1it $-\mathrm{X} 2 i t+X 3 i t+X 4 i t+X 5 i t+D+U$}

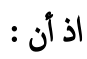

$$
\begin{aligned}
& \text { = = = صافي رأس المال العامل : } \\
& \text { X1 } \\
& \text { X2 } \\
& \text { X3 = نسبة النداول } \\
& \text { = معدل دوران اجلالي الموجودات X4 } \\
& \text { X5 = هامش صافي الريح }
\end{aligned}
$$

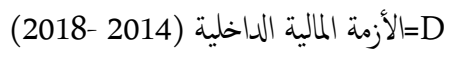

$$
\begin{aligned}
\text { الخطأ العشوائي }=\text { U } & \text { e } \\
\text { عدد المشاهدات }=\text { i } & \text { t }
\end{aligned}
$$

النوذج الثالث : معدل دوران اجلالي الموجودات https://www.isc.gov.iq/ البيانات المنشورة في هيئة الأوراق المالية العراقية الماتية الماتية

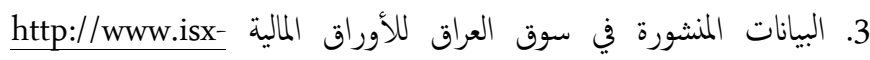
iq.net/isxportal/portal/homePage.html

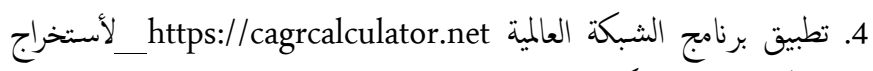

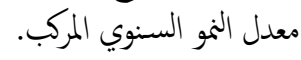

\section{من خلال الجدول رق (6) يتيبن :}

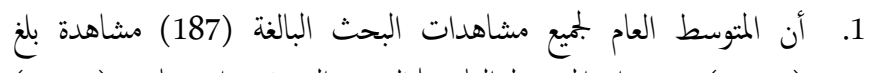

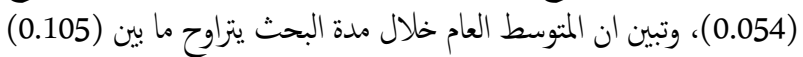

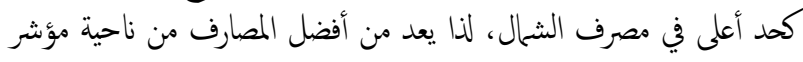

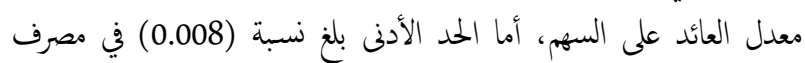

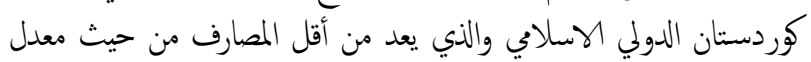

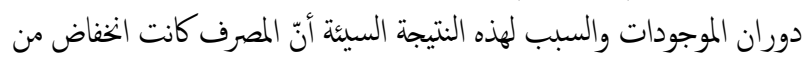

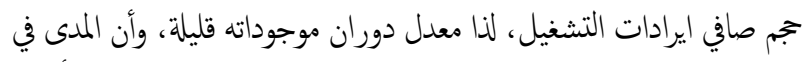

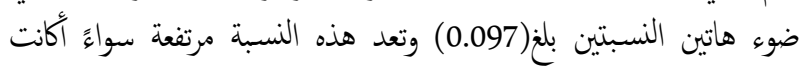

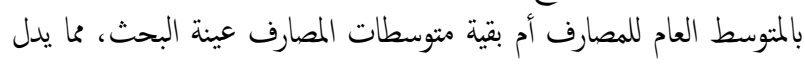

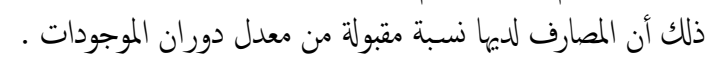

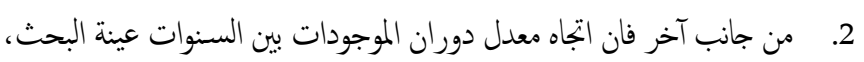

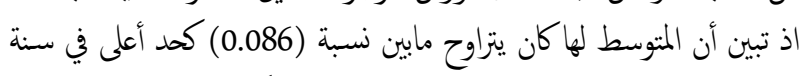

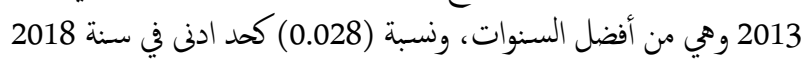
وهي ادنى السنوات، وأن مدى هذه النسبة خلال مدة البحث (0.058)

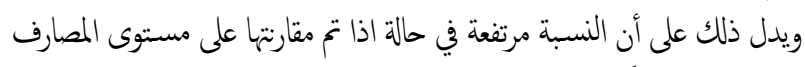

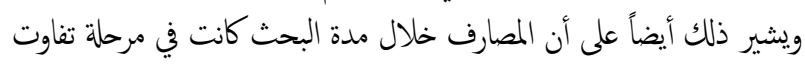

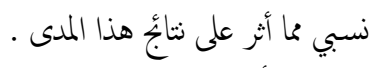

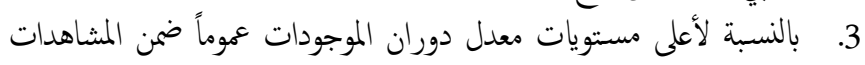

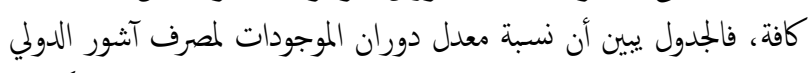

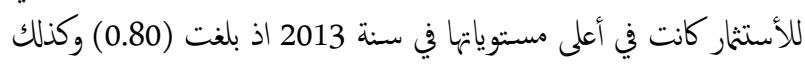

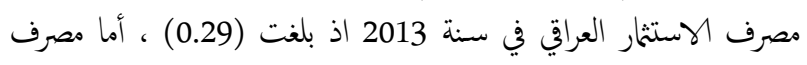

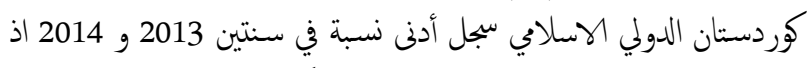

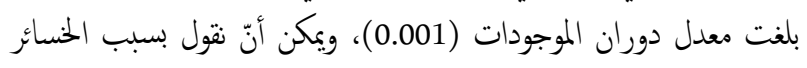
الأيتمانية و الإنخفاض في إيرادات الاستثارات المصرفية.

\section{المبحث الثالث}

\section{الاطار القياسي لثقييم الملالي لكفاءة الاداء للمصارف عينة البحث للمدة (2009 - 2019)}

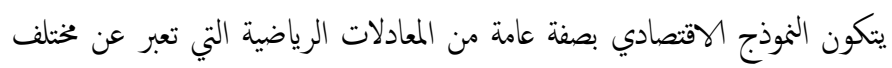

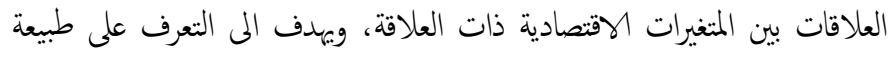

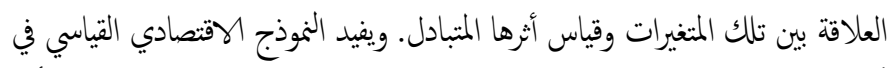

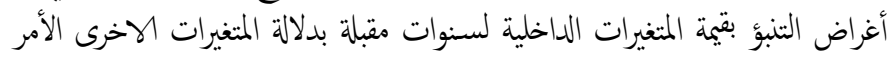

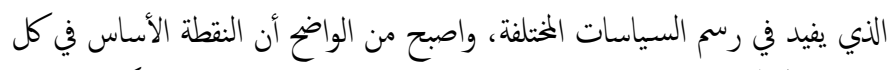

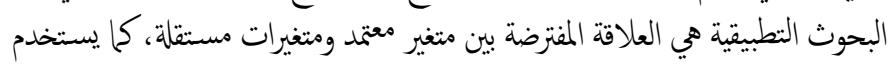




$$
\text { X5 }
$$

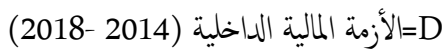

$$
\begin{aligned}
& \text { U = الخطأ العشوائي } \\
& \text { عدد المشاهدات = i } \\
& \text { t }
\end{aligned}
$$

النوذج السادس : العائد على الاسهم

$\mathrm{Y} 6$ it $=\mathrm{X} 1$ it $-\mathrm{X} 2$ it $+\mathrm{X} 3$ it $+\mathrm{X} 4$ it $+\mathrm{X} 5$ it + D + U

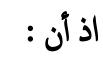

$$
\begin{aligned}
& \text { = معدل العائد على الاسهم = Y6 } \\
& \text { X1 } \\
& \text { X2 } \\
& \text { = معدل دوران اجالي الموجودات X3 }
\end{aligned}
$$

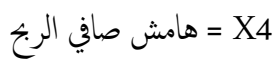

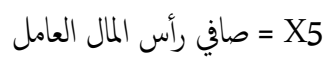

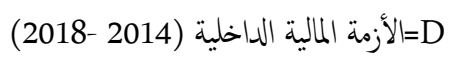

$$
\begin{aligned}
\text { e } & \text { e } \\
\text { e } & \text { t }
\end{aligned}
$$

\begin{tabular}{|c|c|c|c|c|c|c|c|c|c|c|c|c|}
\hline \multicolumn{3}{|c|}{$\begin{array}{l}\mathrm{ADF} \text { at } 1^{\text {st }} \\
\text { difference }\end{array}$} & \multicolumn{3}{|c|}{ ADF at Level } & \multicolumn{4}{|c|}{$\begin{array}{l}\text { PP at } 1^{\text {st }} \\
\text { difference }\end{array}$} & \multicolumn{2}{|c|}{ PP at Level } & \multirow{3}{*}{ متغنغرات } \\
\hline $\begin{array}{l}\overrightarrow{0} \\
\stackrel{0}{0} \\
\end{array}$ & & 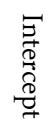 & & 营 & 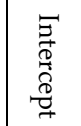 & & 虫 & 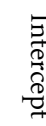 & & $\begin{array}{l}\overrightarrow{0} \\
\stackrel{0}{0} \\
\stackrel{2}{2}\end{array}$ & 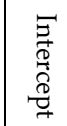 & \\
\hline $\begin{array}{l}G \\
\underline{G} \\
\underline{G} \\
\underline{G} \\
\underline{E}\end{array}$ & 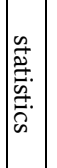 & $\begin{array}{l}6 \\
6 \\
6 \\
6 \\
6\end{array}$ & 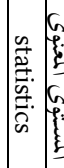 & 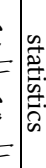 & 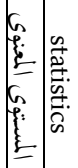 & $\begin{array}{l}6 \\
6 \\
6 \\
6 \\
6 \\
6 \\
\end{array}$ & 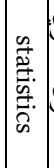 & $\begin{array}{l}6 \\
b \\
6 \\
6 \\
\vdots \\
\vdots\end{array}$ & 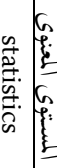 & 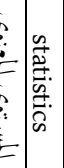 & 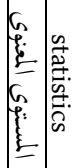 & \\
\hline$\dot{8}$ & 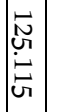 & ஜ் & 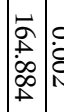 & $\begin{array}{l}b \\
b \\
b \\
ن\end{array}$ & 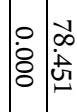 & 영 & 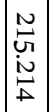 & : & 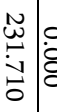 & 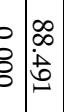 & 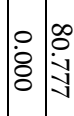 & نسبة التداول \\
\hline
\end{tabular}

ثانيا : البات والاستقرارية (Stationary test - Unit root test) :

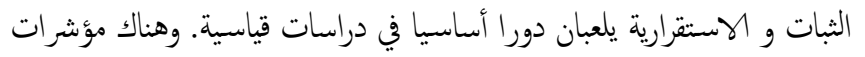

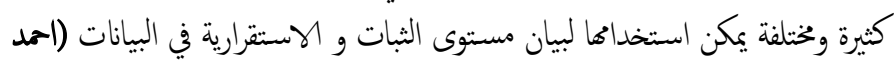

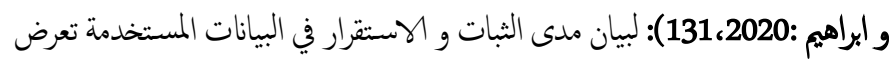

نتائُ التحليل في الجدول (7)

\section{الجدول (7)}

نتائج اختبار الثبات والاستقرارية (Stationary test) للمتغيرات الداخلة في الناذج
Y3it $=$ X1it $-X_{2 i t}+X_{3 i t}+X_{4 i t}+X_{5 i t}+D+U$

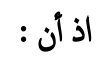

$$
\begin{aligned}
& \text { = معدل دوران اجمالي الموجودات = Y3 } \\
& \text { الايراداتX1 = } \\
& \text { X2 } \\
& \text { هامش صافي الربح = X3 }
\end{aligned}
$$

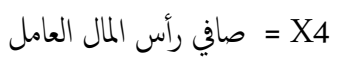

$$
\begin{aligned}
& \text { X5 = القيمة السوقية إلى الدفترية = X4 }
\end{aligned}
$$

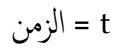

Y4it $=$ X1it $-\mathrm{X} 2 i t+X_{3 i t}+\mathrm{X} 4 i t+\mathrm{X} 5 i t+\mathrm{D}+\mathrm{U}$

$$
\begin{aligned}
& \text { اذ آن : - إن } \\
& \text { = هامش صافي الريح }
\end{aligned}
$$

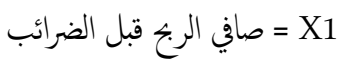

$$
\begin{aligned}
& \text { = X2 } \\
& \text { X3 } \\
& \text { X4 = صافي رأس المال العامل = X5 = X5 = } \\
& \text { X5 قيمة السوقية إلى الدفترية }
\end{aligned}
$$

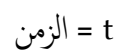

D=الأزمة المالية الداخلية (2014 - D

النموذج الخامس : نسبة قمية السوقية إلى قيمة الدفتية

$\mathrm{Y} 5$ it = X1 it $-\mathrm{X} 2$ it + X3 it + X4 it X5 it + D + U

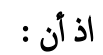

$$
\begin{aligned}
& \text { نسبة قيمة السوقية إلى قيمة الدفترية = Y5 } \\
& \text { X1 } \\
& \text { X2 } \\
& \text { X3 } \\
& \text { X4 = هامش صافي الريخ = X4 }
\end{aligned}
$$


(8) الجدول)

اختبار التكامل المشترك(Cointegration) بين المتغيرات للمناذج الخمتارة

\begin{tabular}{|c|c|c|c|c|}
\hline \multicolumn{5}{|c|}{ اختبار النكمل المشترك بين المتغيرات النموذج الأول (نسبة التداول) } \\
\hline |المستوى المعنوي & statistics & المستوى المعنوي & statistics & اختبارات \\
\hline 0.9988 & -3.024196 & 0.7949 & -0.283547 & Panel v \\
\hline 0.9998 & 3.508614 & 0.9997 & 3.469585 & Panel rho \\
\hline 0.0000 & -8.215785 & 0.0000 & -5.569153 & Panel PP \\
\hline 0.0000 & -4.017417 & 0.1705 & -0.952121 & Panel ADF \\
\hline \multicolumn{2}{|c|}{ المستوى المعنوي } & \multicolumn{2}{|c|}{ statistics } & اختبارات \\
\hline \multicolumn{2}{|c|}{1.0000} & \multicolumn{2}{|c|}{5.192215} & Group rho \\
\hline \multicolumn{2}{|c|}{0.0000} & \multicolumn{2}{|c|}{-10.07178} & Group PP \\
\hline \multicolumn{2}{|c|}{0.0000} & \multicolumn{2}{|c|}{-6.074178} & Group ADF \\
\hline
\end{tabular}

اختبار النكمل المشترك بين المثنيرات المنوذج الثاني (صافي رأس المال العامل)

\begin{tabular}{|c|c|c|c|c|}
\hline المستوى المعنوي & statistics & المستوى المعنوي & statistics & اختبارات \\
\hline 0.9992 & -3.153583 & 0.9180 & -1.392059 & Panel v \\
\hline 0.9993 & 3.189056 & 0.9999 & 3.826123 & Panel rho \\
\hline 0.0007 & -3.177774 & 0.6175 & 0.299011 & Panel PP \\
\hline 0.0001 & -3.811679 & 0.0000 & -7.896613 & Panel ADF \\
\hline \multicolumn{2}{|c|}{ المستوى المعنوي } & \multicolumn{2}{|c|}{ statistics } & اختبارات \\
\hline \multicolumn{2}{|c|}{1.0000} & \multicolumn{2}{|c|}{5.662121} & Group rho \\
\hline \multicolumn{2}{|c|}{0.0119} & \multicolumn{2}{|c|}{-2.259320} & Group PP \\
\hline \multicolumn{2}{|c|}{0.0000} & \multicolumn{2}{|c|}{-4.253062} & Group ADF \\
\hline
\end{tabular}

\begin{tabular}{|c|c|c|c|c|}
\hline \multicolumn{5}{|c|}{ اختبار النكامل المشترك بين المنغيرات النموذج الثالث(معدل دوران اجلالي الأصول) } \\
\hline 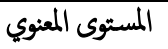 & statistics & المستوى المعنوي & statistics & اختبارات \\
\hline 0.8006 & -0.843645 & 0.8730 & -1.140675 & Panel v \\
\hline 0.9999 & 3.679328 & 0.9998 & 3.594706 & Panel rho \\
\hline 0.0000 & -6.843773 & 0.0000 & -6.674281 & Panel PP \\
\hline 0.0000 & -6.878225 & 0.0000 & -6.460962 & Panel ADF \\
\hline \multicolumn{2}{|c|}{ المستوى الممنوي } & \multicolumn{2}{|c|}{ statistics } & اختبارات \\
\hline \multicolumn{2}{|c|}{1.0000} & \multicolumn{2}{|c|}{4.924841} & Group rho \\
\hline \multicolumn{2}{|c|}{0.0000} & \multicolumn{2}{|c|}{-11.92742} & Group PP \\
\hline \multicolumn{2}{|c|}{0.0000} & \multicolumn{2}{|c|}{-12.15437} & Group ADF \\
\hline
\end{tabular}

اختبار التكامل المشترك بين المتغيرات النموذج الرابع (نسبة هامش صافي الريح)

\begin{tabular}{|c|c|c|c|c|}
\hline المستوى المعنوي & statistics & المستوى المعنوي & statistics & اختبارات \\
\hline 0.8006 & -0.843645 & 0.8730 & -1.140675 & Panel v \\
\hline 0.9999 & 3.679328 & 0.9998 & 3.594706 & $\begin{array}{l}\text { Panel rho } \\
\end{array}$ \\
\hline 0.0000 & -6.843773 & 0.0000 & -6.674281 & $\begin{array}{l}\text { Panel PP } \\
\end{array}$ \\
\hline 0.0000 & -6.878225 & 0.0000 & -6.460962 & Panel ADF \\
\hline \multicolumn{2}{|c|}{ المستوى المعنوي } & \multicolumn{2}{|c|}{ statistics } & اختبارات \\
\hline \multicolumn{2}{|c|}{1.0000} & \multicolumn{2}{|c|}{4.924841} & Group rho \\
\hline \multicolumn{2}{|c|}{0.0000} & \multicolumn{2}{|c|}{-11.92742} & Group PP \\
\hline \multicolumn{2}{|c|}{0.0000} & \multicolumn{2}{|c|}{-12.15437} & Group ADH \\
\hline
\end{tabular}

\begin{tabular}{|c|c|c|c|c|}
\hline \multicolumn{5}{|c|}{ اختبار النكامل المشترك بين المتغيرات المنوذج الخامس (نسبة القيمة السوقية المى الدفترية) } \\
\hline 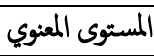 & statistics & 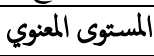 & statistics & اختبارات \\
\hline 0.8249 & -0.934331 & 0.9608 & $\mid-1.760134$ & Panel $\mathrm{v}$ \\
\hline 0.9992 & 3.149040 & 0.9998 & 3.502530 & Panel rho \\
\hline 0.0035 & -2.693159 & 0.0029 & $\mid-2.763661$ & $\begin{array}{l}\text { Panel PP } \\
\end{array}$ \\
\hline 0.0033 & -2.713286 & 0.0027 & -2.778469 & Panel ADF \\
\hline
\end{tabular}

\begin{tabular}{|c|c|c|c|c|c|c|c|c|c|c|c|c|c|}
\hline 总 & $\left|\begin{array}{l}u \\
\infty \\
w \\
v \\
v\end{array}\right|$ & ஜ் & 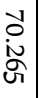 & & & $\begin{array}{l}\hat{t} \\
\dot{0} \\
\infty \\
\infty\end{array}$ & : & 雍 & :ें & & 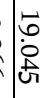 & $\begin{array}{l}\dot{0} \\
\hat{N} \\
\hat{a}\end{array}$ & الموجدواولة \\
\hline$\dot{8}$ & 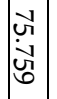 & ஜ் & 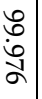 & : & & 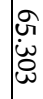 & $\dot{8}$ & $\begin{array}{l}\text { N } \\
\text { in } \\
\text { d }\end{array}$ & :े & $\begin{array}{ll}\vec{\omega} \\
\dot{\omega} \\
\omega\end{array}$ & 依 & $\begin{array}{l}0 \\
\dot{2} \\
\mathrm{~N}\end{array}$ & المطنداولة \\
\hline ஜ் & 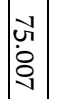 & ஜ் & $\begin{array}{l}0 \\
0 \\
0 \\
\vdots \\
\pm\end{array}$ & 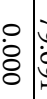 & & $\begin{array}{l}\infty \\
i \\
\tilde{N} \\
\sigma\end{array}$ & : & $\begin{array}{l}\vec{\omega} \\
\dot{\omega} \\
\dot{\omega}\end{array}$ & : & & 焉 & 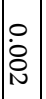 & رأس المال \\
\hline$\dot{8}$ & $\mid \begin{array}{l}\vec{B} \\
\dot{0} \\
i\end{array}$ & ஜ் & 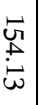 & 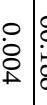 & & $\begin{array}{l}0 \\
y \\
\infty \\
0 \\
v\end{array}$ & : & 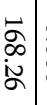 & : & & 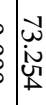 & : & هامش صافي | الربح \\
\hline ஜ் & 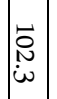 & $\dot{\circ}$ & $\begin{array}{l}\vec{t} \\
\text { iv } \\
\end{array}$ & $\stackrel{\square}{:}$ & & $\stackrel{u}{\dot{v}}$ & : & $\begin{array}{l}\tilde{N} \\
\stackrel{1}{i} \\
\dot{\omega}\end{array}$ & :े & \begin{tabular}{l|l}
\multirow{2}{*}{} & $\circ$ \\
0 & $\stackrel{8}{8}$
\end{tabular} & 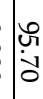 & $\mid \begin{array}{l}0 \\
\dot{0} \\
\omega \\
\omega\end{array}$ & دوران اججالي \\
\hline ஜे & $\begin{array}{l}0 \\
0 \\
\text { in }\end{array}$ & $\dot{8}$ & 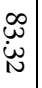 & : & & 离 & : & \begin{tabular}{|l}
$\vec{u}$ \\
$\dot{0}$
\end{tabular} & : & \begin{tabular}{l|l}
$\vec{\omega}$ \\
$\dot{\omega}$
\end{tabular} & $\mid \begin{array}{l}\infty \\
\infty \\
i \pi n\end{array}$ & : & الايرادات \\
\hline $\begin{array}{l}\dot{\circ} \\
\dot{\omega}\end{array}$ & $\begin{array}{l}\vec{t} \\
\dot{\omega} \\
\dot{\infty} \\
0\end{array}$ & ஜ் & 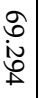 & $\begin{array}{lll}0 \\
\dot{\alpha}\end{array}$ & & $\begin{array}{l}\text { o } \\
\infty \\
0 \\
\text { d }\end{array}$ & : & $\begin{array}{l}\infty \\
0 \\
0 \\
0 \\
0\end{array}$ & : & 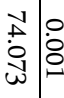 & 赵 & : & اجلي الاصول \\
\hline$\dot{8}$ & $\begin{array}{l}\stackrel{\sim}{\mathbf{N}} \\
\mathrm{N}\end{array}$ & $\dot{8}$ & $\mid \vec{a}$ & $\dot{0}$ & & $\begin{array}{l}w \\
w \\
\dot{\infty} \\
\infty\end{array}$ & $\dot{8}$ & $\begin{array}{l}\infty \\
\stackrel{\infty}{\sim} \\
\stackrel{\sim}{\sim}\end{array}$ & : & 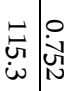 & $\begin{array}{l}\infty \\
\infty \\
\infty \\
\infty\end{array}$ & & قيمةالسوقية الى الدفية \\
\hline$\dot{8}$ & $\begin{array}{l}\infty \\
: \infty \\
\dot{N}\end{array}$ & $\dot{8}$ & $\mid$\begin{tabular}{c}
$\vec{N}$ \\
\hdashline \\
0
\end{tabular} & $\dot{0}$ & & $\overrightarrow{\vec{े}}$ & $\dot{8}$ & 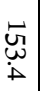 & :े & 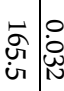 & 空 & $\dot{8}$ & الضرئب قبل \\
\hline : & 栾 & ஜ் & 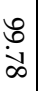 & 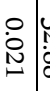 & & $\begin{array}{l}w \\
\dot{\omega} \\
\dot{y}\end{array}$ & : & $\stackrel{\infty}{\stackrel{\infty}{\tilde{\sigma}}}$ & : & 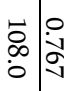 & ב & i & سعرالسوقي \\
\hline$\dot{8}$ & $\begin{array}{l}\mathscr{0} \\
\dot{\hat{N}} \\
\end{array}$ & ஜे & $\left|\begin{array}{c}\vec{w} \\
: \\
\sigma \\
\sigma\end{array}\right|$ & 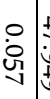 & & $\begin{array}{l}\mathcal{u} \\
N \\
\infty \\
\infty \\
\pm\end{array}$ & : & 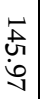 & : & 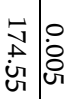 & 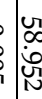 & 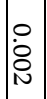 & قلمقالدفرية \\
\hline ஜें & 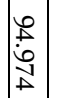 & $\dot{8}$ & 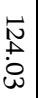 & 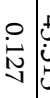 & & 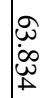 & : & 岕 & : & 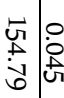 & t: & $\dot{8}$ & معدل عائد على \\
\hline : & $\begin{array}{l}1 \\
\dot{0} \\
2\end{array}$ & $\dot{8}$ & $\vec{\sigma}$ & 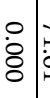 & & for & $\dot{8}$ & 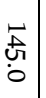 & :े & \begin{tabular}{l|l}
$\vec{v}$ \\
$\stackrel{1}{*}$
\end{tabular} & ڤ & & الضرائب بعد \\
\hline
\end{tabular}

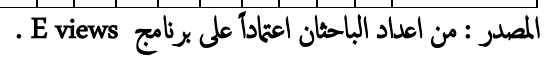

من خلال الجدول اعلاه يتبين لنا أن هناك استقرارية والثبات لكل المتغيرات

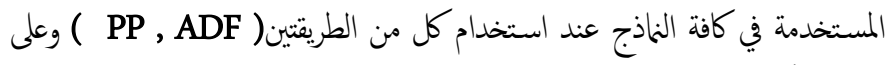

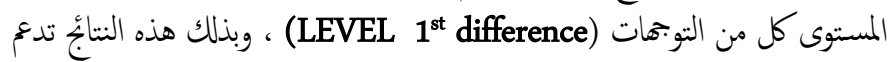
اجراء التكامل المشترك (Cointegration).

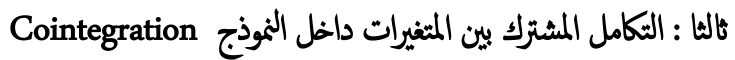

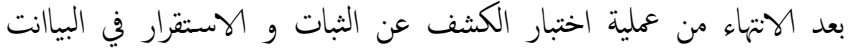

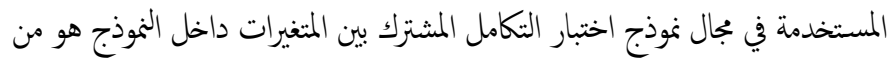

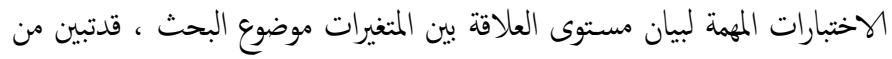

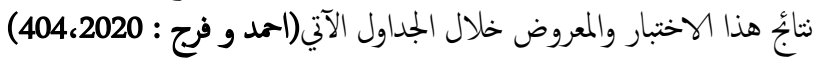




\begin{tabular}{|c|c|c|c|c|c|c|c|c|c|}
\hline $\begin{array}{l}\stackrel{0}{\text { N }} \\
\text { \&े }\end{array}$ & $\begin{array}{l}\ddot{\tilde{N}} \\
\text { 心ू } \\
\text {. }\end{array}$ & & & $\begin{array}{l}\stackrel{0}{\dot{\omega}} \\
\stackrel{+}{\dot{0}}\end{array}$ & 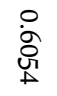 & $\begin{array}{l}\dot{8} \\
\dot{8}\end{array}$ & 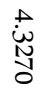 & الأزمة المالية الداخلية & \\
\hline 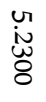 & $\begin{array}{l}\stackrel{w}{w} \\
\dot{w} \\
\dot{b}\end{array}$ & $\begin{array}{l}0 \\
\dot{8} \\
\dot{0}\end{array}$ & $\begin{array}{l}\dot{0} \\
\dot{8}\end{array}$ & 온 & $\begin{array}{l}\text { D } \\
\text { i్ర }\end{array}$ & $\begin{array}{l}\text { 영 } \\
\dot{8}\end{array}$ & $\ddot{2}$ & الموجودات المتداولة & \multirow{6}{*}{ صافي رأس المال } \\
\hline $\begin{array}{l}0 \\
\text { రे } \\
\text { مे }\end{array}$ & $\begin{array}{l}\text { రै } \\
\dot{\infty} \\
\infty\end{array}$ & $\begin{array}{l}0 \\
\dot{0} \\
\stackrel{+}{0} \\
\text { u }\end{array}$ & $\stackrel{\dot{\omega}}{\dot{\omega}}$ & 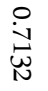 & $\dot{\dot{\infty}}$ & $\begin{array}{l}\circ \\
\dot{8} \\
8\end{array}$ & $\dot{\vec{L}}$ & المطلوبات المتداولة & \\
\hline $\begin{array}{l}\text { vै } \\
\text { ஸे } \\
\text { w్ }\end{array}$ & $\begin{array}{l} \pm \\
\dot{\omega} \\
\text { ơ }\end{array}$ & $\begin{array}{l}\stackrel{\circ}{\dot{8}} \\
\dot{0} \\
\dot{\infty}\end{array}$ & $\dot{\dot{w}}_{\text {du }}$ & $\begin{array}{l}\circ \\
\text { कू } \\
\text { ò }\end{array}$ & 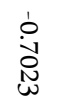 & $\begin{array}{l}\dot{0} \\
\dot{8}\end{array}$ & 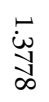 & نسبة التداول & \\
\hline $\begin{array}{l}\stackrel{\overrightarrow{i n}}{\dot{\infty}} \\
\stackrel{\infty}{\omega}\end{array}$ & $\begin{array}{l}\text { जे } \\
\dot{8} \\
\text { \&े }\end{array}$ & $\begin{array}{l}\text { : } \\
\dot{8} \\
\dot{\omega}\end{array}$ & $\begin{array}{l}\dot{1} \\
\dot{1}\end{array}$ & $\begin{array}{l}\stackrel{0}{\infty} \\
\stackrel{\infty}{\infty}\end{array}$ & $\stackrel{\stackrel{N}{*}}{0}$ & $\begin{array}{l}\dot{0} \\
\dot{8}\end{array}$ & $\stackrel{N}{\dot{\omega}}$ & دوران اجالي الأصول & \\
\hline $\begin{array}{l}0 \\
\dot{\infty} \\
+0 \\
10\end{array}$ & 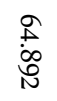 & : & ’் & $\begin{array}{l}\circ \\
\dot{8} \\
\text { ᄋे }\end{array}$ & $\begin{array}{l}\dot{1} \\
\dot{0} \\
\dot{0}\end{array}$ & $\begin{array}{l}\circ \\
\dot{8}\end{array}$ & $\dot{8}$ & هامش صافي الربح & \\
\hline $\begin{array}{l}\stackrel{\mathscr{\psi}}{\text { बे }} \\
\stackrel{\sigma}{0}\end{array}$ & $\begin{array}{l}\text { जू } \\
\text { ¿n }\end{array}$ & & & $\begin{array}{l}0 \\
\dot{8} \\
\stackrel{1}{+}\end{array}$ & ஸे̀ & $\begin{array}{l}\dot{0} \\
\dot{8}\end{array}$ & $\stackrel{N}{\stackrel{N}{H}}$ & الأزمة المالية الداخلية & \\
\hline 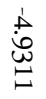 & $\begin{array}{l}: \\
\dot{8} \\
\text { फ़ुb }\end{array}$ & 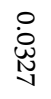 & $\stackrel{\dot{\vec{v}}}{\vec{v}}$ & $\begin{array}{l}\stackrel{0}{N} \\
\stackrel{v}{v}\end{array}$ & نु & $\begin{array}{l}\circ \\
\dot{8} \\
8\end{array}$ & $\overrightarrow{\dot{H}}$ & الايرادات & \multirow{6}{*}{ اجلالي الأصول } \\
\hline $\begin{array}{l}\dot{\dot{d}} \\
\text { Jे } \\
\text { J }\end{array}$ & $\begin{array}{l}\stackrel{0}{0} \\
\dot{\infty} \\
\stackrel{\infty}{1}\end{array}$ & $\begin{array}{l}\stackrel{\circ}{\dot{\omega}} \\
\stackrel{\rho}{\sim}\end{array}$ & $\begin{array}{l}\text { bे } \\
\text { के }\end{array}$ & $\begin{array}{l}\text { ㅇ } \\
\text { 心్ } \\
\text { 心 }\end{array}$ & $\stackrel{N}{\vec{A}}$ & $\begin{array}{l}\dot{8} \\
\dot{8}\end{array}$ & $\stackrel{v}{y}$ & اججالي الأصول & \\
\hline $\begin{array}{l}+ \\
\dot{\omega} \\
+\infty \\
\infty \\
\sigma\end{array}$ & $\begin{array}{l}0 \\
\text { 엉 } \\
\text { ర్ర }\end{array}$ & $\begin{array}{l}\dot{0} \\
\dot{8}\end{array}$ & $\stackrel{\bigcup}{N}_{N}$ & 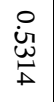 & $\begin{array}{l}1 \\
\dot{0} \\
\text { O্் } \\
\infty\end{array}$ & $\begin{array}{l}\dot{0} \\
\dot{8}\end{array}$ & 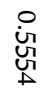 & هامش صافي الربح & \\
\hline 峁 & 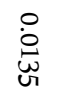 & $\begin{array}{l}\dot{0} \\
\dot{8} \\
\dot{U}\end{array}$ & $\dot{\vec{v}}$ & 品 & $\begin{array}{l}\circ \\
\dot{8} \\
\dot{0}\end{array}$ & $\begin{array}{l}\dot{0} \\
\dot{8}\end{array}$ & : & صافي رأس المال & \\
\hline 崩 & $\begin{array}{l}\circ \\
\dot{8} \\
\text { ă }\end{array}$ & 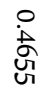 & $\dot{\dot{w}}_{\text {du }}$ & $\begin{array}{l}\text { 엉 } \\
\text { 峁 }\end{array}$ & $\begin{array}{l}\dot{1} \\
\dot{0} \\
\text { ज } \\
\text { ث̀ }\end{array}$ & $\begin{array}{l}\dot{0} \\
\dot{8}\end{array}$ & $\begin{array}{l}\circ \\
\text { 囱 } \\
\text { ज़ }\end{array}$ & قيمة السوقية الى الدفتية & \\
\hline \begin{tabular}{l}
+ \\
\multirow{2}{*}{} \\
$\infty$ \\
$+\infty$
\end{tabular} & 号 & & & 엃 & $\begin{array}{l}\text { : } \\
\dot{\$} \\
\text { ळे }\end{array}$ & $\begin{array}{l}\dot{8} \\
\dot{8}\end{array}$ & $\begin{array}{l}\circ \\
\dot{0} \\
\text { O }\end{array}$ & الأزمة المالية الداخلية & \\
\hline 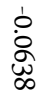 & 只 & $\begin{array}{l}0 \\
\text { o } \\
\text { : } \\
\text { Oे }\end{array}$ & ’े & $\begin{array}{l}\dot{8} \\
\dot{8} \\
\dot{0}\end{array}$ & مa & $\begin{array}{l}\circ \\
\dot{8}\end{array}$ & $\begin{array}{l}0 \\
\infty \\
+\infty\end{array}$ & الريح قبل الضرائب & \multirow{4}{*}{ هامش صافي } \\
\hline 点 & $\begin{array}{l}\circ \\
\dot{8} \\
\text { ర్ల్ }\end{array}$ & $\begin{array}{l}\circ \\
\dot{8}\end{array}$ & 它 & $\begin{array}{l}\circ \\
\stackrel{े}{\text { W }}\end{array}$ & $\stackrel{\dot{\sim}}{\dot{\leftrightarrow}}$ & $\begin{array}{l}\circ \\
\dot{8}\end{array}$ & $\begin{array}{l}0 \\
\dot{H}\end{array}$ & الايرادات & \\
\hline $\begin{array}{l}\text { ì } \\
\text { : } \\
\text { d } \\
\text { w }\end{array}$ & $\stackrel{\circ}{\stackrel{.}{\omega}}$ & ஜ & $\begin{array}{l}\dot{0} \\
\dot{8}\end{array}$ & $\begin{array}{l}\stackrel{0}{\dot{\alpha}} \\
\stackrel{\infty}{\infty}\end{array}$ & 号 & 영 & $\begin{array}{l}0 \\
\dot{8} \\
\text { D }\end{array}$ & نسبةالتداول & \\
\hline 岕 & $\begin{array}{l}\stackrel{\circ}{\dot{S}} \\
\stackrel{\leftrightarrow}{\omega}\end{array}$ & 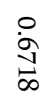 & $\stackrel{P}{\perp}$ & $\begin{array}{l}\circ \\
\text { ì } \\
\text { \& } \\
+\end{array}$ & $\begin{array}{l}\dot{1} \\
\dot{8} \\
\dot{0}\end{array}$ & $\begin{array}{l}\dot{0} \\
\dot{8}\end{array}$ & : & صافي رأس المال & \\
\hline
\end{tabular}

\begin{tabular}{|c|c|c|c|c|}
\hline \multicolumn{2}{|c|}{ المستوى المعنوي } & \multicolumn{2}{|l|}{ statistics } & اختبارات \\
\hline \multicolumn{2}{|c|}{1.0000} & \multicolumn{2}{|l|}{4.808681} & Group rho \\
\hline \multicolumn{2}{|l|}{0.0000} & \multicolumn{2}{|l|}{-3.942665} & Group PP \\
\hline \multicolumn{2}{|l|}{0.0000} & \multicolumn{2}{|c|}{-4.093356} & Group ADF \\
\hline \multicolumn{5}{|c|}{ اختبار النكامل المشترك بين المتغبرات النموذج السادس(معدل العائد على سهم) } \\
\hline المستوى المعنوي & statistics & المستوى المعنوي & statistics & اختبارات \\
\hline 0.8888 & $\begin{array}{c}- \\
1.220043\end{array}$ & 0.7233 & -0.592642 & Panel v \\
\hline 0.9503 & 1.647705 & 0.8668 & 1.111258 & Panel rho \\
\hline 0.0000 & $\begin{array}{c}- \\
6.741298\end{array}$ & 0.0000 & -9.442447 & Panel PP \\
\hline 0.0000 & $\begin{array}{c}- \\
6.224720\end{array}$ & 0.0000 & -8.377280 & Panel ADF \\
\hline 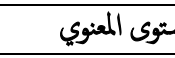 & & statistics & & اختبارات \\
\hline 0.9998 & & 3.487424 & & Group rho \\
\hline 0.0000 & & -7.926592 & & Group PP \\
\hline 0.0000 & & -6.505220 & & Group ADF \\
\hline
\end{tabular}

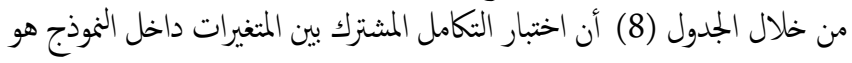

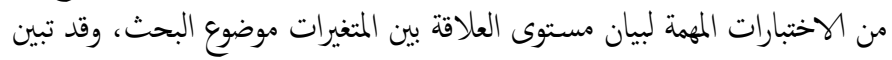
من نتاجُ هذا الاختبار والمعروض خلاتل لمان من الجدول (25):

ثالثاً : تقدير الثاذج القياسية (Estimation) : بعال

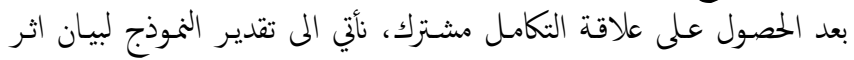

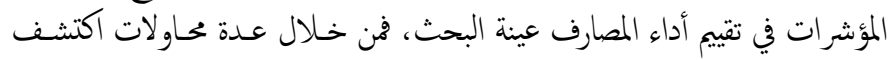

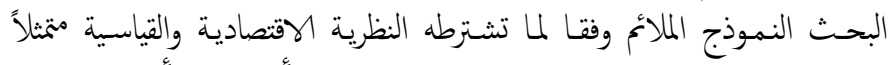

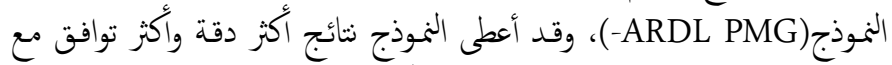

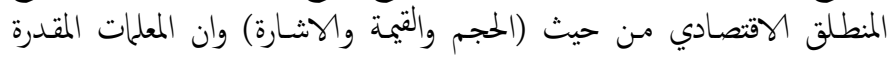

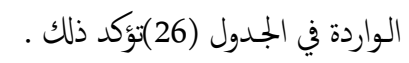
(9) الجدول نتابُ المعلمات المقدرة لناذج المستخدمة مع المثغيرات النموذج (ولم

\begin{tabular}{|c|c|c|c|c|c|c|c|c|c|}
\hline 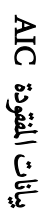 & 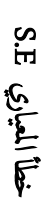 & $\frac{\xi^{2 *}}{\xi}$ & $\frac{{ }^{2}}{E}$ & $\frac{\xi}{\xi}$ & 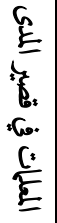 & $\frac{\xi}{\xi}$ & $\begin{array}{l}E \\
\xi \\
E \\
E \\
E \\
E \\
E \\
E\end{array}$ & 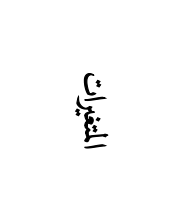 & المستخدمة الناذج \\
\hline 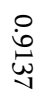 & $\begin{array}{l}\dot{0} \\
\dot{9} \\
\dot{\phi} \\
\dot{1}\end{array}$ & $\begin{array}{l}\text { 영 } \\
\text { \& }\end{array}$ & $\dot{\dot{\theta}}$ & 品 & ب⿱艹 & $\begin{array}{l}\circ \\
\dot{8}\end{array}$ & ب்̃ & الموجودات المتداولة & \multirow{4}{*}{ نسبةالتداول } \\
\hline$\stackrel{w}{\stackrel{N}{N}}$ & $\stackrel{\vec{a}}{\stackrel{+}{N}}$ & : & 'े & $\begin{array}{l}0 \\
\dot{8} \\
\text { ui }\end{array}$ & $\stackrel{\dot{\sigma}}{\dot{\sigma}}$ & $\begin{array}{l}\text { 영 } \\
\dot{8}\end{array}$ & $\dot{\vec{ٌ}}$ & المطلوبات المتداولة & \\
\hline 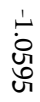 & 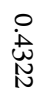 & $\begin{array}{l}\text { O } \\
\text { 苻 }\end{array}$ & dे & $\stackrel{\circ}{\stackrel{D}{\infty}}$ & $\begin{array}{l}\circ \\
\dot{8} \\
\dot{f}\end{array}$ & 영 & 웅 & صافي رأس المال & \\
\hline 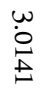 & 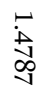 & $\begin{array}{l}\circ \\
\dot{8}\end{array}$ & $\stackrel{\dot{d}}{\dot{\omega}}$ & $\begin{array}{l}\circ \\
\text { : } \\
\text { No } \\
\text { v }\end{array}$ & 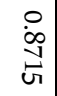 & $\begin{array}{l}\text { ㅇ } \\
\text { ᄋ̊ }\end{array}$ & $\begin{array}{l}\dot{\omega ্}_{\text {J }} \\
\text { J }\end{array}$ & هامش صافي الربح & \\
\hline
\end{tabular}


بعقدار(5.42\%) .ومن خلال نفس الجدول فان نقطة التوازن بلغت (0.90-) وهذا يعنى أن هناك جزز في الموجودات المتداولة بمقدار (0.10) ولتصحيح الاخطاء والتوصل إلى نقطة التوازن نحتاج مقدار (0.10) لتحقيق التوازن في

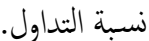

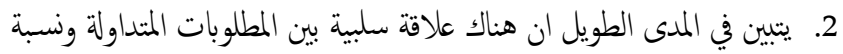
التداول أي ان زيادة المطلوبات المتداولة بمقدار (1\%) تؤدي إلى الخفاض الماض

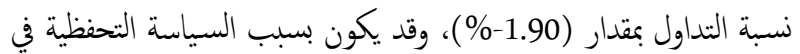

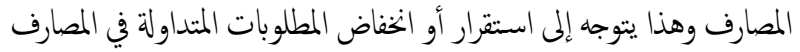

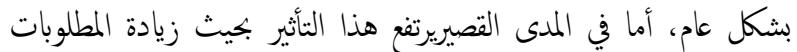

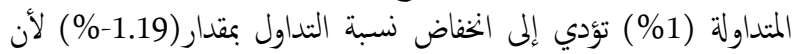

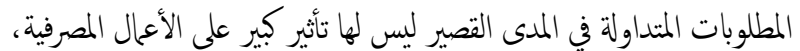

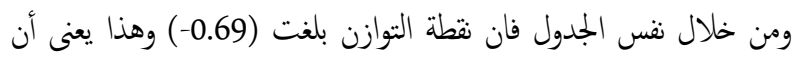

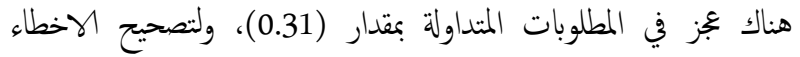

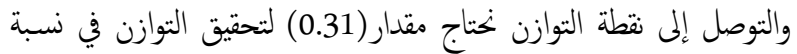

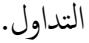
3. يتبين في المدى الطويل ان هناك علاقة إيهابية بين صافي رأس المال العامل

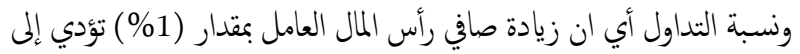

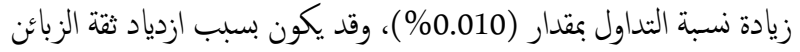

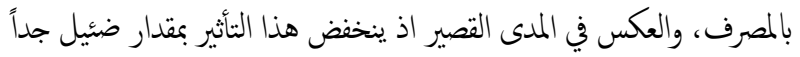

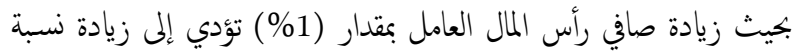

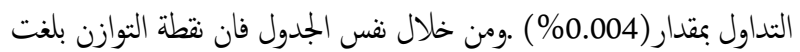

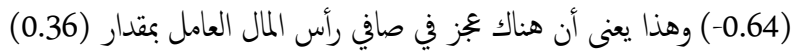

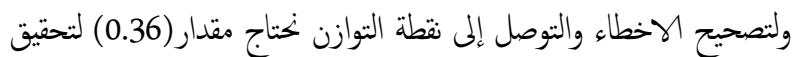
التوازن في نسبة التداول.

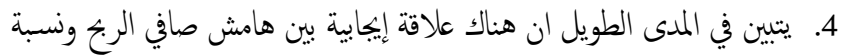

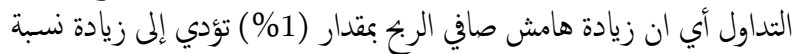

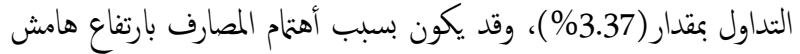

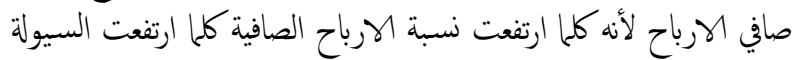

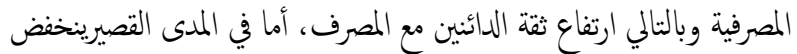

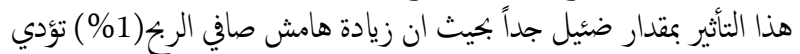

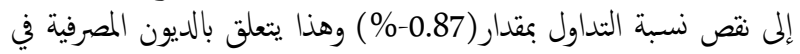

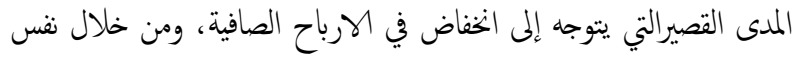

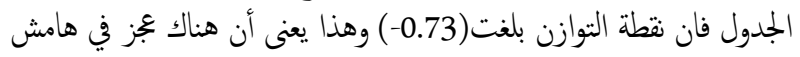

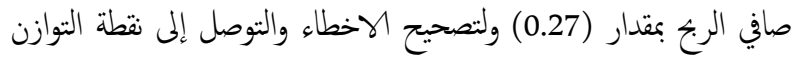
نتاج مقدار (0.27) في تحقيق التوازن في نسبة التداول.

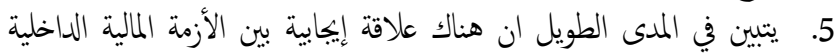

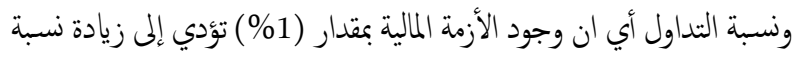
التداول بمقدار (4.32\%)، وقد يكون بسبب تداول الأنة الأموال في العمليات

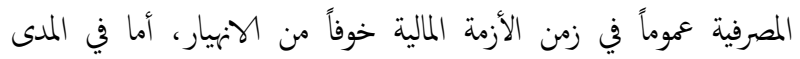

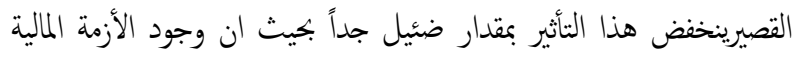
بعقدار (1\%) تؤدي إلى زيادة نسبة التداول بمقدار (0.60\%).

\begin{tabular}{|c|c|c|c|c|c|c|c|c|c|}
\hline $\begin{array}{l}\dot{b} \\
\dot{\omega} \\
\dot{1} \\
\dot{v}\end{array}$ & $\begin{array}{l}0 \\
\dot{8} \\
\dot{\Delta}\end{array}$ & ஜे & $\begin{array}{l}\dot{8} \\
\dot{8}\end{array}$ & 莕 & 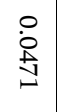 & $\dot{\circ}$ & \begin{tabular}{l}
0 \\
$\dot{N}$ \\
\multirow{N}{a}{}
\end{tabular} & قيمة السوقية الى الدفرية & \\
\hline$\underset{\dot{\infty}}{\dot{\infty}}$ & $\dot{\dot{U}}$ & & & 영 & $\begin{array}{l}\dot{0} \\
\dot{0} \\
\dot{0} \\
\end{array}$ & $\begin{array}{l}0 \\
\dot{0} \\
\infty \\
\circ\end{array}$ & $\begin{array}{l}\dot{0} \\
\dot{0}\end{array}$ & الأزمة المالية الداخلية & \\
\hline 帒 & $\begin{array}{l}\dot{P} \\
\dot{\infty} \\
\substack{0 \\
0}\end{array}$ & $\dot{\dot{\theta}}$ & $\begin{array}{l}\dot{b} \\
\dot{v}\end{array}$ & 怘 & 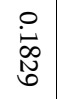 & $\dot{8}$ & 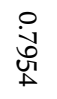 & سعر السوقي للسهم & \multirow{6}{*}{ قيمة السوقية المى } \\
\hline 它 & 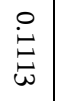 & : & $\begin{array}{l}\dot{\dot{\omega}} \\
\dot{\omega}\end{array}$ & $\stackrel{\dot{U}}{\stackrel{0}{0}}$ & $\begin{array}{l}\text { D } \\
\text { 总 } \\
\end{array}$ & ஜ் & $\begin{array}{l}\text { o } \\
\dot{0} \\
\dot{\infty}\end{array}$ & قيمة الدفترية للسهم & \\
\hline$\dot{\dot{\omega}}_{\substack{\infty \\
\infty}}$ & 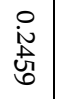 & ஜें & $\dot{\dot{\vec{v}}}$ & 宓 & $\begin{array}{l}\dot{\circ} \\
\dot{\Xi} \\
\dot{v}\end{array}$ & $\dot{8}$ & 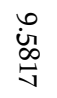 & دوران اجالي الأصول & \\
\hline $\begin{array}{l}\dot{b} \\
\text { 它 } \\
\text { t }\end{array}$ & 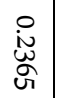 & 通 & 定 & : & $\underset{\substack{\dot{N} \\
\perp}}{+}$ & ஜ் & $\stackrel{n}{8}$ & هامش صافي الريح & \\
\hline $\begin{array}{l}\dot{0} \\
\stackrel{i}{0} \\
\stackrel{i}{v}\end{array}$ & 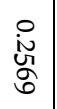 & ஜे & $\begin{array}{l}\dot{d} \\
\dot{a}\end{array}$ & 䓪 & 宓 & :் & 追 & صافي رأس المال & \\
\hline $\begin{array}{c}\dot{\vec{\omega}} \\
\stackrel{\infty}{\infty} \\
\stackrel{\infty}{\infty}\end{array}$ & 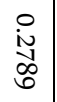 & & & ஜें & $\begin{array}{l}\dot{b} \\
\dot{\vec{\sigma}}\end{array}$ & $\dot{\dot{\leftrightarrow}}$ & : & الأزمة المالية الداخلية & \\
\hline 离 & $\begin{array}{l}\dot{P} \\
\dot{\phi} \\
\text { 讨 }\end{array}$ & $\begin{array}{l}\text { in } \\
\text { in } \\
\text { 今 }\end{array}$ & $\dot{\grave{c}}$ & 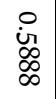 & نِ & $\dot{8}$ & $\stackrel{n}{\vec{L}}$ & الربح بعد الضرائب & \multirow{5}{*}{ معدل عائد على السهم } \\
\hline $\begin{array}{l}\dot{\dot{\vec{D}}} \\
\stackrel{\sim}{\infty}\end{array}$ & $\begin{array}{l}\dot{0} \\
\vec{\omega} \\
ज\end{array}$ & $\begin{array}{l}0 \\
\infty \\
\text { के } \\
\text { o }\end{array}$ & ’े & \begin{tabular}{l}
$\dot{i}$ \\
$\underset{\omega}{\omega}$ \\
\multirow{b}{*}{}
\end{tabular} & $\stackrel{\grave{y}}{\dot{y}}$ & ஜ் & 崔 & الايرادات & \\
\hline $\begin{array}{l}\text { ì } \\
\text { ì } \\
\text { i }\end{array}$ & 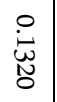 & $\begin{array}{l}\dot{i} \\
\text { d̀ } \\
\infty\end{array}$ & $\stackrel{\dot{i}}{i}$ & 离 & $\begin{array}{l}\dot{b} \\
\dot{0} \\
\dot{\Delta}\end{array}$ & ஜ் & 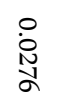 & نسبة التداول & \\
\hline $\begin{array}{l}\dot{\vec{N}} \\
\stackrel{\alpha}{\alpha}\end{array}$ & 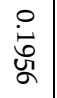 & 总 & $\begin{array}{l}\dot{0} \\
\dot{0}\end{array}$ & 总 & 意 & ஜे & $\begin{array}{l}\omega_{0} \\
\dot{0} \\
\stackrel{0}{0}\end{array}$ & دوران اجالي الأصول & \\
\hline $\begin{array}{l}\dot{1} \\
\infty \\
\infty \\
心 \\
\omega\end{array}$ & 客 & & & : & \begin{tabular}{l}
$\dot{Q}$ \\
$\dot{\tilde{O}}$ \\
\multirow{+}{*}{}
\end{tabular} & $\dot{8}$ & $\begin{array}{l}\text { ì } \\
\text { ơ }\end{array}$ & الأزمة المالية الداخلية & \\
\hline
\end{tabular}

المصدر : من اعداد الباحثان اعتماداً على برنامج E views.

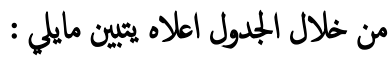
اولا : النموذج الأول (نسبة الثداول) :

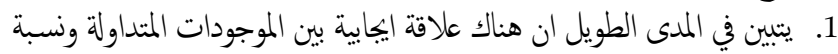

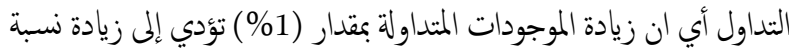

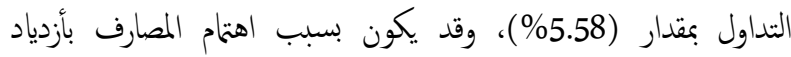

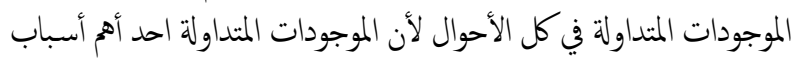

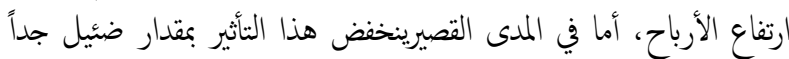

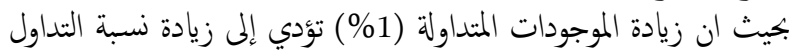


كملاقة طردية كلما زادت هامش صافي الربح كلما زادت صافي رأس المال،

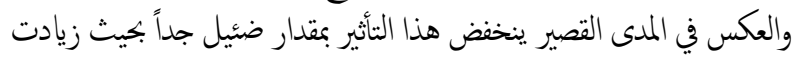

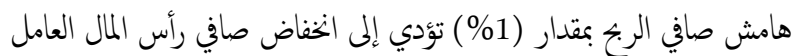

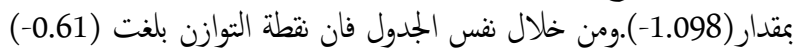

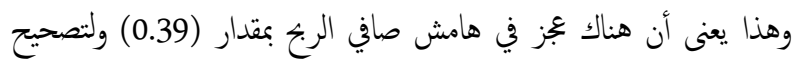

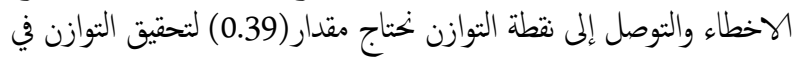

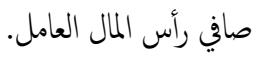

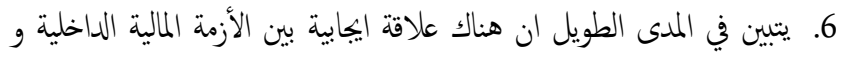

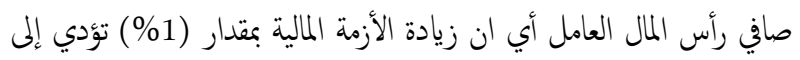

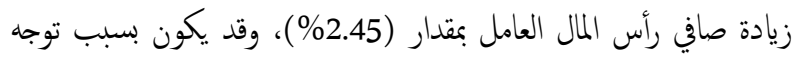

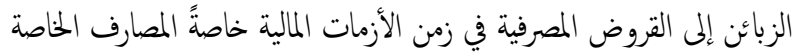

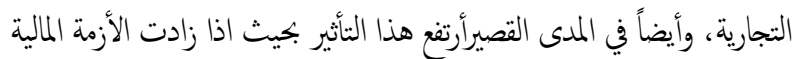

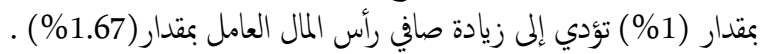

\section{النوذج الثالث : معدل دوران اجلالي الموجودات:}

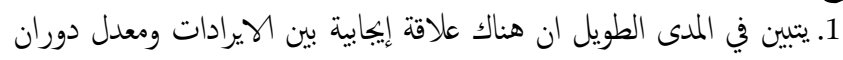

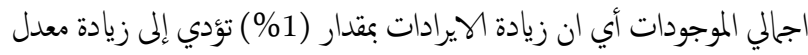

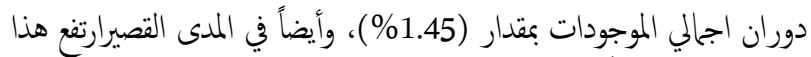

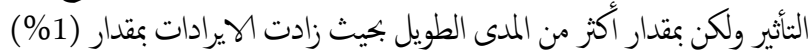

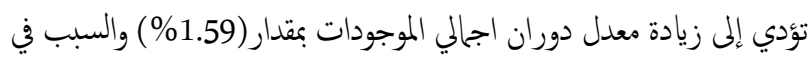

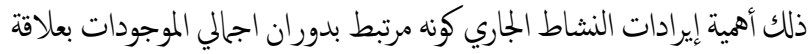

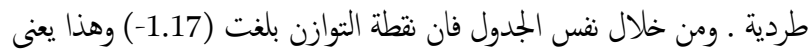

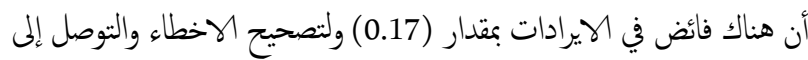

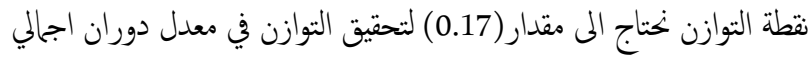

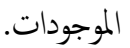

2. يتيبن في المدى الطويل ان هناك علاقة ايهابية بين اجالي الموجودات وجات ومعدل

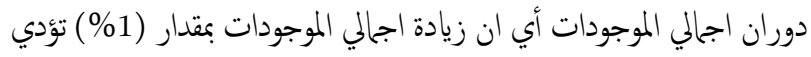

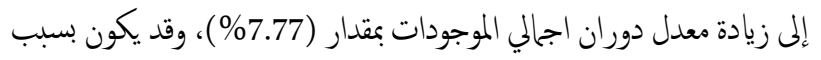

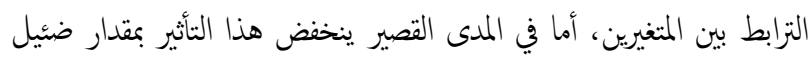

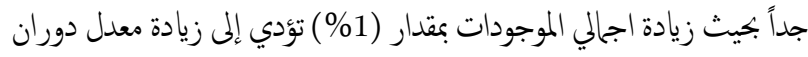

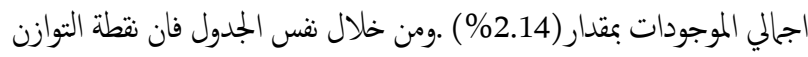

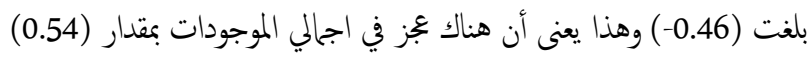

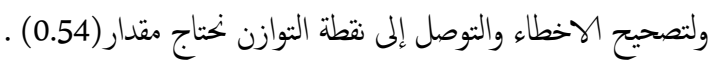

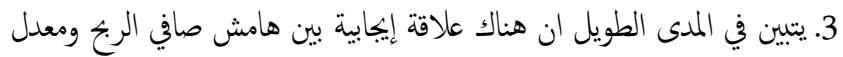

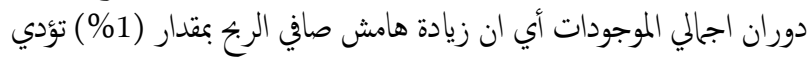

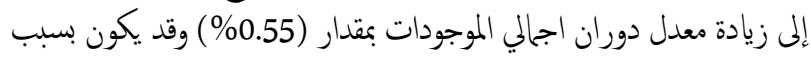

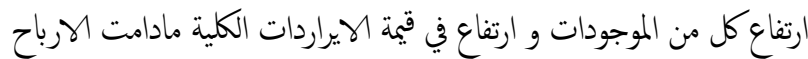

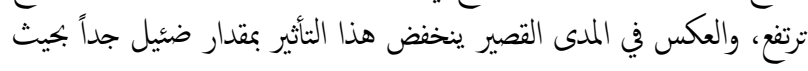

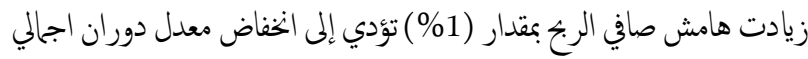

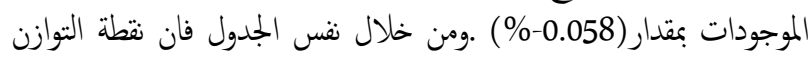

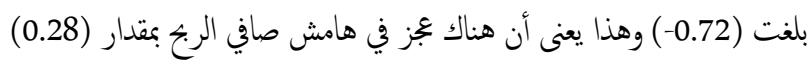

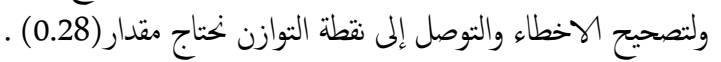

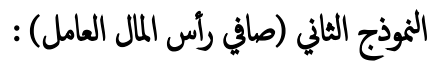

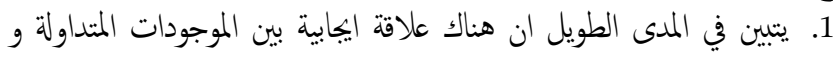

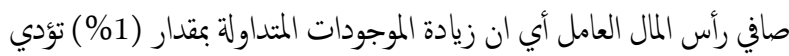

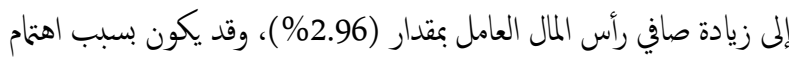

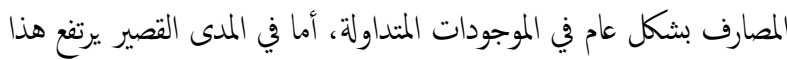

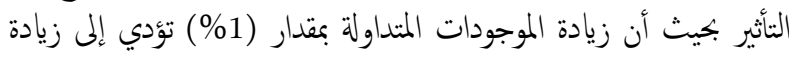

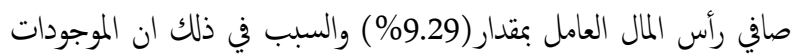

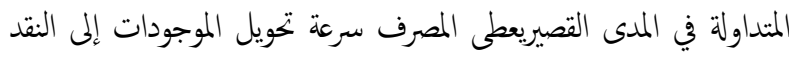

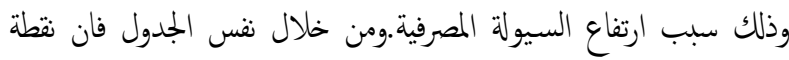
التوازن بلغت (0.60-) وهذا يعنى أن هناك جعز في الموجودات المنات المتداولة بمقدار

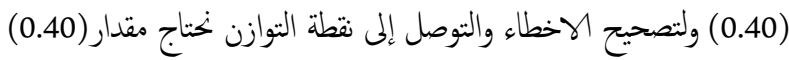
لتحقيق التوازن في صافي رأس المال العامل.

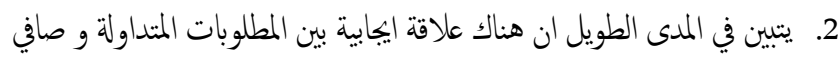

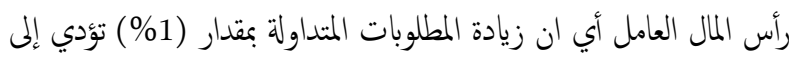

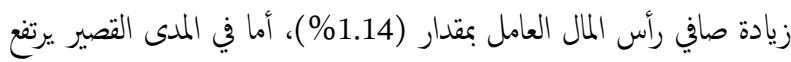

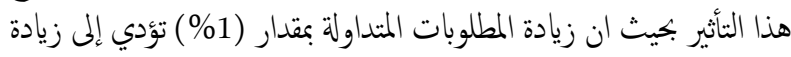

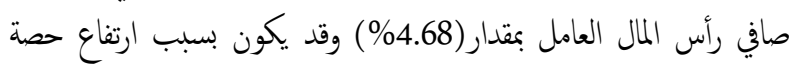

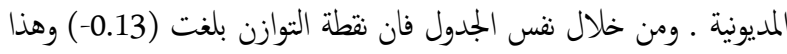

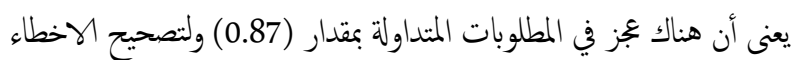
والتوصل إلى نقطة التوازن نختاج مقدار (0.87) لحقيق التوازن في صافي رأس المقال

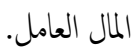

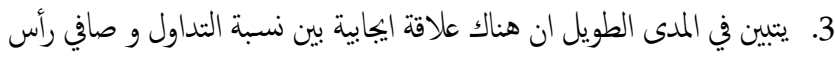

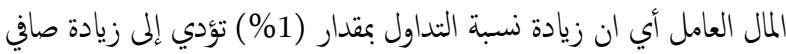

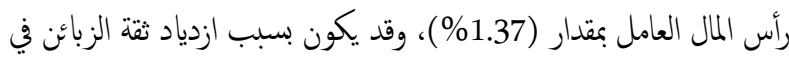

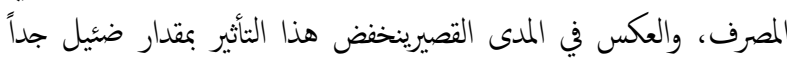

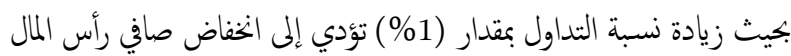

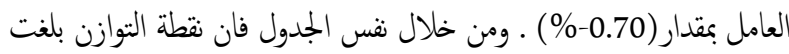

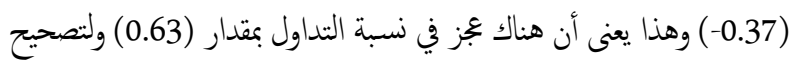

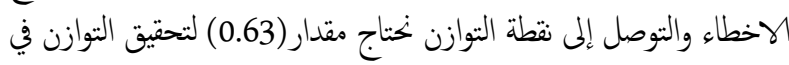
صافي رأس المال العامل.

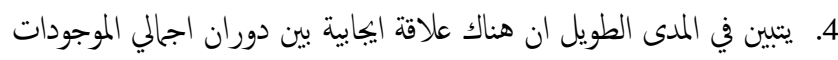

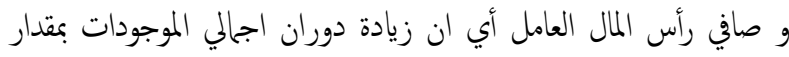

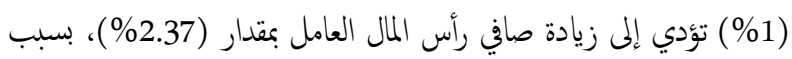

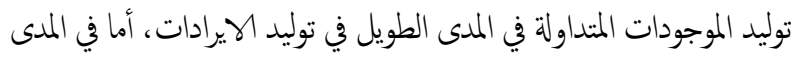

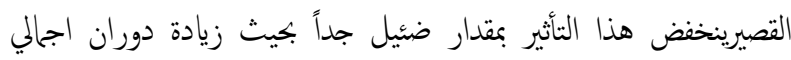

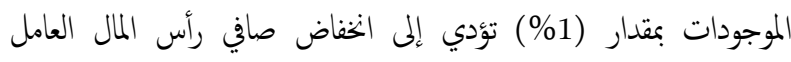

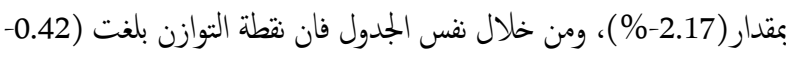

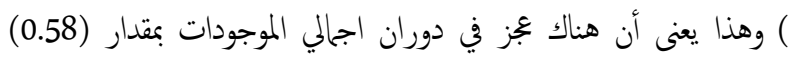

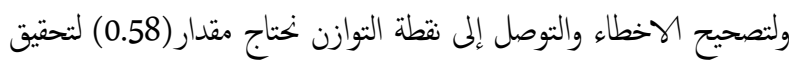
التوازن في صافي رأس المال العامل.

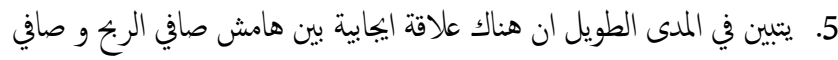

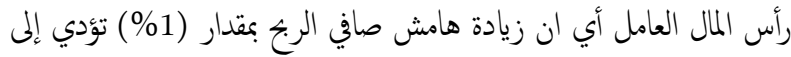

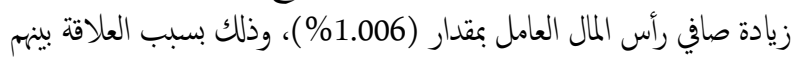


خلال نس الجدول فان نقطة التوازن اذ بلغت (0.52-) وهذا يعنى أن هناك

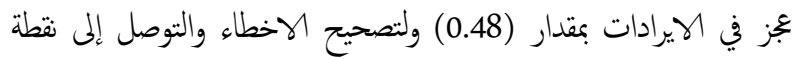

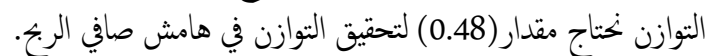

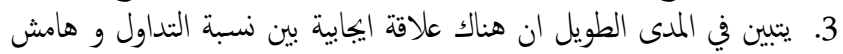

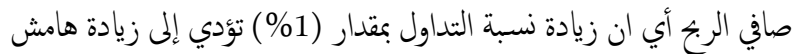

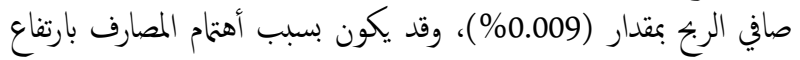

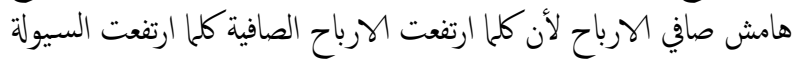

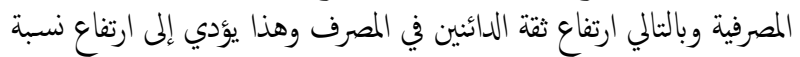

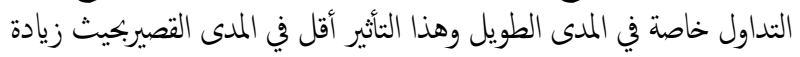

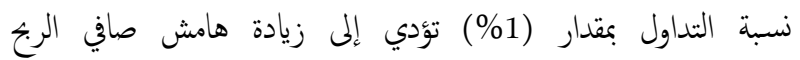

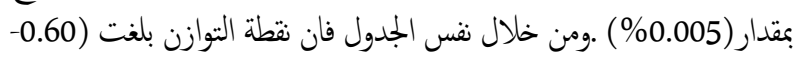

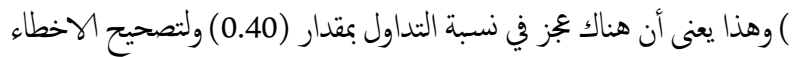

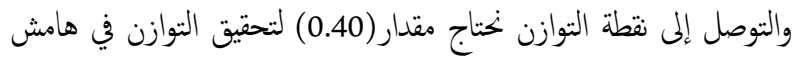
صافي الربح.

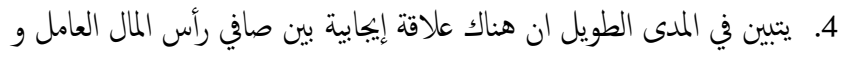

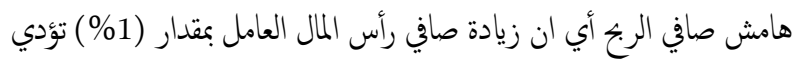

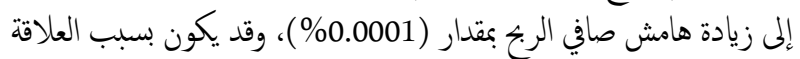

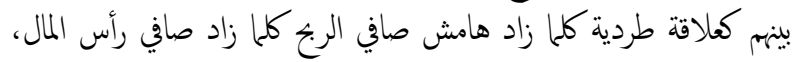

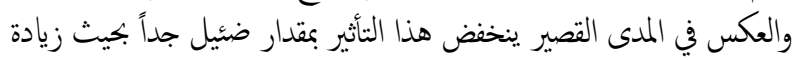

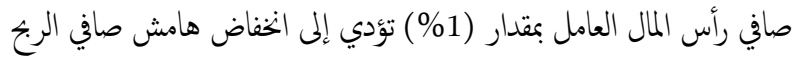

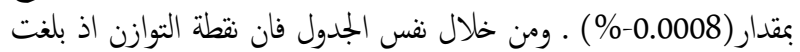

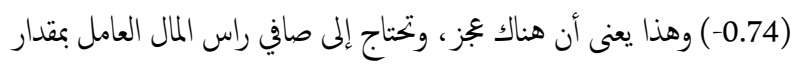

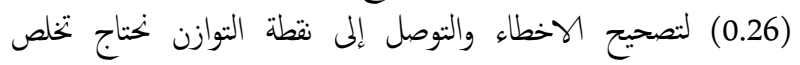
بمقدار(0.26) لتحقيق التوازن في هامش صافي الربح.

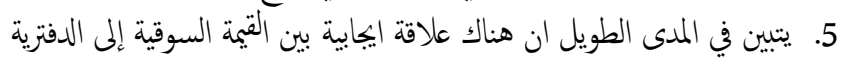

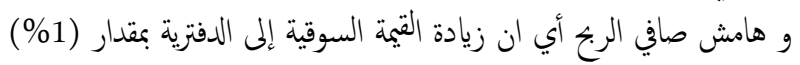

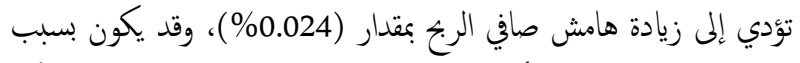

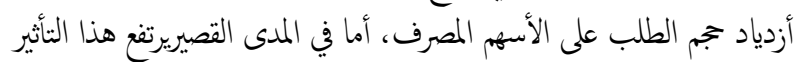

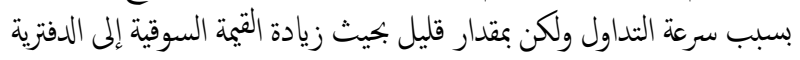

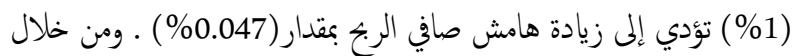

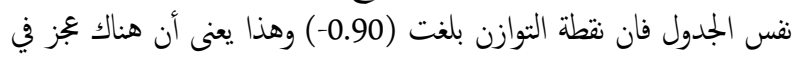

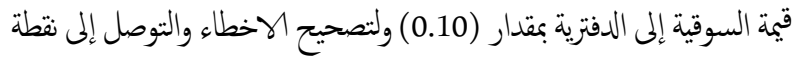

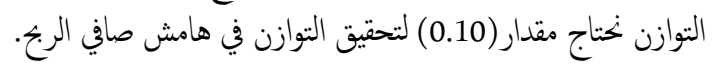

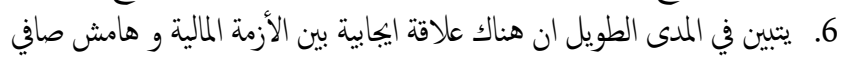

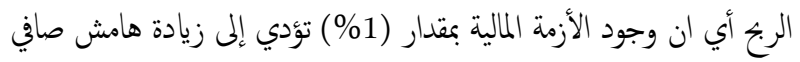

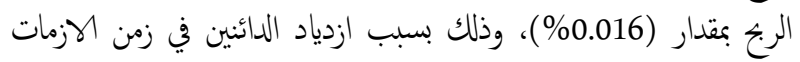

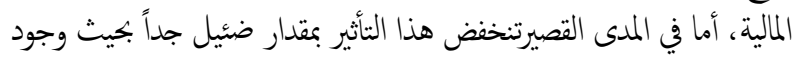

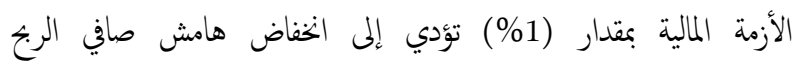

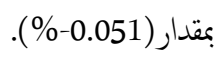

النموذج الخامس : نسبة قمة السوقية المى الدفترية :

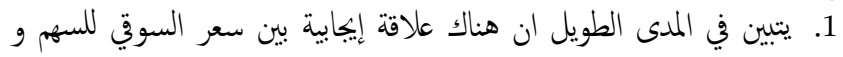

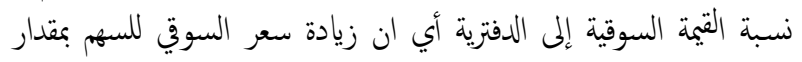

4. يتبين في المدى الطويل ان هناك علاقة ايجابية بين صافي رأس المال العامل

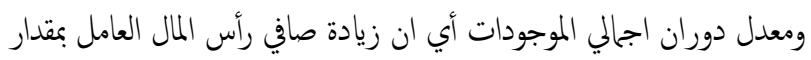

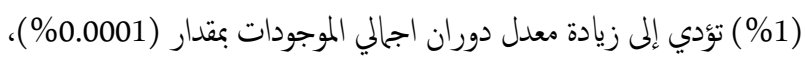

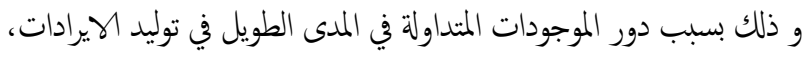

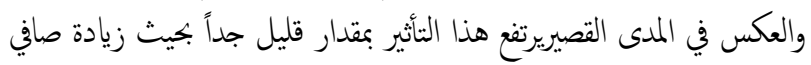

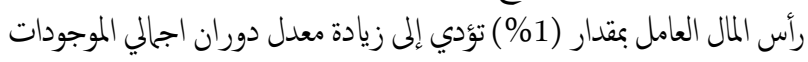

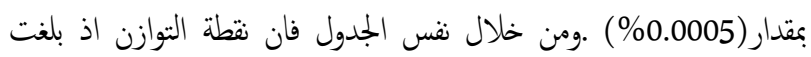

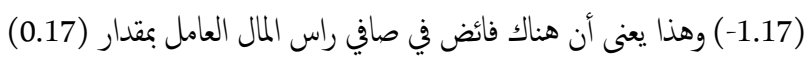

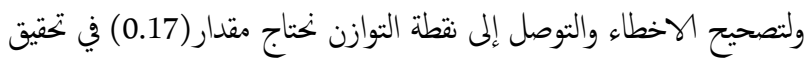
التوازن في معدل دوران اجلالي الموجودات.

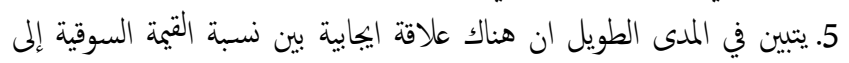

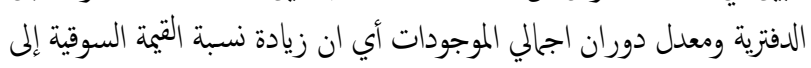

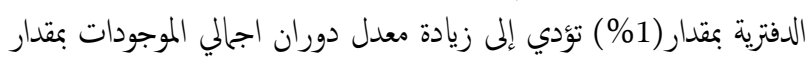

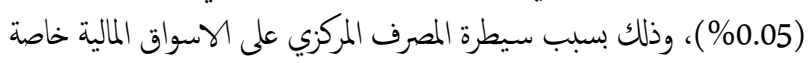

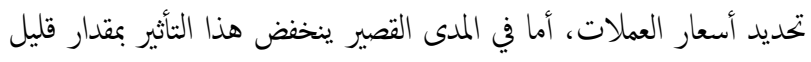

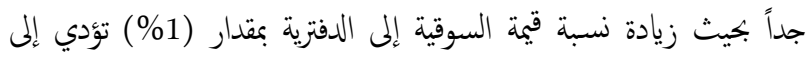

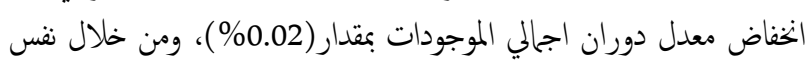

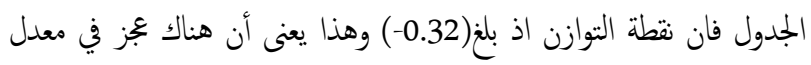

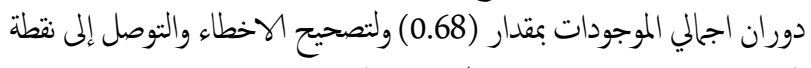

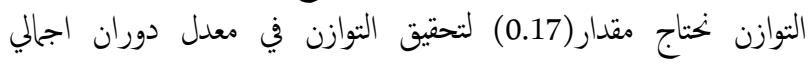
الموجودات. 6. يتبين في المدى الطويل ان هناك علاقة إيجابية بين الأزمة المالية ومعدل دوران

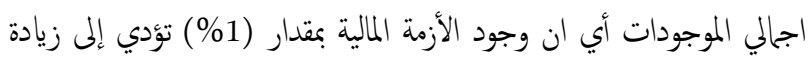

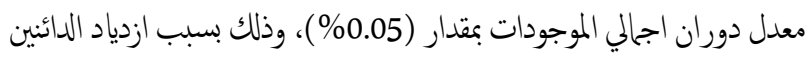

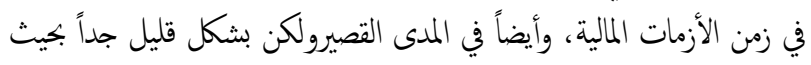

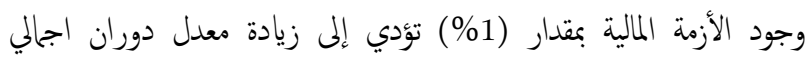

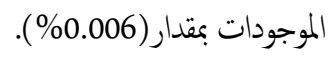

\section{النوذج الرابع : هامش صافي الريخ:}

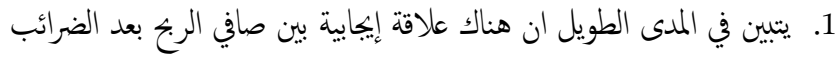

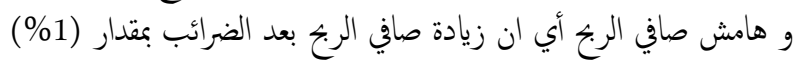

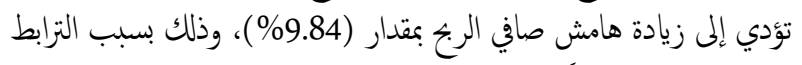

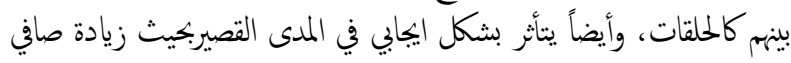

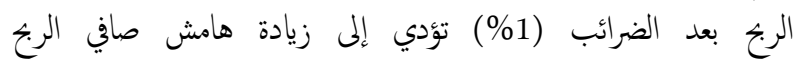

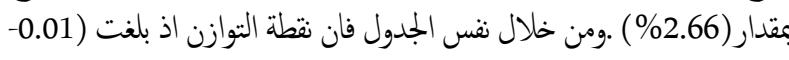

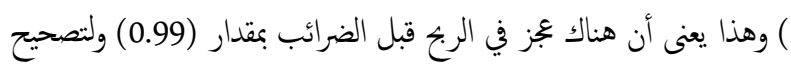
الاخطاء والتوصل إلى نقطة التوازن نختاج مقدار (0.99) لتحقيق التوازن في التي

هامش صافي الربح.

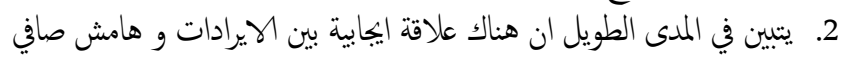

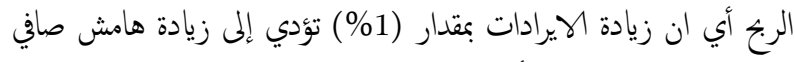

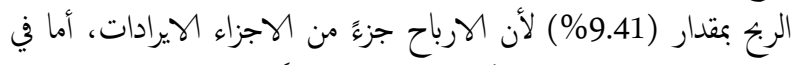

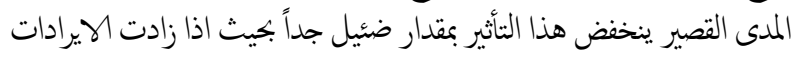

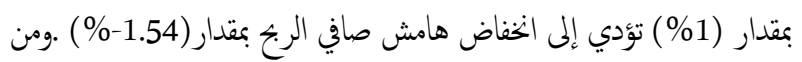


جداً بجيث زيادة صافي رأس المال العامل بعقدار (1\%) تؤدي إلى زيادة القيمة

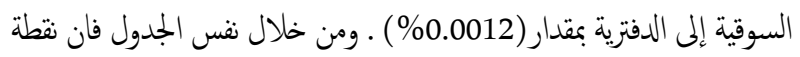

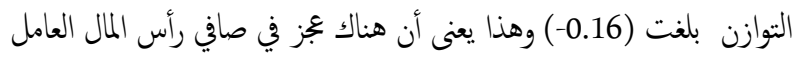

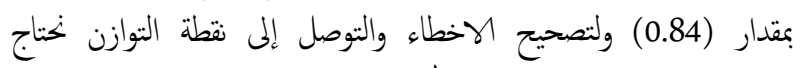
مقدار(0.84) لتحقيق التوازن في التيمة السوقية إلى الدفترية.

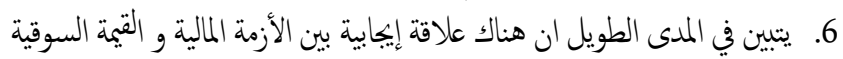

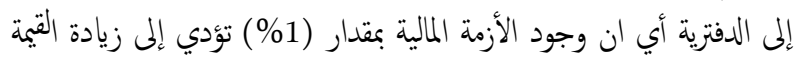

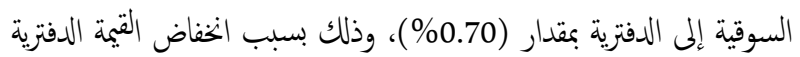

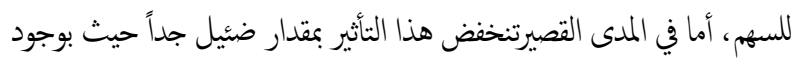

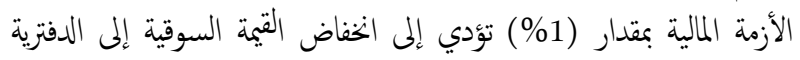

$$
\text { بمقدار(0.16-\%) بسبب انخفاض سعر السوقي للسهم. }
$$

\section{النموذج السادس : معدل العائد على السهم:}

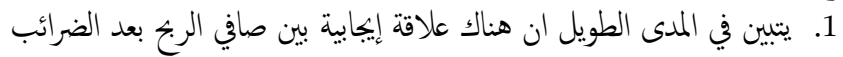

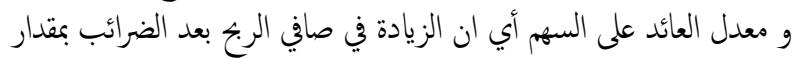

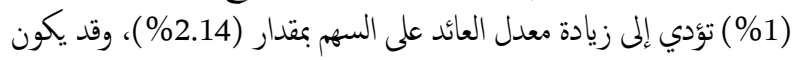

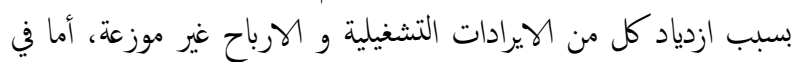

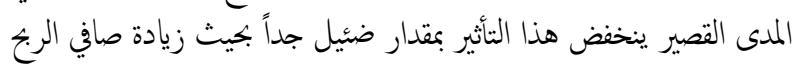

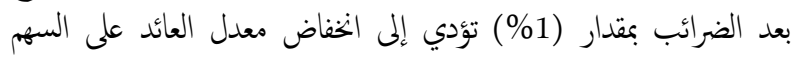

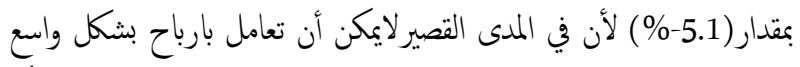

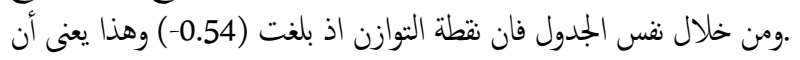

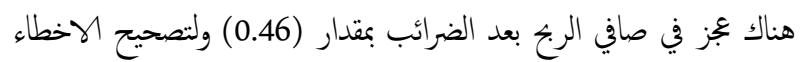

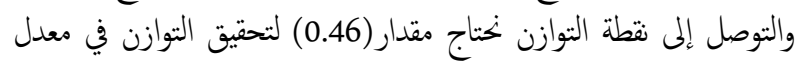
العائد على السهم. 2. يتبين في المدى الطويل ان هناك علاقة إيمابية بين الهيرادات و معدل العائد

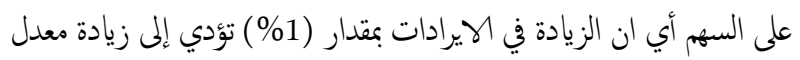

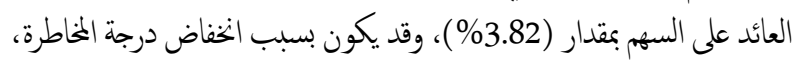

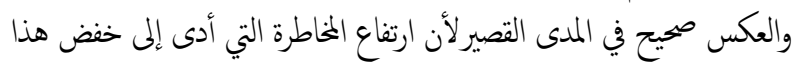

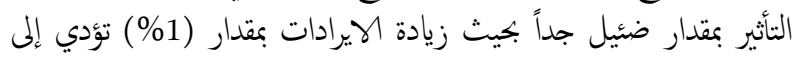

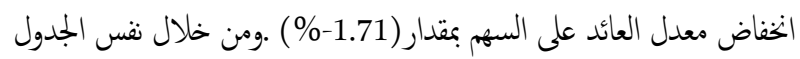

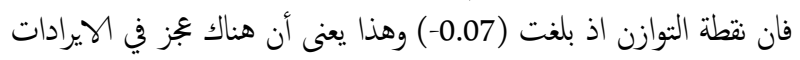

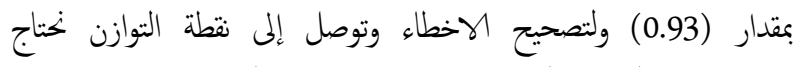
مقدار (0.93) لتحقيق التوازن في معدل العائد على السهم.

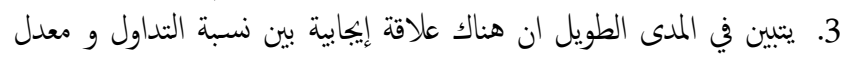

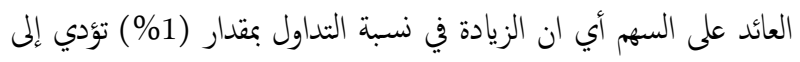

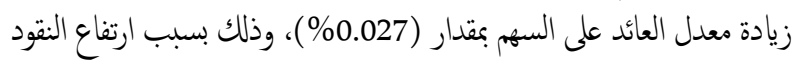

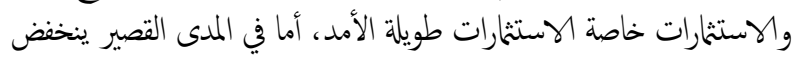

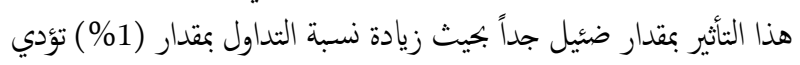

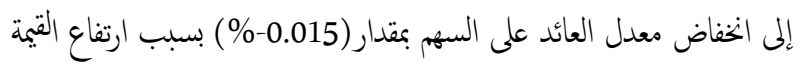

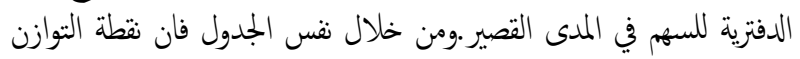

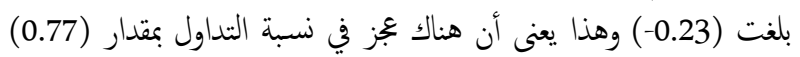

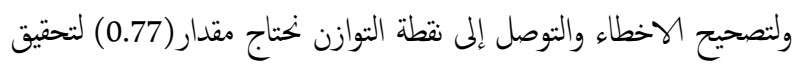
التوازن في معدل العائد على السهم.

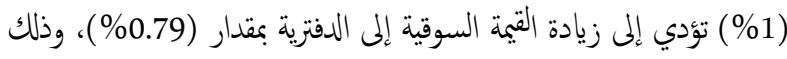

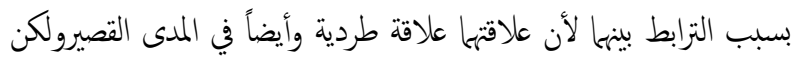

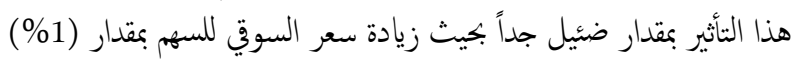

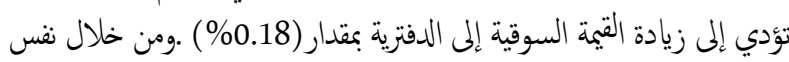

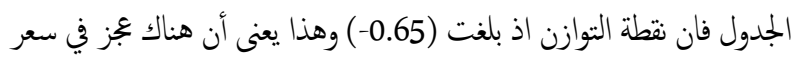

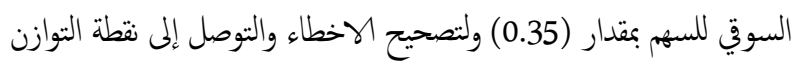
نتتاج مقدار (0.65) لتحقيق التوازن في الثيمة السوقية إلى الدفترية.

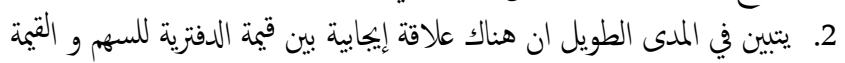

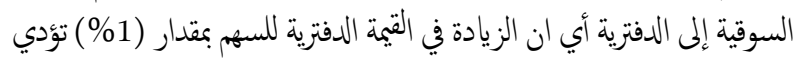

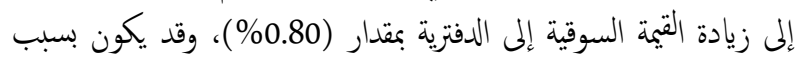

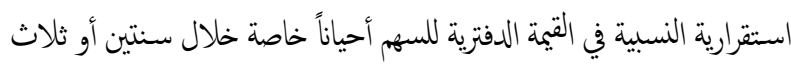

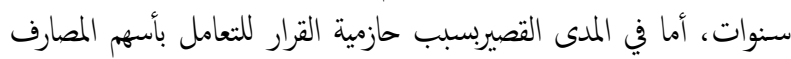

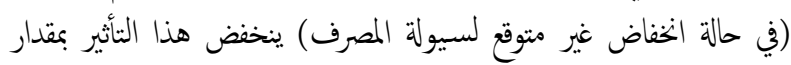

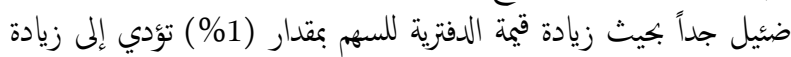

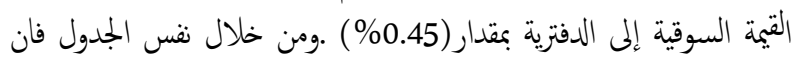

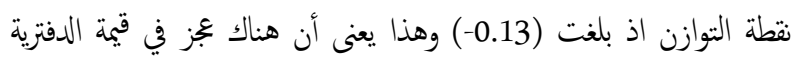

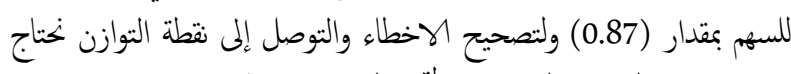
مقدار(0.87) لتحقيق التوازن في القيمة السوقية إلى الدفترية.

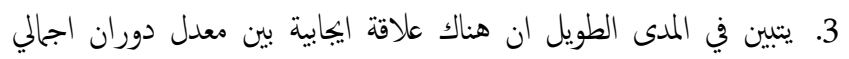

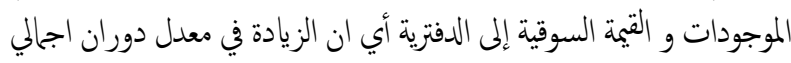

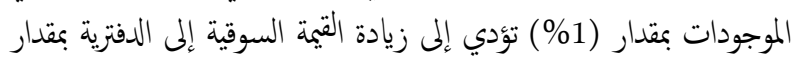

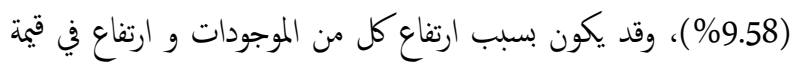

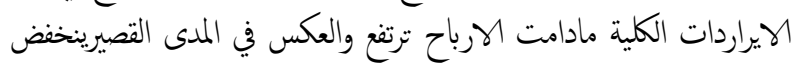

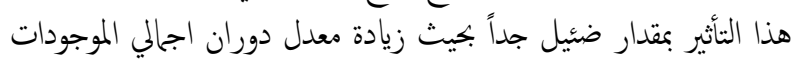

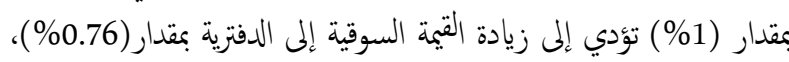

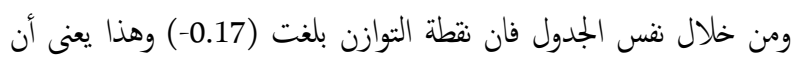

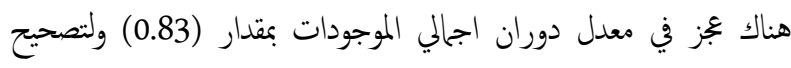
الاخطاء والتوصل إلى نقطة التوازن نختاج مقدار (0.83) لتحقيق التوازن في القيمة السوقية إلى الدفترية.

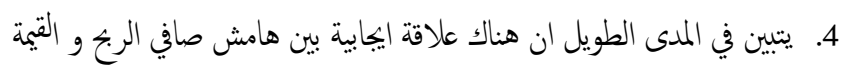

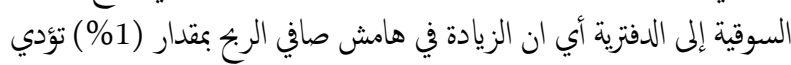

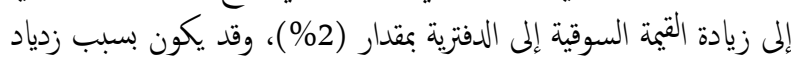

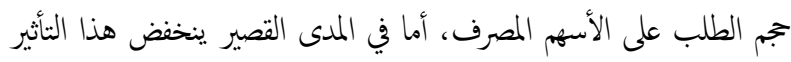

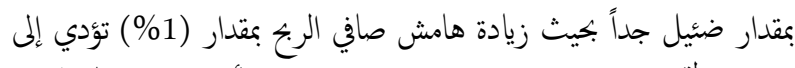

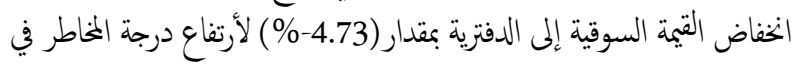

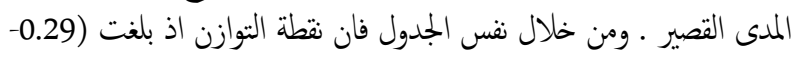

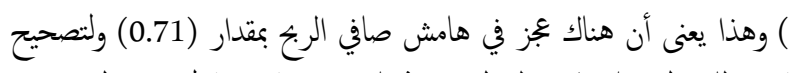

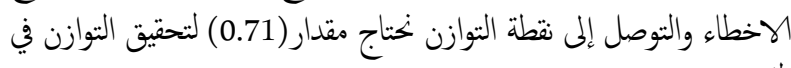
القيمة السوقية إلى الدفترية.

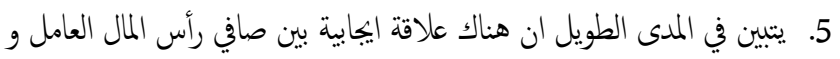

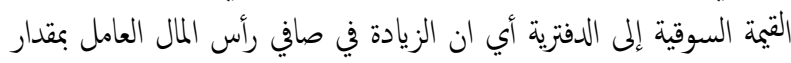

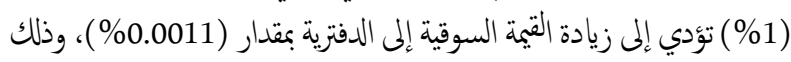

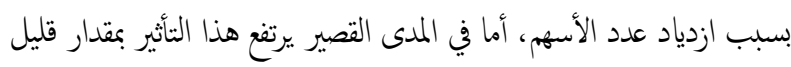




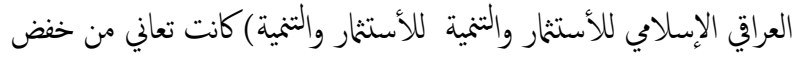
قيمة العوائد على السهم، لذا معدل العائد على السهم قليلة.

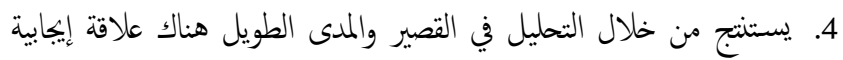

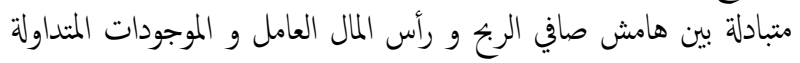

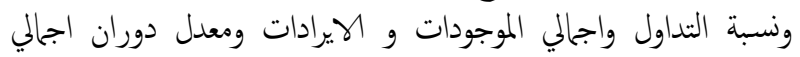

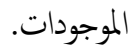

5. يتبين من خلال نتائج التحليل أن كثرة عدد الفروع للمصارف لهات دور ايجابي

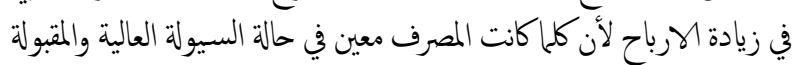

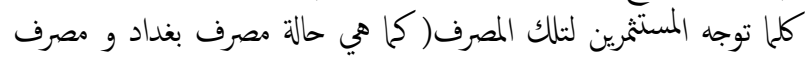

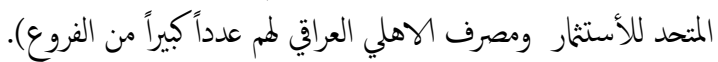

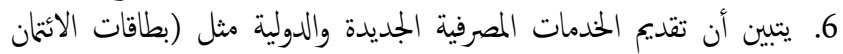

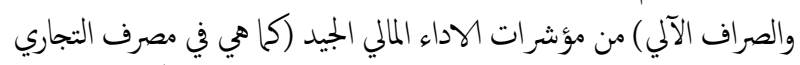
العراقي و مصرف كوردستان الدولي الإسلاي للاستثمار والتنمية للاستثار والنمية). 7. من خلال التحليل اتضحت فان الازمة المالية الداخلية في العراق يؤثر تاثيرا

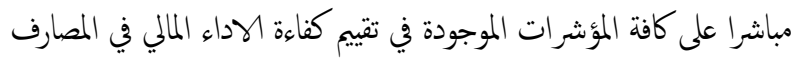

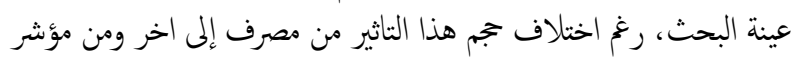
إلى اخر. 8. يظهر من خلال التحليل اجتياز النماذج المقدرة كل الاختبارات الاحصائية

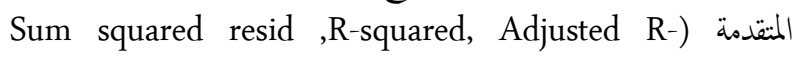
) squared, Standard Error , F , AIC التياسية الاساسية (كالارتباط الذاتي، التعدد الخطي، عدم تجانس التباينت،

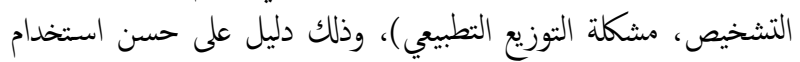

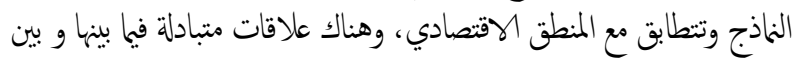

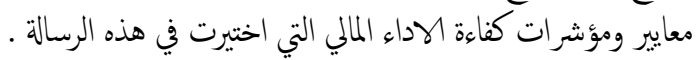

ثانيا: المتترحات:

\section{في ضوء ماسبق من الاستناجات من الممكن أن يتم اقتراح الأتي:}

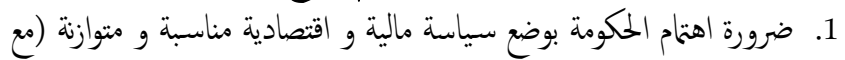
مراعاة البيئة و الظروف الاقتصادية و السياسية داخليا) لتطوير الاداء

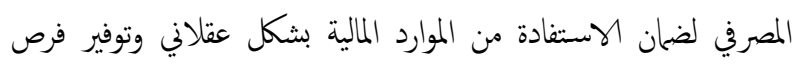

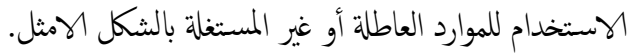

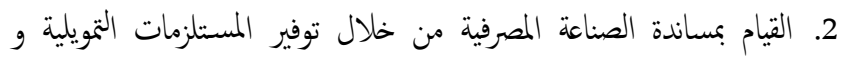

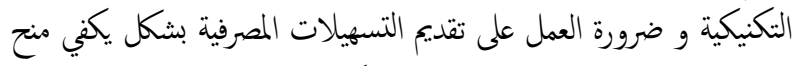

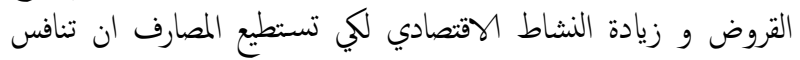

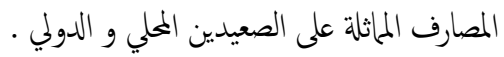

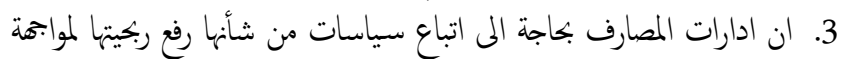

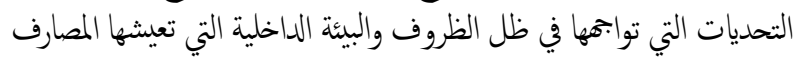

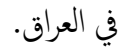
4. زيادة رؤوس أموال المصارف لتوفير مايكني من السيولة لتغطية كافة نشاطاتها

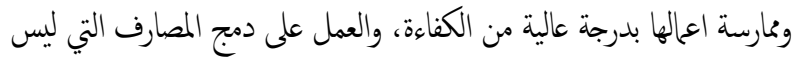

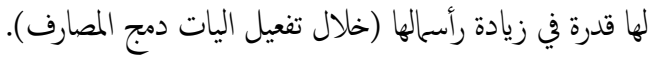

4. يتبين في المدى الطويل ان هناك علاقة إيجابية بين معدل دوران اجلالي

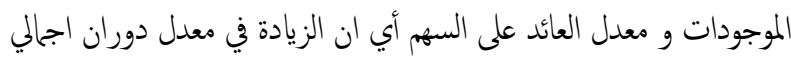

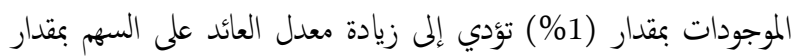

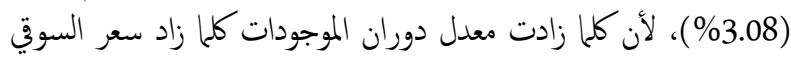

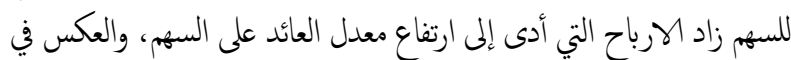

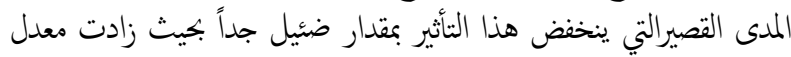

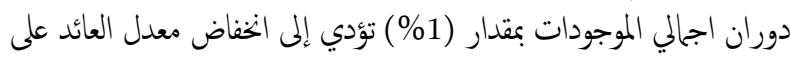

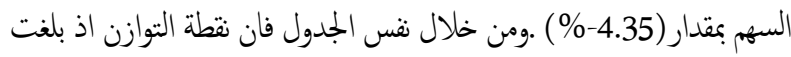

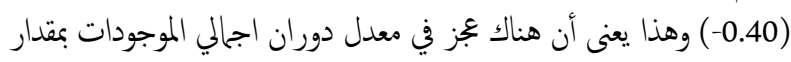
(0.60) ولتصحيح الاخطاء والتوصل إلى نقطة التوازن نختاج مقدار (0.60) لتحقيق التوازن في معدل العائد على السهم.

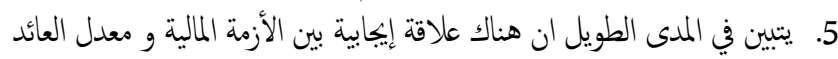

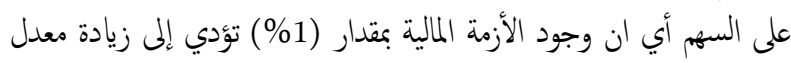

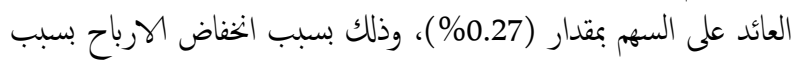

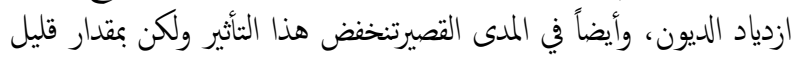

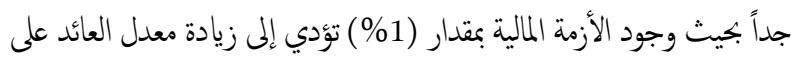

السهم بمقدار (0.20\%) - (

\section{الاستنتاجات والمقترحات}

اولا: الاستناجات : البات

توصل البحث المى الاستنتاجات الاتية:

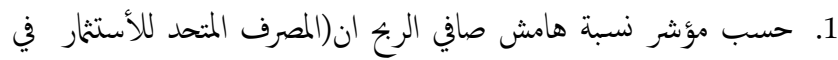

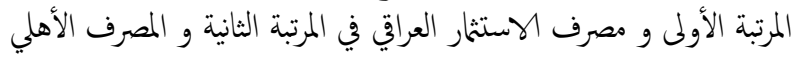

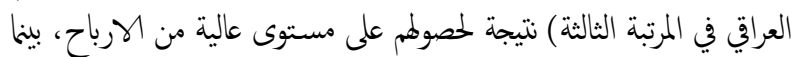

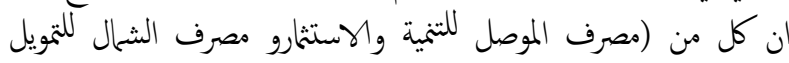

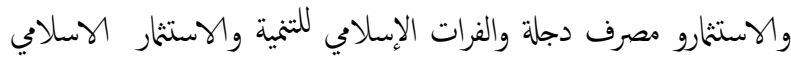

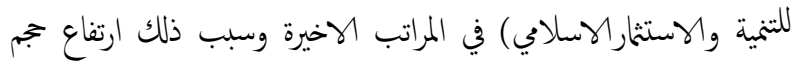
المصاريف و انخفاض ججم ارباح من بيع العملات.

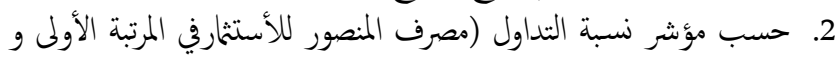
مصرف كوردستان الدولي الإسلاي للاستثمار والتنمية للاستثمار والتنمية

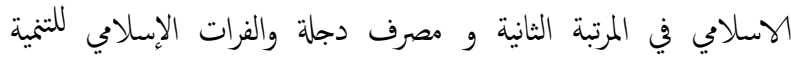

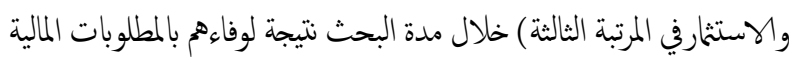

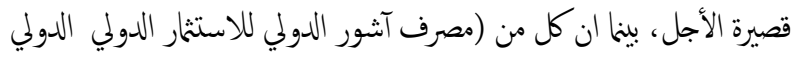
للاستثمار و مصرف الأهلي العراقي و مصرف الشهال للنمويل والاستثمار للتمويل

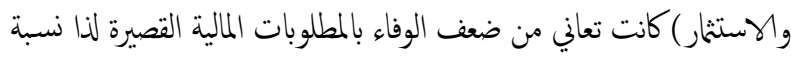
التداول فيهم منخفضة. 3. حسب مؤشر معدل العائد على السهم (مصرف كوردستان الدولي الإسلاي

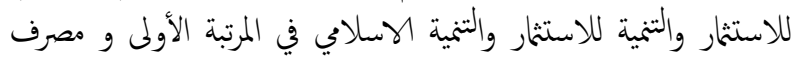

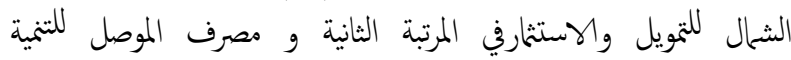
والاستثارفي المرتبة الثالثة) نتيجةً لرفع معدل عائدهم على الأسهم المصرفي، بلينا

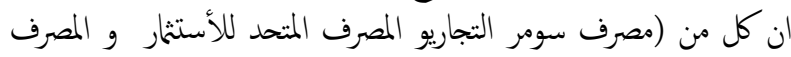


أديب برهوم, منذر مرهج, \& عتاب يوسف حسون. (2007). تقويم كفاءة معايير التقويم الملالي والإداري المستخدمة في قطاع النقل البحري (نموذج مرفائي اللاذقية Tishreen University Journal-Economic and Legal وطرطوس) Sciences Series السورية. أسيد,وسام (2019). دور الاندماج البنكي في تحسين اداء البنوك التجارية. رسالة ماجستير منشورة،

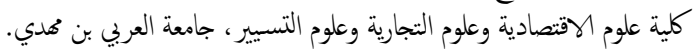

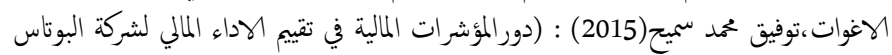
العربية)، رسالة ماجستير منشورة، جامعة الاسراء الاردنية.

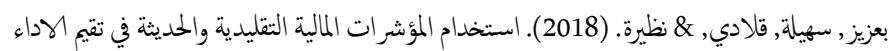

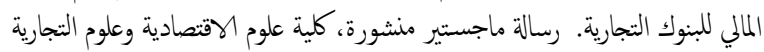
وعلوم التسبير ، جامعة أم البواقي.

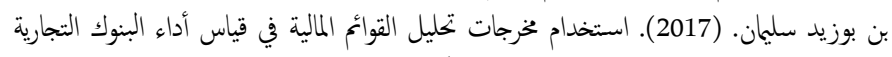

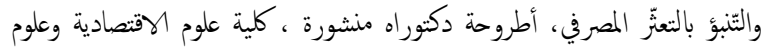
التجارية وعلوم التسيير ، جامعة محمد بوضياف بالمسيلة. بودبوز, خليدة, بوكثير, \& جبار. (2015). SCF التشخيص المالي في البنوك التجارية من منظور. رسالة ماجستير ، كلية العلوم الاقتصادية والتجارية وعلوم التسيير ، جامعة أم البواقي.

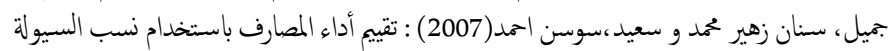

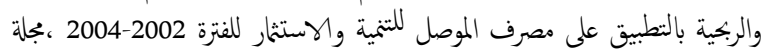

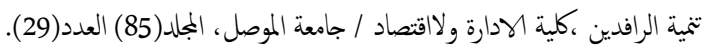

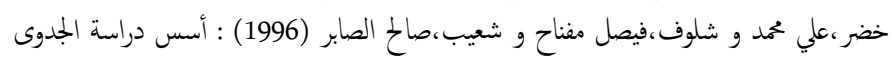

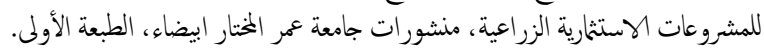

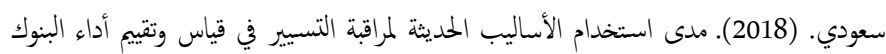

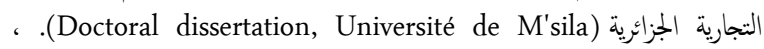

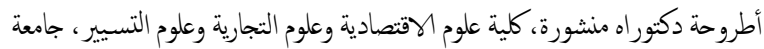
محمد بوضياف بالمسيلة. سقار , وحيد, برك, \& زهير. (2018). إستخدام البنوك التجارية للنسب المالية في إتخاذ القرار التمويلي.

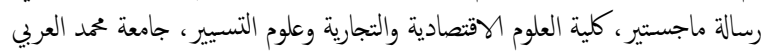
بن محدي-أم البواقي. شادي, فاطمة الزهراء, بوكثير, \& جبار. (2014). آليات تقويم الأداء الملالي في البنوك التجارية

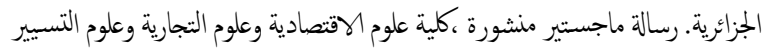
ا جامعة أم البواقي.

صالحهاوزين ابوبكر (2021) : قياس وتحليل أثر الانفاق السياحي في النمو الاقتصادي في دول

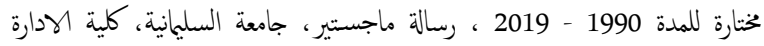
والاقتصاد، قسم الاقتصاد. عارف، سامان علي و فرج، ماردين محسوم(2021) : (أثر الديون الخارجية والمساعدات الانمائية في

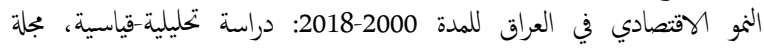

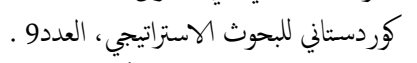

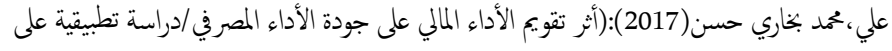

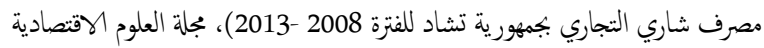
والادارية والقانونية، العدد 5، المجلد1 التجائ. القريشي، مدحت كاظم (2001) : الاقتصاد الصناعي ، دار وائل للطباعة والنشر والتوزيع، عمان، الكان، الاردن.

لطيف زيود, ماهر الأمين, \& منيرة المهندس. (2005). تقو.يم أداء المصارف باستخدام أدوات التحليل المالي دراسة ميدانية للمصرف الصناعي السوري. Tishreen University Journal-Economic and Legal Sciences Series تشرين للدراسات والبحوث العلمية، مجلد(27) العدد(4).

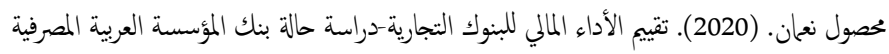
خلال الفترة 2013-2018، مجلة نماء للاقتصاد والتجارة، مجلد(3)، عدد(2).
5. من الضروري عمل المصارف عينة البحث على رفن مستوى الخدمات المصرفية الحديثة و التسهيلات للزبائن و توجه المصارف نحو الخدمات العالمية والكترونية، وضرورة فتح فروع المصارف في المناطق البعيدة عن مركز المحافظات.

6. العمل على توسيع دائزة الارتباط و التعاون والاندماج بين المصارف الأهلية والمصارف الحكومية داخل العراق و خاربجا من اجل الاستفادة من الفوائد

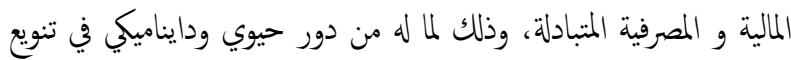
العمل و النشاط المصرفي.

7. قيام المصارف والاداراتهم بتقييم الأداء المالي المستمر والدوري لادائم لاظهار نقاط الضعف والعمل على تلافيها و لبيان نقاط القوة وتطويرها.

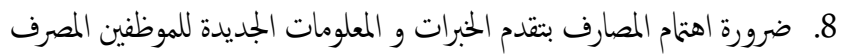

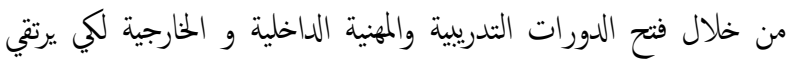
بمستوى اداء العاملين وموظفين.

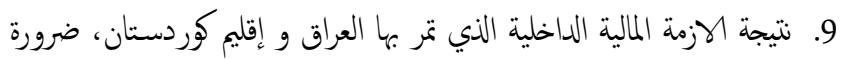

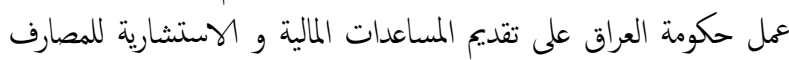
الذي وابهت الخنسائر لكي تجاوز المشاكل السيولية و النقدية والائتانية. 10. بغية المصرف المركزي والسلطات المالية اهتمام أكثر بالبحوث العلمية المقدمة من قبل ذوي الخختصين في الجامعات والندوات العلمية المرتبطة بالاعمال المالية والمصرفية، وتقديم المساعدات للجهات التي تقام الندوات والمؤتمرات بهذات الصدد.

\section{قائمة المصادر والمراجع}

آ سية كروي. (2016). تقييم أداء البنوك التجارية بواسطة النسب المالية دراسة تطبيقية خلال الفترة

.2014-2005)، مجلة البشائر الاقتصادية، العدد(5).

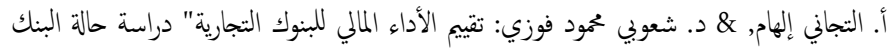

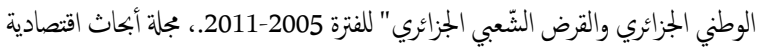

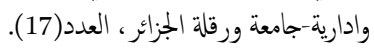

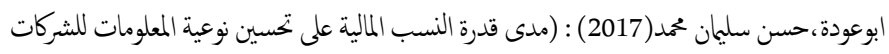
الخدمية المدرجة في بورصة فلسطين / دراسة حالة مجموعة الاتصالات الفلسطينية)، رسالة ماجستير ، كلية التجارة، جامعة الاسلامية-غزة.

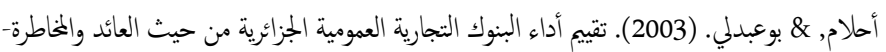

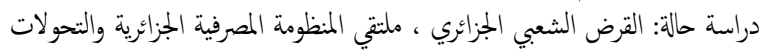

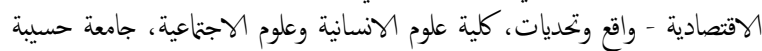
بوعلي بالشلف. احمد، عثان امين(2018) : تقييم الاداء المصرفي باستخدام ادوات التحليل المالي(النسب المالية)

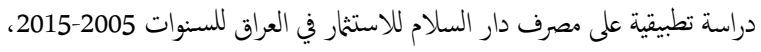
بحث منشور، مجلة جامعة جيهان/العراق ، العدد1، المجلد2.

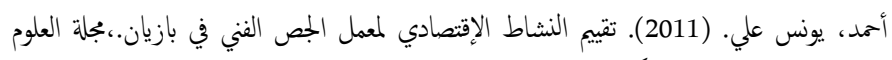

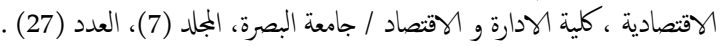

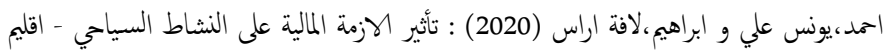

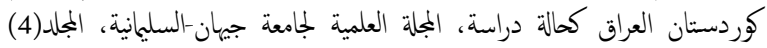

العدد)(1). 


\section{المصادر الانجليزية : n}

Haile, A., Getacher, T., \& Tesfay, H. (2014). Financial Performance Analysis of Selected Commercial Banks in Ethiopia. Ethiopian Journal of Business and Economics (The), 4(2), 251-282.

Lingga, D. S. K., \& Tirok, J. (2012). Empirical Studies on EVA and Profitability Ratios Association with Annual Stock Return for Indonesia Companies. Journal of Applied Finance \& Accounting, 4(2), 95-111.

Pinto, P., Hawaldar, I. T., Rahiman, H. U., TM, R., \& Sarea, A. (2017). An evaluation of financial performance of commercial banks. International Journal of Applied Business and Economic Research, 15(22), 605-618.

Ram Karan Singh (2020): Financial Performance Evaluation of Commercial Banks by AHP : Anevidence from India, Pacific Business Review International,volume 12 , issue 12.

Said, R. M., \& Tumin, M. H. (2011). Performance and financial ratios of commercial banks in Malaysia and China. International Review of Business Research Papers, 7(2), 157-169.
محمد، بةيمان رفيق(2008) : المحاسبة عن الاداء البيتي للوحدات الاقتصادية وامكانية رقابته و تقويمه

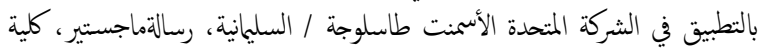

$$
\text { الادارة والاقتصاد، جامعة السليمنية. }
$$

• (2011). Analyzing and Evaluations The Financial مشعل، المطيري \& Performance of The Kuwaiti Oil Corporation (Doctoral جامعة الشرق الاوسط. رسالة ماجستير منشورة، جامعة شرق الاوسط. مطيري،عادل نايف خالد (2015) : (امكانية التنبؤ بالفشل المالي باستخدام النسب المالية من وبهة

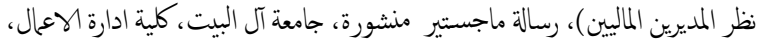
قسم المحاسبة.

الهاجري، فهد راشد مسعود (2016) : أثر نسب ومؤشرات التحليل المالي على الاداء المالي

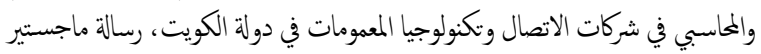

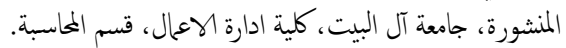

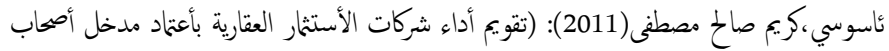

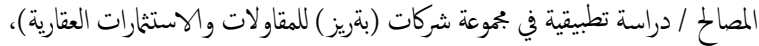
رسالة ماجستير، كلية الادارة والاقتصاد، جامعة السليمنية. 